Portland State University

PDXScholar

\title{
The Application of Smart Phone, Weight-Mile Truck Data to Support Freight-Modeling, Performance Measures and Planning
}

Katherine E. Bell

Portland State University

Miguel A. Figliozzi

Portland State University, figliozzi@pdx.edu

Follow this and additional works at: https://pdxscholar.library.pdx.edu/cengin_fac

Part of the Civil and Environmental Engineering Commons, Transportation Commons, and the Urban Studies and Planning Commons

Let us know how access to this document benefits you.

\section{Citation Details}

Bell, Katherine E., and Miguel A. Figliozzi. "The Application of Smart Phone, Weight-Mile Truck Data to Support Freight-Modeling, Performance Measures and Planning." ORTREC-RR-13-10. Portland, OR: Transportation Research and Education Center (TREC), (2013). https://dx.doi.org/10.15760/trec.105

This Report is brought to you for free and open access. It has been accepted for inclusion in Civil and Environmental Engineering Faculty Publications and Presentations by an authorized administrator of PDXScholar. Please contact us if we can make this document more accessible: pdxscholar@pdx.edu. 

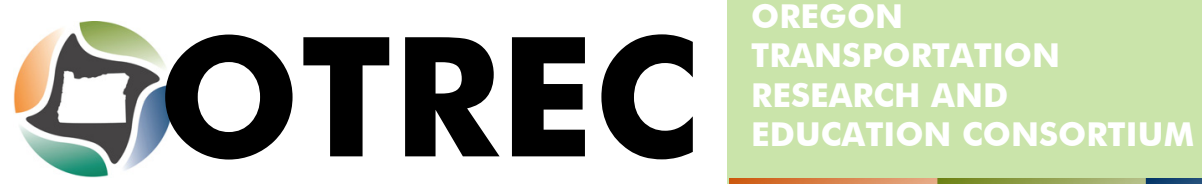

FINAL REPORT

The Application of Smart Phone, Weight-Mile Truck Data to Support Freight-Modeling, Performance Measures and Planning

OTREC-RR-13-10 August 2013 



\title{
THE APPLICATION OF SMART PHONE, WEIGHT- MILE TRUCK DATA TO SUPPORT FREIGHT- MODELING, PERFORMANCE MEASURES AND PLANNING
}

\author{
Final Report
}

OTREC-RR-13-10

by

Katherine E. Bell, P.E.

Miguel A. Figliozzi, Ph.D.

Portland State University

for

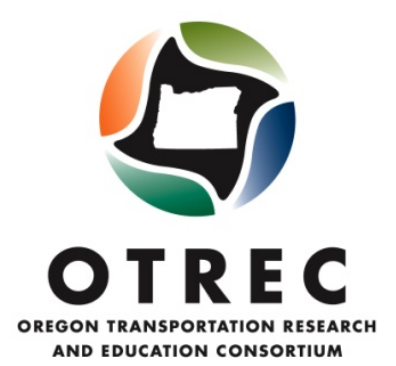

P.O. Box 751

Portland, OR 97207

August 2013 



\section{Technical Report Documentation Page}

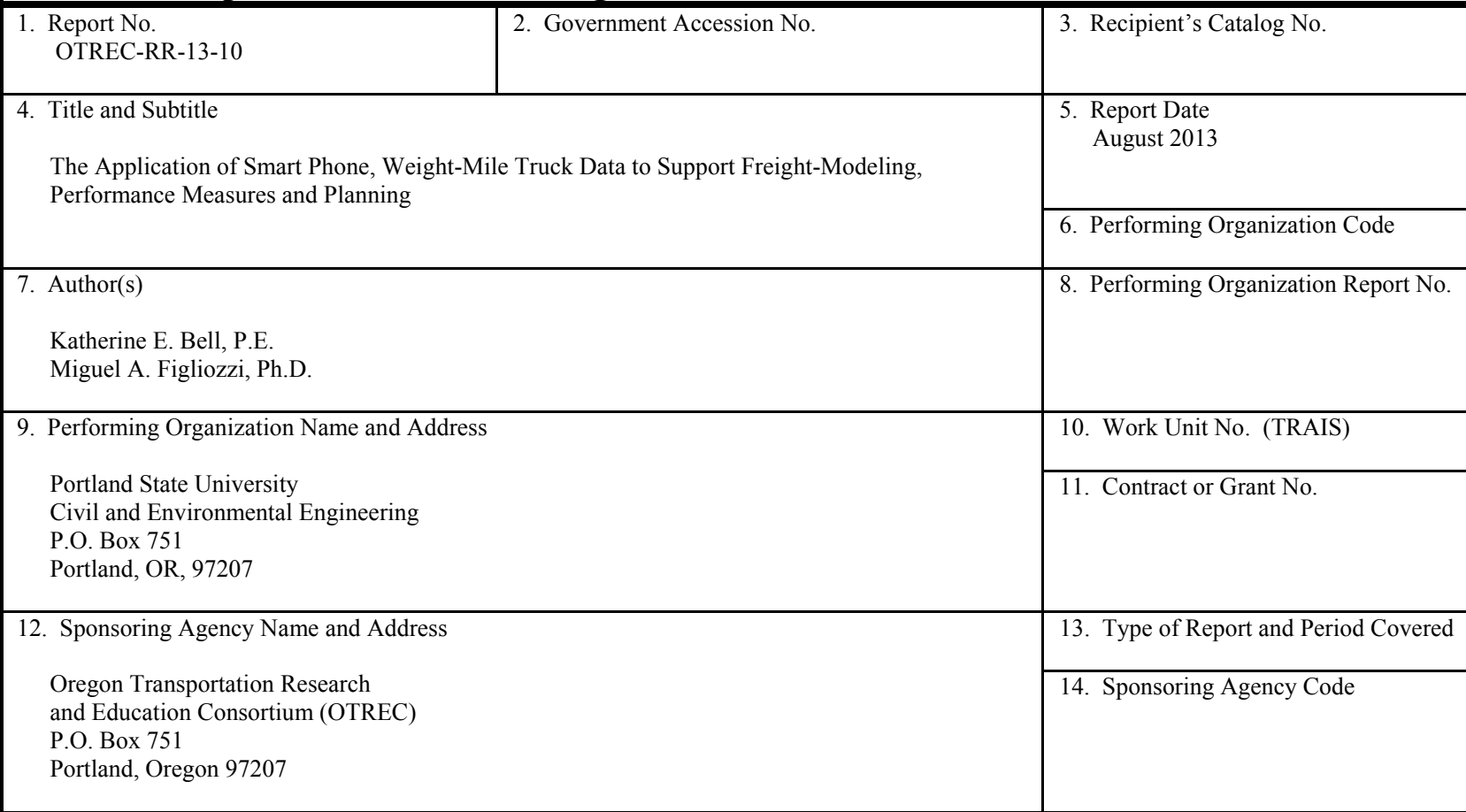

15. Supplementary Notes

16. Abstract

Oregon is one of the few states that currently charge a commercial truck weight-mile tax (WMT). The Oregon Department of Transportation (ODOT) has developed a data-collection system - Truck Road Use Electronics (TRUE) - to simplify WMT collection. The TRUE system includes a smart phone application that collects and records Global Positioning System (GPS) data. The TRUE data has enormous advantages over GPS data used in previous research due to its level of geographic detail and the potential to also integrate trip origin and destination, vehicle class, and commodity-type data. This research evaluates the accuracy of the TRUE data and demonstrates its use for significant ODOT ancillary applications. Specifically, ancillary applications that address ODOT freight modeling, performance measures, and planning needs are explored. The use of the data for highly accurate trip-generation rates and mobility performance measures is demonstrated. In addition, it is shown that the TRUE data has strong potential to be used for safety, accessibility and connectivity, system condition and environmental stewardship performance measures. The potential use of the TRUE data for emissions estimates that take into account truck-type details, truck weight and detailed speed profiles is considered. Results indicate that TRUE data, integrated with ODOT weigh-in-motion (WIM) data, will greatly improve the accuracy of emission estimates at the project and regional level. This research confirms the potential use of the TRUE data for significant ancillary applications and demonstrates the regional value of the TRUE data to enhance existing freight modeling, performance measures and planning.

\begin{tabular}{|c|c|c|c|}
\hline \multicolumn{2}{|l|}{ 17. Key Words } & \multicolumn{2}{|c|}{$\begin{array}{l}\text { 18. Distribution Statement } \\
\text { No restrictions. Copies available from OTREC: } \\
\text { www.otrec.us }\end{array}$} \\
\hline $\begin{array}{l}\text { 19. Security Classification (of this report) } \\
\text { Unclassified }\end{array}$ & $\begin{array}{l}\text { 20. Security Classification (of this page) } \\
\text { Unclassified }\end{array}$ & $\begin{array}{l}\text { 21. No. of Pages } \\
98\end{array}$ & 22. Price \\
\hline
\end{tabular}




\section{ACKNOWLEDGMENTS}

Support for this research from the Oregon Transportation Research and Education Consortium (OTREC) and the Oregon Department of Transportation (ODOT) is gratefully acknowledged. Sirisha Kothuri contributed to the "Emissions Estimates" section of this report. In addition, input from Brian Davis and other graduate research assistants contributed to this report. The authors would also like to thank Myra Sperley (ODOT Research Section); Becky Knudson (ODOT Transportation Analysis Unit); and Greg Dal Ponte, Gina Salang, Steve Ross, Chris Howell, Peter Douglas and Michael Bolliger (ODOT Motor Carrier Applications Development) for providing data and/or useful comments and feedback. Any omissions or mistakes are the sole responsibility of the authors.

\section{DISCLAIMER}

This document is disseminated under the sponsorship of the Oregon Department of Transportation and the United States Department of Transportation in the interest of information exchange. The State of Oregon and the United States Government assume no liability of its contents or use thereof.

The contents of this report reflect the view of the authors who are solely responsible for the facts and accuracy of the material presented. The contents do not necessarily reflect the official views of the Oregon Department of Transportation or the United States Department of Transportation.

The State of Oregon and the United States Government do not endorse products of manufacturers. Trademarks or manufacturers' names appear herein only because they are considered essential to the object of this document.

This report does not constitute a standard, specification, or regulation. 


\section{CONTENTS}

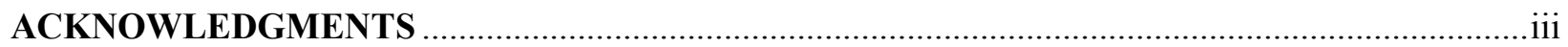

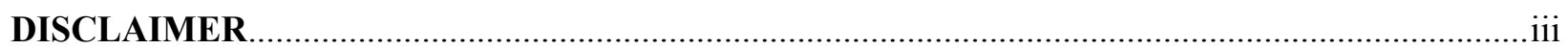

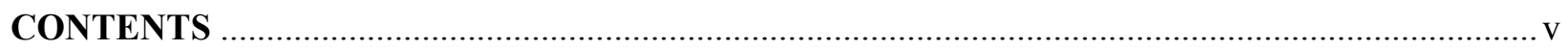

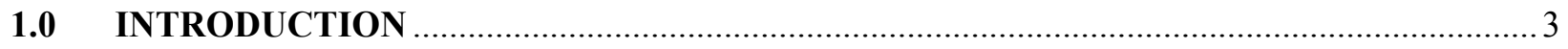

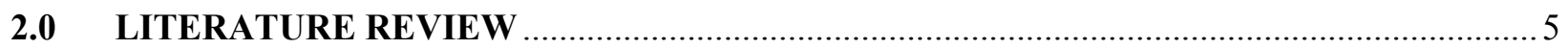

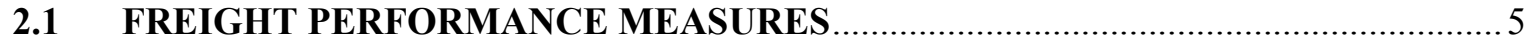

2.2 SMART PHONE APPLICATIONS IN TRANSPORTATION .................................. 14

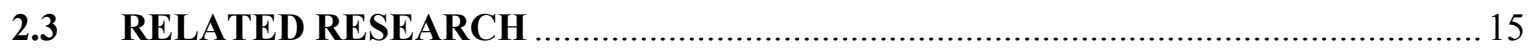

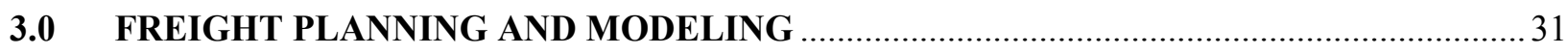

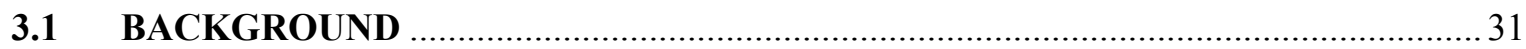

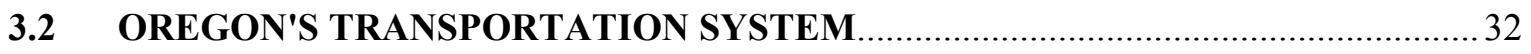

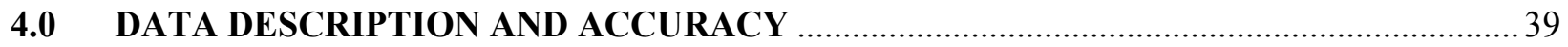

5.0 WEIGH-IN-MOTION DATA INTEGRATION AND COMPARISON ….......................... 47

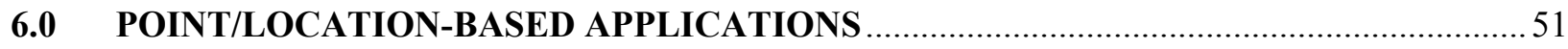

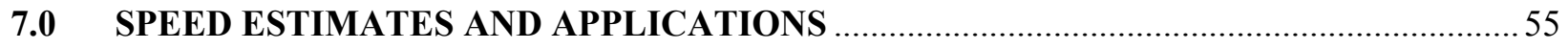

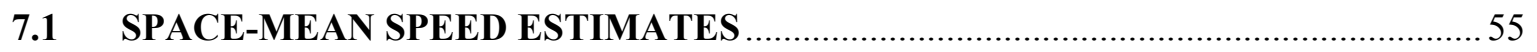

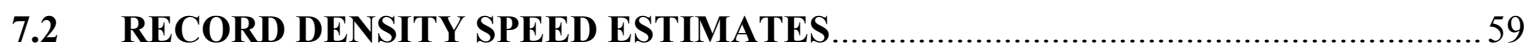

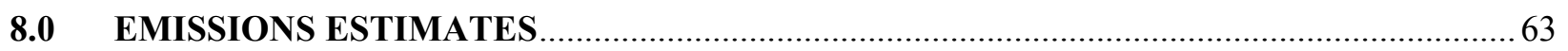

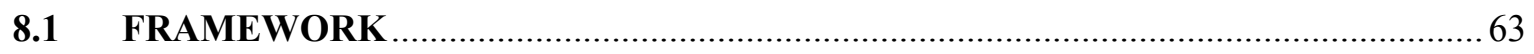

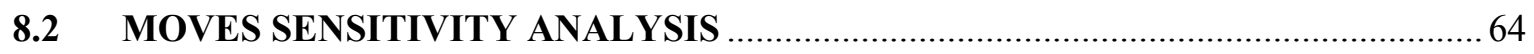

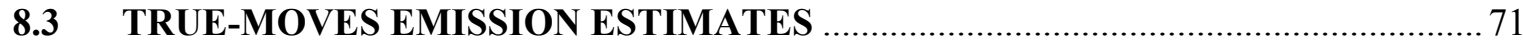

8.4 EMISSION ESTIMATES - CONCLUSIONS AND FUTURE …............................ 72

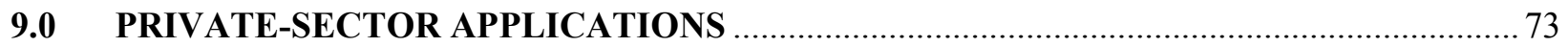

9.1 COMMERCIAL-TRUCK GPS DATA - PROPRIETARY APPLICATIONS............ 73

9.2 COLLABORATION WITH THE PRIVATE SECTOR ............................................ 75

9.3 PRIVATE- AND PUBLIC-SECTOR APPLICATIONS FRAMEWORK ................. 76

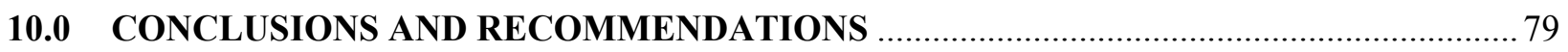

REFERENCES 


\section{LIST OF TABLES}

Table 1 - Freight Performance Measure Categories ............................................................................ 5

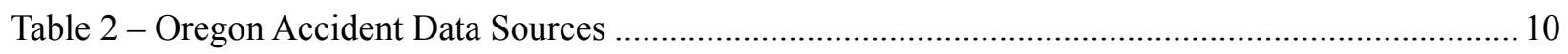

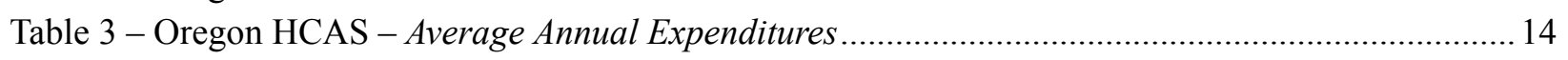

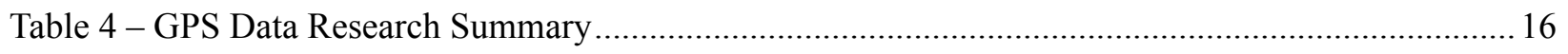

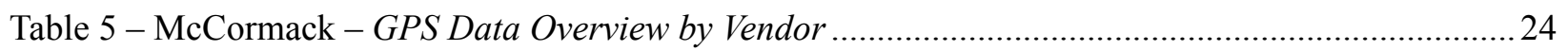

Table 6 - You \& Ritchie - Reason Codes for Recording GPS Data ...........................................................2 27

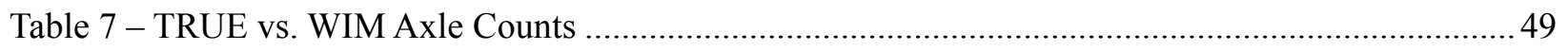

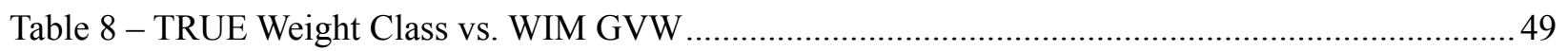

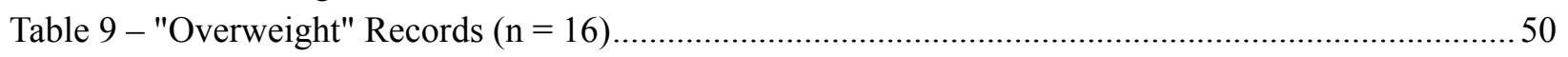

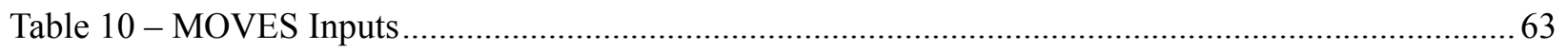

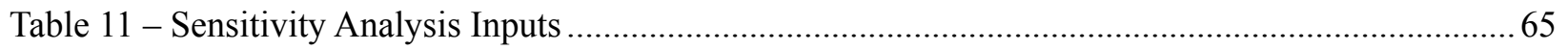

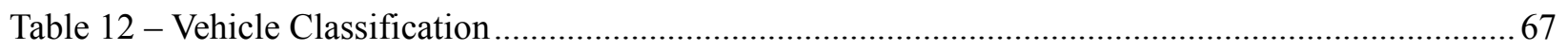

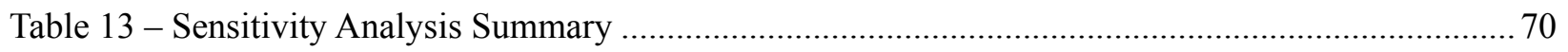

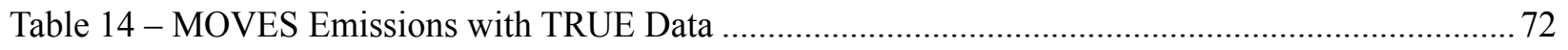

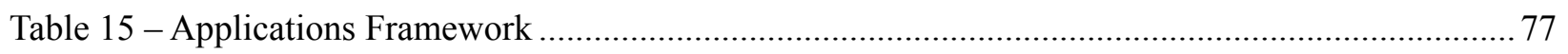




\section{LIST OF FIGURES}

Figure 1 - McMullen \& Monsere - Oregon Freight Transportation Figure 1 ........................................ 12

Figure 2 - McMullen \& Monsere - Oregon Freight Transportation Figure 2 ......................................... 12

Figure 3 - McMullen \& Monsere - Oregon Freight Transportation Figure 3 ....................................... 13

Figure 4 - Greaves \& Figliozzi - Example GPS Plot and Tabular Data of Truck Trips .......................... 18

Figure 5 - Wheeler \& Figliozzi - Diagram Showing User-defined Parameters for Filtering Process 1 and

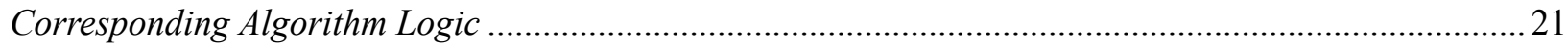

Figure 6 - McCormack et al. - Online Truck Freight Performance Measures System Flow Chart ........... 26

Figure 7 - Wigan \& Southworth - A Typology of Categories of Freight Models Linked to Four-step Tools

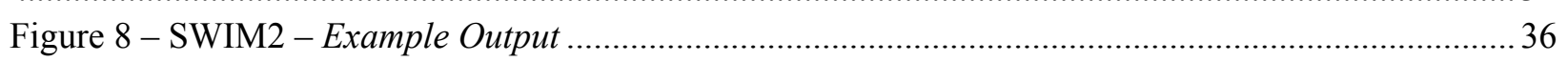

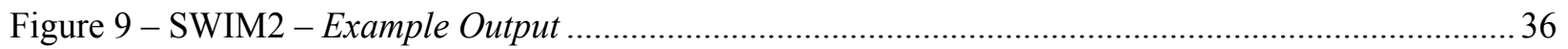

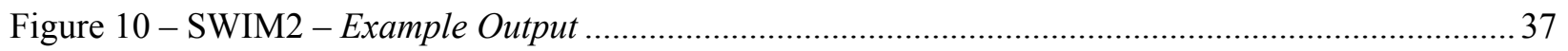

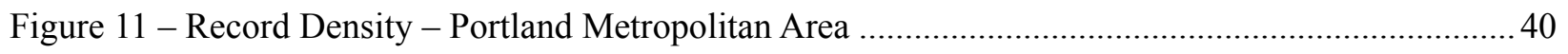

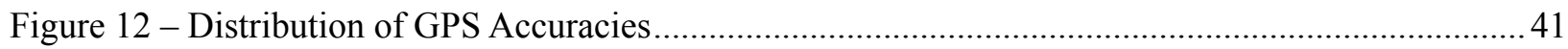

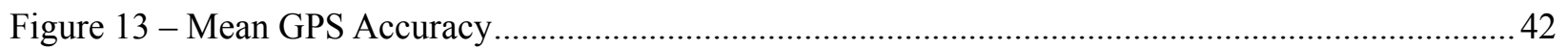

Figure 14 - Density of Records with Accuracy Worse than $95^{\text {th }}$ Percentile (53 feet) .............................. 43

Figure 15 - Percentage of Records with Accuracy Worse than $95^{\text {th }}$ Percentile (53 feet) ......................... 43

Figure 16 - Density of Records with Accuracy Worse than $99^{\text {th }}$ Percentile (105 feet) .............................. 44

Figure 17 - Percentage of Records with Accuracy Worse than $99^{\text {th }}$ Percentile (105 feet) ........................ 44

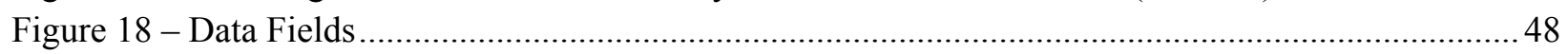

Figure 19 - Density of GPS Records by Weight Class and Land Use .................................................. 52

Figure 20 - GPS Record Counts for 1030 Weight Class ...................................................................... 52

Figure 21 - Space-Mean Speed Measurement Accuracy ..................................................................... 57

Figure 22 - Average Space-Mean Speeds - Columbia River Crossing Case Study .................................. 59

Figure 23 - Record Density Speed Estimates - Columbia River Crossing Case Study ........................... 61

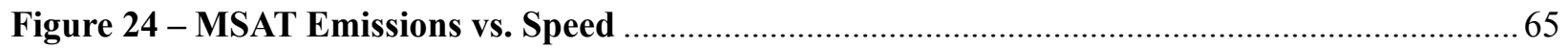

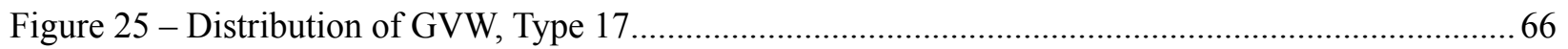

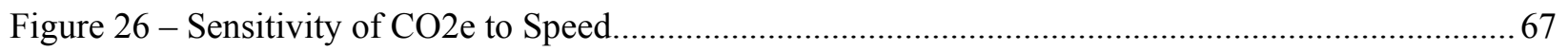

Figure 27 - Combination Short-Haul Emission Sensitivity to Speed - Grade 0\% ................................... 68

Figure 28 - Combination Short-Haul Emission Sensitivity to Grade - Speed 60 mph ............................ 69

Figure 29 - Combination Short-Haul Emission Sensitivity to Weight - Grade 0\% ................................. 70

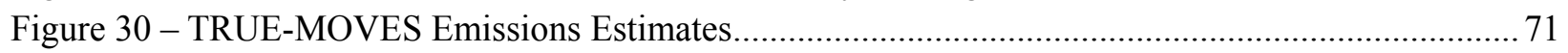




\begin{abstract}
Oregon is one of the few states that currently charge a commercial truck weight-mile tax (WMT). The Oregon Department of Transportation (ODOT) has developed a data-collection system - Truck Road Use Electronics (TRUE) - to simplify WMT collection. The TRUE system includes a smart phone application that collects and records Global Positioning System (GPS) data. The TRUE data has enormous advantages over GPS data used in previous research due to its level of geographic detail and the potential to also integrate trip origin and destination, vehicle class, and commodity-type data. This research evaluates the accuracy of the TRUE data and demonstrates its use for significant ODOT ancillary applications. Specifically, ancillary applications that address ODOT freight modeling, performance measures, and planning needs are explored. The use of the data for highly accurate trip-generation rates and mobility performance measures is demonstrated. In addition, it is shown that the TRUE data has strong potential to be used for safety, accessibility and connectivity, system condition and environmental stewardship performance measures. The potential use of the TRUE data for emissions estimates that take into account truck-type details, truck weight and detailed speed profiles is considered. Results indicate that TRUE data, integrated with ODOT weigh-in-motion (WIM) data, will greatly improve the accuracy of emission estimates at the project and regional level. This research confirms the potential use of the TRUE data for significant ancillary applications and demonstrates the regional value of the TRUE data to enhance existing freight modeling, performance measures and planning.
\end{abstract}




\subsection{INTRODUCTION}

Reliable freight transportation is particularly important to Oregon due to its geographic location. According to The Oregon Freight Plan, Oregon is the ninth most trade-dependent state in the nation and is expected to see significant increases in freight flows in the future (Cambridge Systematics Inc. and ODOT Freight Mobility Unit, 2011). This trade dependency comes with pressures on the general transportation system, as well as the freight-specific system, such as congestion, travel unreliability, environmental and health concerns, and increased transport costs (Wheeler and Figliozzi, 2011; Figliozzi et al., 2011. In this regard, recent research stresses the importance of freight performance measures and associated data-management processes in sustaining an affective transportation planning system (McMullen and Monsere, 2010; NCFRP, 2011). Freight data that might be used for such measures is usually incomplete, scarce, and expensive to collect. The primary challenges with freight data and performance measurement have been said to be the lack of publicly available data and the data's proprietary nature. Due to privacy concerns, spatial and temporal aggregations of analyzed data are often required, making detailed measurement difficult (McMullen and Monsere, 2010). In addition, traditional analysis processes associated with passenger transportation data have been found to be unsuitable for freight analysis (You and Ritchie, 2012; Wigan and Southworth, 2006).

Oregon is one of the few states that currently charge a commercial truck weight-mile tax (WMT); Oregon's WMT applies to trucks operating at weights of over 26,000 pounds. In February 2010, the Oregon Department of Transportation (ODOT) Motor Carrier Transportation Division (MCTD) implemented a pilot project for the use of Truck Road Use Electronics (TRUE), a system to simplify WMT collection (ODOT, 2010). The TRUE system provides an automated process for WMT collection that reduces the administrative burden on trucking firms and ODOT while also reducing reporting errors and tax avoidance. The system includes a smart phone application with a Global Positioning System (GPS) device and microprocessor. The application can be uploaded to the phones of truck drivers in order to track miles traveled; the data is then sent electronically to ODOT to produce the company's WMT "invoice," which can be paid online. The TRUE application was developed with the intention that it could be used in the form of a smart phone application on a wide variety of hardware, so that in the future trucking companies could use a wireless device of their choosing (ODOT, 2010). In April 2012, ODOT concluded collection of the TRUE pilot project data. Subsequently, a private company, EROAD, with a similar product to TRUE, has successfully negotiated a signed agreement with the Oregon Trucking Association (OTA) to collaborate on a pilot demonstration project of their product in Oregon (ODOT, n.d.)

Both the TRUE and EROAD systems provide a highly promising source of commercial-truck GPS data. Data collected through these systems not only provides commercial truck origin-destination, space/time coordinates and trajectories, but also weight class, truck type and commodity codes when combined with weigh-in-motion (WIM) data. It could be integrated into existing data sources and disaggregated by vehicle type and trip characteristics. Such freight data can equip decision-makers and stakeholders to better understand the intricacies of truck tours, and to make more cost-efficient decisions towards mitigating the consequences of freight transportation. As similar systems to TRUE and EROAD become more common, freight GPS data will become more widely available. As such, it is important for agencies that might have access to such data to develop and understand methodologies to process and analyze it. 
Oregon is ideally suited for statewide implementation of a system such as TRUE as it already has an established WMT system. Under Oregon law, motor carriers operate as a regulated industry and are required to report miles traveled. However, Oregon Revised Statute 825.517 specifies that data collected for the WMT system is not public record. Therefore, the privacy of motor carriers using the TRUE system is protected by Oregon law. Under Oregon's existing WMT system, companies self-report the miles traveled in Oregon for each axle combination; taxes are paid on a monthly or quarterly basis. Truck drivers must maintain log books to track hours of service, truck combination, number of axles, and trip odometer readings and then calculate their WMT. The administration of WMT in Oregon has traditionally been very paperwork intensive. In 2003 ODOT implemented Oregon Trucking Online in order to simplify WMT collection (Wheeler and Figliozzi, 2011). In recent years, approximately 25\% of WMT payments were made online. TRUE provides the opportunity for further regulatory streamlining and reduction of paperwork associated with WMT, thus reducing the time and resources required (of both the state and trucking companies) to calculate, pay and process WMT.

Previous work related to the use of freight GPS data provides a valuable starting point for this research. However, Oregon WMT GPS data has enormous advantages over data used in previous research due to its level of disaggregation and its potential to differentiate between vehicle types. The information presented herein includes a literature review of research and industry developments that provide examples of potential applications and data processing methods for commercial truck GPS data. This report will also provide an evaluation of new applications that would be possible for Oregon given the unique characteristics of the WMT GPS data. Further, the accuracy of TRUE data will be evaluated, as well as the potential use of the data to develop trip-generation rates for a variety of truck types and land use categories. This research confirms the potential use of WMT GPS data for these purposes, and demonstrates the regional value of the TRUE data to enhance existing ODOT transportation modeling, performance measures and planning. 


\subsection{LITERATURE REVIEW}

The information presented in this section was obtained through a literature review of research and industry developments that provide examples of potential ancillary applications and associated data processes for commercial-truck GPS data. The work reviewed in this section is not intended to be an exhaustive list, but rather a representation of relevant research. A review of developments relevant to the following topics is provided:

- Freight performance measures

- Smart phone applications in transportation

- Related research

\subsection{TREIGHT PERFORMANCE MEASURES}

Recent research stresses the importance of freight performance measures and associated datamanagement processes in sustaining an affective transportation planning system (McMullen and Monsere, 2010; NCFRP, 2011). In fact, in 2011 the National Cooperative Freight Research Program (NCFRP) released NCFRP Report 10, Performance Measures for Freight Transportation. Performance measures have traditionally been focused on the movement of passenger vehicles; however, the NCFRP report proposes their use to evaluate freight transportation systems. Specifically, the report provides a framework for development of freight performance measures using a Freight System Report Card with 29 performance measures in six categories. The report stresses a "balanced" approach that takes into account the range of stakeholders associated with the national transportation system. NCFRP Report 10 further suggests that given the ability to disaggregate freight data, the framework proposed in the report could also be used to assist decision-making at the regional or local level to analyze the performance of individual links or bridges. The authors also note that a major challenge towards such efforts is the availability of useful data. At the state level, a report completed for ODOT in May 2010 entitled Freight Performance Measures: Approach Analysis provides recommendations for freight performance measures to be used in Oregon. Most of the measures suggested in the report overlap with those suggested by NCFRP, as shown in Table 1.

\begin{tabular}{|c|c|}
\hline \multicolumn{2}{|c|}{ FREIGHT PERFORMANCE MEASURE CATEGORIES } \\
\hline NCFRP Report 10 & ODOT Report \\
\hline Demand & Mobility, Congestion and Reliability \\
\hline Efficiency & Maintenance \& Preservation \\
\hline System Condition & Environmental \\
\hline Environmental Impact & Safety \\
\hline Safety & Accessibility \& Connectivity \\
\hline & \\
\hline Adequacy of Investment & \\
\hline
\end{tabular}

Table 1 - Freight Performance Measure Categories 
Although NCFRP Report 10 suggests use of a freight performance measurement framework at a state level, the report also suggests that a major challenge towards such efforts is the availability of useful data. In addition, the Oregon Freight Performance Measures report notes that in order to apply some of the suggested performance measures to the freight system, the following conditions must be met: 1) freightspecific corridors or links should be identified; and 2) the volume of freight-specific activity should be quantified.

\subsubsection{Mobility, Congestion \& Reliability}

Mobility is one of the primary concerns for highway systems as it has direct connection to levels of congestion, travel-time variability, and increased emissions, not to mention significant costs to commercial truck companies (i.e., penalties for late deliveries) (NCFRP, 2011; Figliozzi et al., 2011; Wheeler and Figliozzi, 2011). According to NCFRP Report 10, "Negative impacts of freight bottlenecks are expected to become more severe as the demand for freight transportation continues to grow and peak period congestion increases." Of the six performance measures included in the NCFRP Report 10, freight efficiency has probably received the most attention on a national level, specifically as it relates to traveltime reliability and congestion at bottlenecks (McMullen and Monsere, 2010). One of the more significant documents published by the Texas Transportation Institute is the Urban Mobility Report, which provides mobility measures for each state. Further, many efforts towards freight transportation models have been focused towards improving mobility. In fact, Strategy 11.2 of the Oregon Freight Plan seeks to develop models that "evaluate effects of disruptions on freight movement at the state, regional and urban levels." Below are some commonly used mobility performance measures:

- $\quad$ Travel Time: the time taken by a driver to travel between an origin and a destination (Figliozzi et al., 2011).

- Travel-Time Reliability: NCHRP 618 recommends use of $90^{\text {th }}$ and $95^{\text {th }}$ percentile travel times (reflecting travel-time delays that can occur during heavy congestion) as an indicator of travel-time reliability (Figliozzi et al., 2011).

- $\quad$ Travel-Time Index (TTI) is the ratio of the average $\mathrm{s}^{\mathrm{pe}}$ ed for ${ }^{\mathrm{a}}$ given highway segment at a particular time of day to the functional free-flow speed of the same segment of highway (Park, Pierce and Short, 2012).

- $\quad$ Planning-Time Index (PTI) is the ratio of the "worst-case scenario" average travel speed for a given highway segment at a particular time of day to the functional free-flow speed of the same segment of highway.

NCFRP Report 10 designates "demand" as a separate freight performance measurement category from mobility. However, many of the freight-demand measures used by DOTs tend to overlap with freightmobility measures. Some measures addressing freight demand directly include: volume-to-capacity ratio $(\mathrm{V} / \mathrm{C})$, percent of congested miles, interstate motor carrier vehicle miles traveled, and freight tonnage by mode (McMullen and Monsere, 2010). 
Freight data available to ODOT with potential for mobility measurement includes that from their 22 Green Light-equipped WIM stations. Some data from these stations has been uploaded to the Portland Oregon Regional Transportation Archive Listing (PORTAL) - the official Archived Data User Service (ADUS) for the Portland metropolitan area. The Green Light data provides an opportunity to estimate travel time for commercial trucks. The penetration rate of transponder-equipped trucks was found to be about $40 \%$ and covers key rural interstate and freight corridors throughout Oregon (McMullen and Monsere, 2010). Research associated with this data has been successful in developing mobility and congestion measures of performance by quantifying:

- Overweight vehicles

- Ton-miles on corridors

- Empty vehicles

- Penetration of trucks with truck transponders

- Origin-destination estimations

- Seasonal variability in various measures

- Travel-time estimations (Wheeler and Figliozzi, 2011).

\subsubsection{System Condition - Maintenance, Preservation and Design}

Maintenance and preservation efforts by state DOTs typically focus on highway bridge and pavement management. Of the loads applied to these forms of infrastructure, those from commercial trucks are perhaps the most significant in terms of damage caused and resulting expenditures. The estimate of appropriate design loads for bridges is a complex process, and the related technical research and knowledge is constantly expanding. However, per standard practice, bridge wear is primarily a function of vehicle gross weights. ODOT's Bridge Engineering Section maintains the state's Bridge Log, which includes data for each bridge in Oregon such as highway number, milepoints, vertical and horizontal clearances, and design loading. The MCTD Freight Mobility Map shows routes that are restricted as well as horizontal and vertical restrictions (McMullen and Monsere, 2010).

According to Infrastructure Costs Attributable to Commercial Vehicles (Boile, Ozbay and Narayanan, 2001), transportation departments allocate $40 \%$ or more of their annual budgets to pavement maintenance and rehabilitation projects. In addition, most pavement damage is caused by heavy vehicles. In fact, the relationship between axle loads and consequent pavement damage is known to be exponential (Pavement Interactive, 2012). Pavements are typically designed to serve a certain number of equivalent single-axle loads or load equivalence factors over a 20-year design life (Econorthwest, 2011). ODOT and many other states design pavement structures for a 20-year design life using the Mechanistic Empirical Pavement Design Guide (ODOT and DLCD, 2011). The guide's design methods are based on the concept that pavement damage is a function of axle loading. ODOT's Pavement Management Unit currently evaluates the state highway system every two years using pavement condition surveys. National Highway System highways are rated by a distress survey method; all other highways are typically rated by a Good-FairPoor approach (McMullen and Monsere, 2010). The ODOT Pavement Management System then uses the survey data to determine appropriate maintenance, preservation and design proposals for the highway pavement system. 
The ways in which loads impact bridges and pavements differ. Bridge wear is primarily a function of vehicle gross weights; pavement wear is primarily a function of axle weights. As a result, data that provides estimates of both gross vehicle weight as well as axle spacing of the vehicles using different highway segments is useful when estimating road user impacts on the transportation system. ODOT's transportation volume tables provide ADT volumes from the last 10 years as measured by automated traffic records (McMullen and Monsere, 2010). These tables are published annually and provide average weekday traffic volumes by month and percentage of vehicles in each of 14 vehicle classifications. Annual average daily traffic (AADT) volumes by milepoint are also included for some locations. Tonnage estimates can be derived by applying an average weight per truck.

\subsubsection{Environment}

In a survey conducted in 2010, the second most frequently stated transportation policy goal (listed by 32 of the DOT websites reviewed) was environmental stewardship (McMullen and Monsere, 2010). Performance measures used by state DOTs to measure the success of environmental stewardship include emissions of:

- Volatile organic compounds (VOC)

- Nitrous oxides (NOx)

- Carbon monoxide (CO)

- Ozone (O3)

- Particulate matter (PM)

- Greenhouse gasses (GHG)

Many of the emission types measured are known to be causes of health concerns. In particular, NOx is linked to respiratory problems; particulate matter $\left(\mathrm{PM}_{10}\right)$ and ultrafine particulate matter $\left(\mathrm{PM}_{2.5}\right)$ are linked to cancer and heart problems.

Measurements such as "clear air days" and "fuel usage per capita" are also sometimes used. However, many of the measures used are affected by sources other than the transportation or freight sectors, and the tools used for measurement are typically not transportation or freight specific. As a result, quantifying environmental impacts of the freight system is difficult. If data is available, emissions estimates can be calculated using data related to traffic, speed and fuel type (McMullen and Monsere, 2010). Research has shown that major increases in emission rates can be caused by: speeds outside the 30 to $60 \mathrm{mph}$ range, heavy vehicle loads, and increases in grade (Wheeler and Figliozzi, 2011), vehicle age and poor maintenance of vehicles (Singh, 2012). Changes in speed during congestion have a significant impact on emissions during peak hours. Agencies are able to link transportation performance to environmental and health goals through estimations of tailpipe emissions. A three-step process is often used where outputs from one step are the input for the next. This process typically consists of the following models: a) transportation demand-traffic models; b) emissions rate models; and c) pollution dispersion models.

The U.S. EPA Office of Transportation and Air Quality provides a variety of models to estimate emissions. However, MOVES2010b is EPA's current official model for estimating air pollution emissions from mobile sources (i.e., cars, trucks, motorcycles) (U.S. EPA, 2012). In the future the program will also model non-road emissions (i.e., ships, locomotives, aircraft). The simulator covers a broad range of 
pollutants including GHG, select mobile source air toxics (MSAT), and criteria pollutants. According to Oregon's Freight Performance Measures report (McMullen and Monsere, 2010), MOVES is the "best tool for quantifying criteria pollutant and precursor emissions." MOVES2010b, released in June 2012, and MOVES2010a, released in August 2010, are minor updates to MOVES 2010. The Federal Highway Administration (FHWA) performed a sensitivity analysis in 2009 using MOVES (Houk, 2009). The results indicated that emissions estimates from MOVES are very sensitive to speed, vehicle types and vehicle age. In 2010, Choi et al. completed research to analyze the sensitivity of MOVES emission estimates to changes in temperature and humidity. Results emphasize the importance of obtaining accurate local meteorological data when using MOVES.

More recently, a "regional level" sensitivity analysis was performed by the FHWA in an effort to highlight areas where air-quality practitioners should focus to refine their MOVES model inputs. This study focused on running emissions processes for CO, PM2.5, NOx and VOCs. The variables considered and input ranges used included:

$\begin{array}{ll}\text { - } & \text { Temperature (-40F to } 120 \mathrm{~F}) \\ \text { - } & \text { Humidity (0 to } 100 \%) \\ \text { - } & \text { Anamp fraction (0 to } 0.20) \\ \text { - } & \text { Age distribution (three groups) } \\ \text { - } & \text { Average speed distribution }\end{array}$

The results were generally consistent with those from the aforementioned sensitivity analyses. Emissions rates were found to be very sensitive to changes in speed, vehicle type, age, humidity and temperature.

NCFRP Report 10, which focuses on performance measurements specific to the freight sector, addresses the concern of rising GHG emissions. According to the report, national targets for other types of large/heavy-duty truck emissions are on track, but the truck industry's GHG emissions continue to rise. Unlike with other types of emissions, methods to reduce vehicular GHG emissions have not yet been developed (NCFRP, 2011).

ODOT recognizes the need to address this concern and has developed the GreenSTEP (Greenhouse Gas Statewide Transportation Emissions) Planning Model to assess the effects of policies and other factors (i.e., gas prices) on GHG emissions from the transportation sectors (ODOT and DLCD, 2011). The GreenSTEP Planning Model will be discussed in more detail in the "ODOT Transportation Planning \& Modeling" section of this report.

\subsubsection{Safety}

In a survey conducted in 2010, the most frequently listed transportation policy goal (listed by 42 of the states surveyed) was safety (McMullen and Monsere, 2010). "Fatality rate" (fatalities per 100 million vehicle miles traveled (VMT)) was the most frequently referenced safety performance measure (listed by 19 states). Accident rates, crash rates and personal injury rates are other measures states often use. Some states also collect data to classify the location of accidents (i.e., work zones, signalized intersections) to 
determine appropriate safety improvements. These performance measures are usually considered in the context of passenger transportation; however, data can be filtered for incidents involving commercial vehicles. Safety performance measures currently used by Oregon include:

- Fatality rate (per 100 million VMT)

- Alcohol-related fatality rate (per 100 million VMT)

- Rate of personal injury accidents (per 100,000 VMT)

- Percent of drivers without traffic violations or accidents during the past three years

- Rail derailments

- Highway-railroad at-grade incidents

In Freight Performance Measures: Approach Analysis, the researchers suggest the following as the ideal safety freight performance measure for both statewide and specific highway segments:

Total cost of freight loss and damage from accidents

Total freight VMT

where "total cost of freight loss" includes: 1) cost of lost and damaged equipment; 2) value of lost and damaged cargo; and 3) delay imposed to other freight carriers on that highway or corridor. This measure provides both an indication of safety and mode reliability. Further, values of damaged equipment and cargo are likely valuable measures for the freight industry as they could impact insurance claims, thus increasing premiums. However, in the survey of states conducted for the Approach Analysis it was determined that no other states currently measure such costs and values. The researchers discussed the following accident data sources for Oregon's existing and proposed freight safety performance measures:

\begin{tabular}{|c|c|c|}
\hline Agency & Data Resource & Data \\
\hline \multirow{3}{*}{$\begin{array}{l}\text { ODOT } \\
\text { DMV }^{1}\end{array}$} & \multirow{3}{*}{$\begin{array}{l}\text { Oregon Traffic Accident } \\
\text { and Insurance Report }\end{array}$} & Citizens must file within 72 hours of a "significant" accident \\
\hline & & $\begin{array}{l}\text { Vehicle type included - data can be filtered for freight } \\
\text { vehicles }\end{array}$ \\
\hline & & Crash location \\
\hline \multirow{5}{*}{$\begin{array}{l}\text { ODOT } \\
\text { CAR }^{2}\end{array}$} & \multirow{5}{*}{$\begin{array}{c}\text { Annual Motor Carrier } \\
\text { Crash Rates (Crashes / } \\
\text { VMT) }\end{array}$} & Crash rates for all motor carriers \\
\hline & & Truck at fault crashes \\
\hline & & Fatal crashes \\
\hline & & Triple crashes \\
\hline & & $\begin{array}{l}\text { Annual "Estimated Societal Costs of Truck Crashes in } \\
\text { Oregon" }\end{array}$ \\
\hline \multirow{4}{*}{$\mathrm{FMCSA}^{3}$} & \multirow{2}{*}{$\begin{array}{l}\text { Accident forms submitted } \\
\text { (managed by ODOT CAR) }\end{array}$} & Commodity carried \\
\hline & & Property damage estimates \\
\hline & \multirow{2}{*}{$\begin{array}{l}\text { Motor Carrier Safety } \\
\text { Inspections }\end{array}$} & Reported by states via $S A F E R^{4}$ system \\
\hline & & Targeted at violations "more likely to cause a crash" \\
\hline \multirow{2}{*}{ ODOT } & Truck WMT Statewide & weight-mile tax records \\
\hline & Truck VMT Hwy Specific & "other counting programs" \\
\hline
\end{tabular}

Table 2 - Oregon Accident Data Sources 
1 - ODOT Driver and Motor Vehicle (DMV) Service Division

2 - ODOT Crash Analysis and Reporting (CAR) Unit

3 - Federal Motor Carrier Safety Administration (FMCSA)

4 - Safety and Fitness Electronic Records (SAFER)

The Estimated Societal Costs of Truck Crashes in Oregon is a graph published annually by the CAR Unit. "Societal Costs" of crashes for this graph are determined by assigning values to each crash based on its relative severity. The accident forms submitted to FMCSA by motor carriers are another useful source of data as they include information that is not collected for Oregon's statewide dataset (i.e., commodities, property damage estimates). This data could be used in conjunction with the performance measure suggested by Equation 1. Although the FMCSA data provides only property damage values, and not cargo damage estimates, average cargo value for trucks in Oregon could be determined via other data sources such as the Bureau of Transportation Statistics' Commodity Flow Survey. The proportion of cargo damaged could then be estimated with the FMCSA crash severity data.

The Approach Analysis also suggested the following highway safety performance measures that could be directly estimated for both specific highway segments as well as the statewide system via the data listed in Table 2:

- Motor carrier crash rate and triple-trailer crash rate

- Motor carrier truck at-fault crash rate

- Total cost of freight loss and damage from accidents per VMT

\subsubsection{Accessibility \& Connectivity}

Performance measures for accessibility and connectivity often overlap with those for mobility, congestion and reliability as they include measures such as the number of miles traveled by various classes of customers on various classes of roads. Speed data for freeway and interconnector roads is critical to estimate conditions for intercity long-distance truck activity, although speed is often considered a mobility measure as well (McMullen and Monsere, 2010). Oregon's Freight Performance Measures: Approach Analysis lists the following connectivity measures used by other states:

- Percent of freeway lane-miles and arterial lane-miles with AADT at or above congested levels used by Maryland.

- Travel speed on state interregional connections - used by Maine.

- Average truck turnaround time at key marine ports - used by Maryland.

Oregon's intermodal freight system consists of marine facilities (ports), airports and highways, as shown in

Figure 1 and Figure 2. Figure 2 shows the location of intermodal connections (truck-to-rail, truck-toair, and truck-to-ship). The 2005 Oregon Highway Plan designates specific highway segments as part of the freight system (see Figure 3). This data is provided by the Bureau of Transportation Systems National Transportation Atlas and is updated annually (McMullen and Monsere, 2010). 


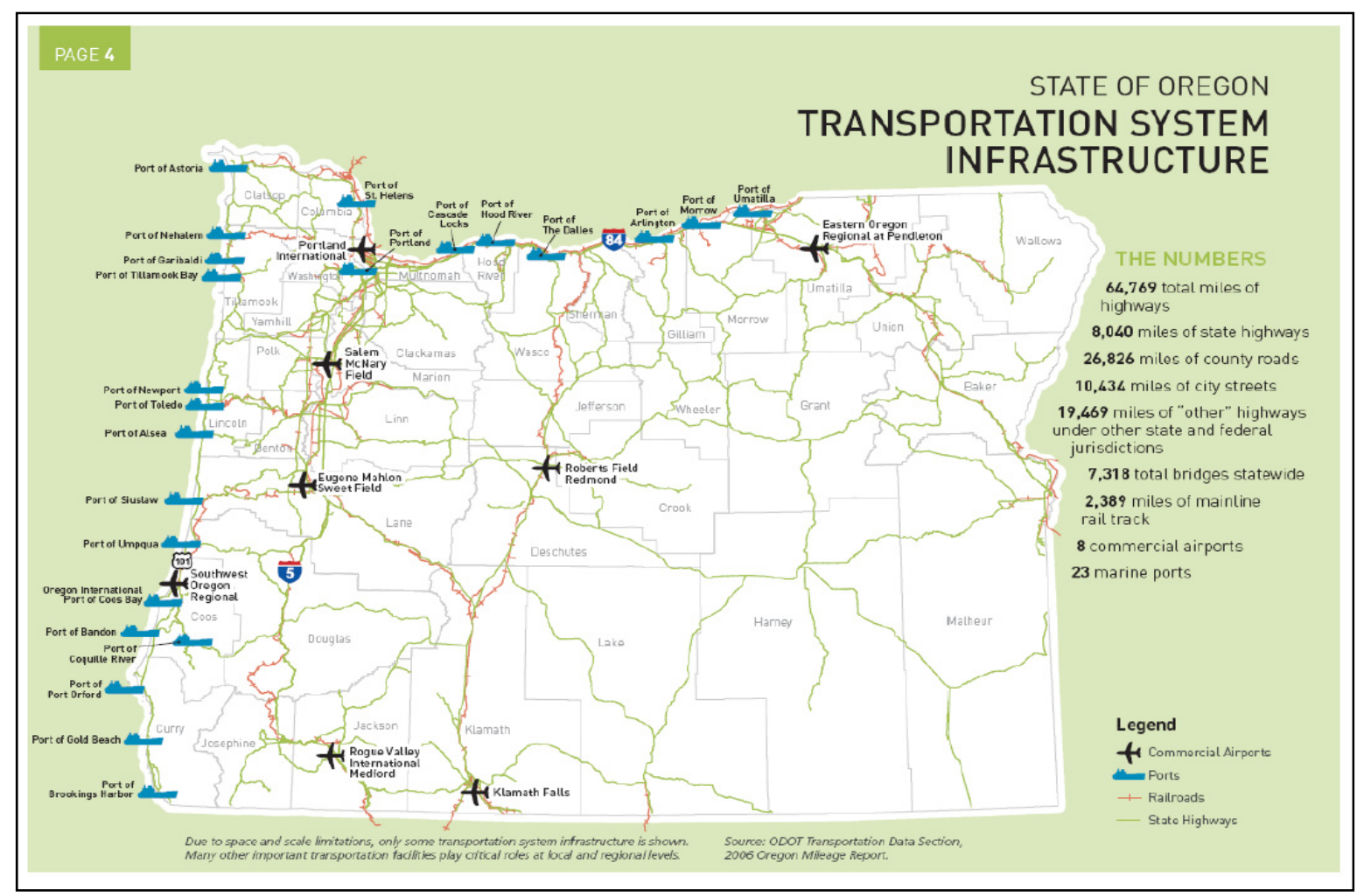

Figure 1 - McMullen \& Monsere - Oregon Freight Transportation Figure 1

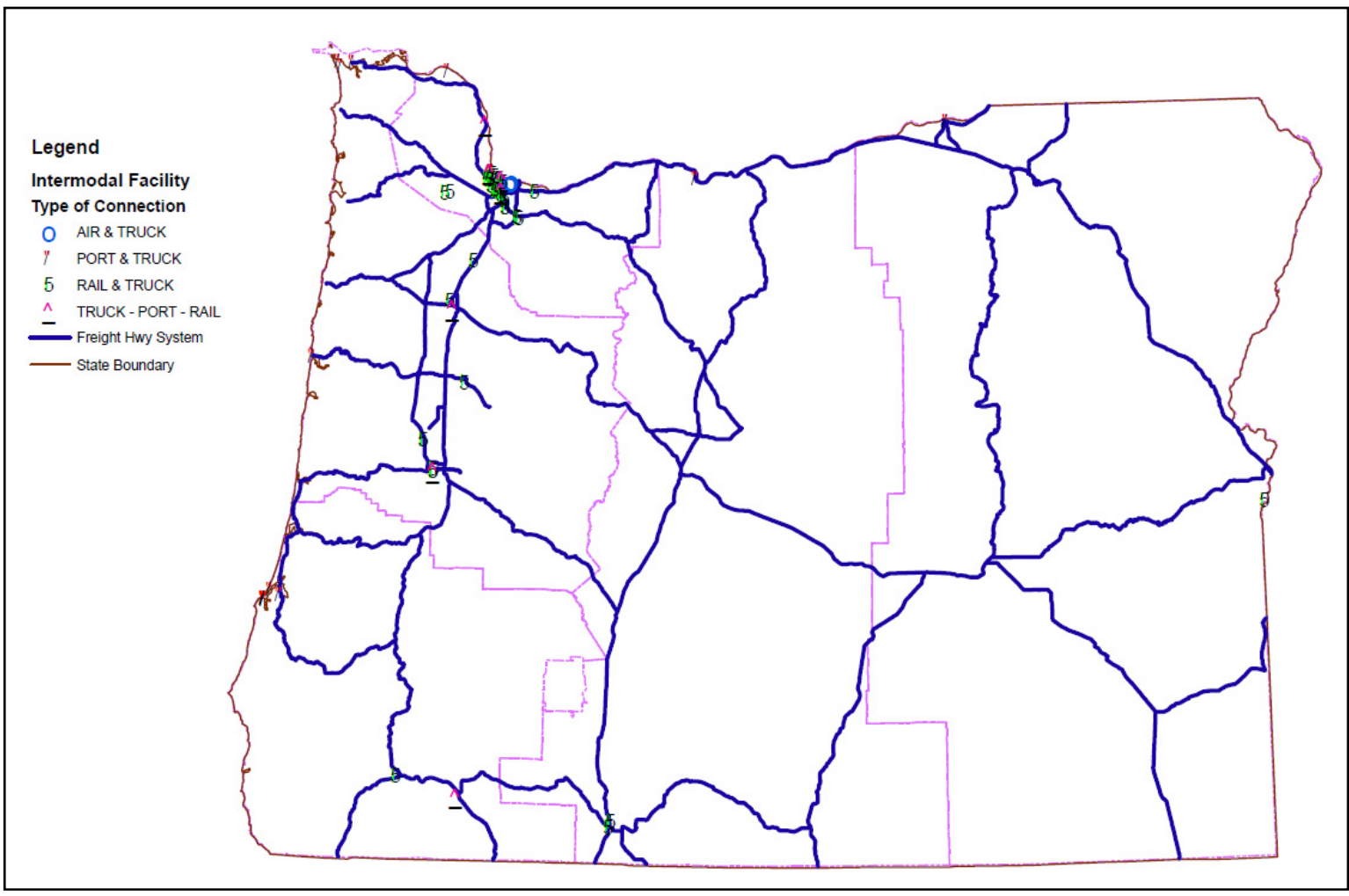

Figure 2 - McMullen \& Monsere - Oregon Freight Transportation Figure 2 


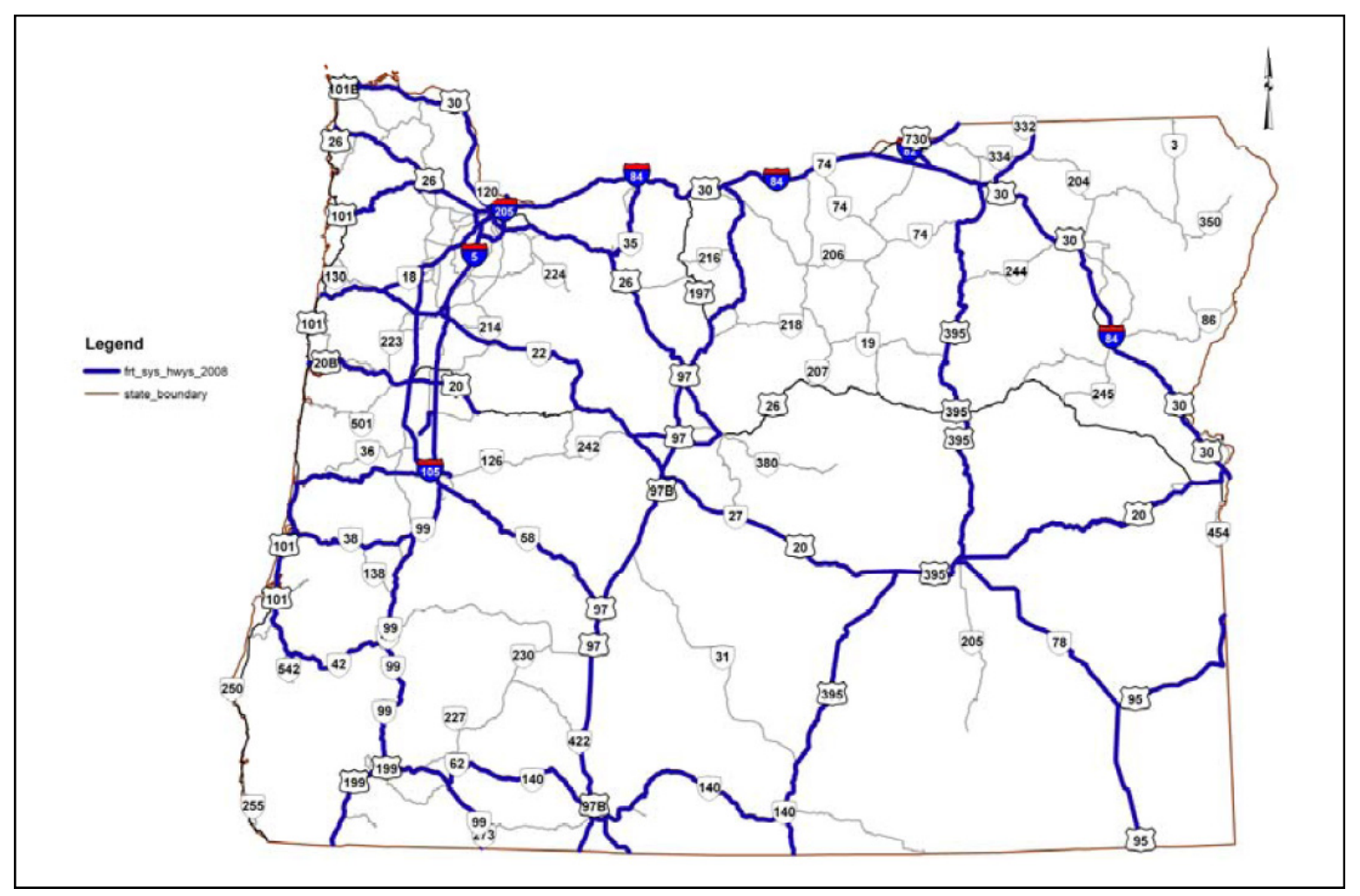

Figure 3 - McMullen \& Monsere - Oregon Freight Transportation Figure 3

Potential existing data sources to measure accessibility and connectivity include Oregon's weight-mile tax records. ODOT currently uses this data to estimate truck VMT as well as the VMT for longer combination vehicles (LCVs), also known as "triples." Expansion of the LCV network was frozen by the Intermodal Surface Transportation Efficiency Act (ISTEA) in 1991 (McMullen and Monsere, 2010). As such, not all ports and airports may have direct access to the LCV network. In addition to the connectivity measures previously suggested, McMullen and Monsere suggest "percent of freight originating or terminating within a certain number of miles of LCV corridors" as a potential measure of accessibility; however, they note that shipment origin or destination data "does not contain that level of specificity."

\subsubsection{Adequacy of Investment in Freight System}

Freight system investment measurements are those which measure the adequacy of proposed investment amounts to sustain both the condition and performance of the freight system. At a federal level, the NCFRP Report 10 defines this measure as the ratio of the total estimated national investment in the National Highway System over the next 10 years to the amount necessary to sustain current performance (NCFRP, 2011). The Conditions and Performance Report, completed biannually by the FHWA, provides data to determine this ratio. At the state level, the Oregon Highway Cost Analysis Study (HCAS) provides an overview of the estimated costs of maintaining Oregon's highway system. The Oregon Constitution requires that such a study be completed every two years to ensure that road fees are allocated appropriately between "light" and "heavy" vehicles. The Oregon Department of Administrative Services' Office of Economic Analysis completes the study with assistance from consultants (Econorthwest, 2011). Highway costs are typically classified into two categories: agency costs and user costs. Agency costs include initial construction, future rehabilitation and preventive maintenance, project overhead, and traffic 
control. User costs include vehicle operation, user delay and crash costs (Boile, Ozbay and Narayanan, 2001). The most recent Oregon HCAS estimated an average annual expenditure amount of $\$ 1,505,483,000$ towards "highway costs," as outlined in Table 3.

\begin{tabular}{|c|c|c|c|c|c|c|c|c|c|}
\hline \multicolumn{10}{|c|}{ Exhibit 4-5: Average Annual Expenditures by Category and Funding Source (thousands of dollars) } \\
\hline $\begin{array}{l}\text { Major Expenditure } \\
\text { Category }\end{array}$ & $\begin{array}{l}\text { State } \\
\text { Funds }\end{array}$ & $\begin{array}{l}\text { Percent } \\
\text { of All } \\
\text { Sources }\end{array}$ & $\begin{array}{l}\text { Federal } \\
\text { Funds }\end{array}$ & $\begin{array}{l}\text { Percent } \\
\text { of All } \\
\text { Sources }\end{array}$ & $\begin{array}{l}\text { Local } \\
\text { Funds }\end{array}$ & $\begin{array}{l}\text { Percent } \\
\text { of All } \\
\text { Sources }\end{array}$ & $\begin{array}{l}\text { Bond } \\
\text { Funds }\end{array}$ & $\begin{array}{l}\text { Percent } \\
\text { of All } \\
\text { Sources }\end{array}$ & $\begin{array}{l}\text { All Funding } \\
\text { Sources }\end{array}$ \\
\hline Modernization & 92,570 & $42.7 \%$ & 102,601 & $47.3 \%$ & 19,014 & $8.8 \%$ & 2,535 & $1.2 \%$ & 216,720 \\
\hline Preservation & 40,526 & $33.0 \%$ & 69,490 & $56.7 \%$ & 12,463 & $10.2 \%$ & 157 & $0.1 \%$ & 122,636 \\
\hline Maintenance & 324,521 & $70.6 \%$ & 80,064 & $17.4 \%$ & 55,281 & $12.0 \%$ & 119 & $0.0 \%$ & 459,986 \\
\hline Bridge $\theta$ & 25,137 & $17.3 \%$ & 109,180 & $75.3 \%$ & 1,088 & $0.7 \%$ & 9,671 & $6.7 \%$ & 145,075 \\
\hline Other & 397,221 & $70.8 \%$ & 124,717 & $22.2 \%$ & 31,250 & $5.6 \%$ & 7,878 & $1.4 \%$ & 561,066 \\
\hline All Expenditures & 879,975 & $58.5 \%$ & 486,051 & $32.3 \%$ & 119,096 & $7.9 \%$ & 20,361 & $1.4 \%$ & $1,505,483$ \\
\hline
\end{tabular}

Table 3 - Oregon HCAS - Average Annual Expenditures

\subsection{SMART PHONE APPLICATIONS IN TRANSPORTATION}

As cell phone technology has evolved, so too have efforts and interest in using these devices in a variety of roles in the transportation sector. There is evidence of research, dating back to the earliest cell phones, that deployed technology to glean information about travel behavior, travel times and other factors.

A common goal of cell phone applications is the estimation of travel times. A report for the Florida Department of Transportation (Wunnava et al., 2007) evaluated the travel-time measurements that were estimated by five companies using cell phone technology. Estimates were evaluated on the basis of methodologies, data filtering and aggregation, reliability of data, and other key measures. The study observed good results in free-flow or fast traffic conditions; the study was inconclusive as to the accuracy of estimations in heavy traffic.

In order to accurately estimate travel times and other performance measures, determining the location of a cell phone is clearly a key consideration. In 2000, Zhao reviewed the three most common location detecting technologies - stand-alone (dead reckoning), satellite-based (GPS), and terrestrial-based (navigation systems, cell networks) - and discussed the accompanying tradeoffs, the attempts at standardization of the technologies, and their potential impacts on safety, response time, crash avoidance, etc. Zhao also provided an extensive technical description of each technology, and concluded that the cellID-based method has the worst positional accuracy, while assisted GPS has the best positional accuracy.

Along these lines, in 2008 Barbeau et al. addressed the consideration that with location-based GPS, several issues arise, including the tradeoff between data accuracy and battery life, data transmission costs and burden on the server. The researchers introduced two algorithms, a "Critical Point" algorithm and a "Location-Aware State Machine" algorithm, intended to ensure that the GPS devices did not waste battery power obtaining fixes when these would not enhance the quality of the position data. 
Newer uses that involve smart phones tend to utilize the increased computing power of these devices by taking calculations one step further to emissions estimates, and can communicate information back to the driver regarding emissions, green driving, etc. There is a young body of literature exploring the possibilities of integrating the smart phone apps with various intelligent transportation systems. Zheng et al. (2008) presented an approach based on supervised learning that is proposed to infer transportation mode via raw GPS data, from which other information such as emissions estimates could be obtained. Similarly, Manzoni et al. (n.d.) introduced a two-step algorithm to identify transportation mode and estimate the corresponding emissions in a study using new Google Nexus One smart phones. Froehlich et al. (2009) conducted surveys to gauge respondent's willingness to engage in more green transportation, and found willingness among participants but lack of knowledge. Accordingly, they introduced an app to track transportation habits and "semi-automatically" sense mode choice, providing feedback to the user about eco-friendly behavior.

Summary:

- Efficient battery usage - "Critical Point" and "Location-Award State Machine" algorithms to ensure GPS devices do not waste battery power.

- Emissions estimates - results and suggestions to user.

- Transportation mode - determined via raw GPS data.

- Track transportation habits - mode choice reports and suggestions to user.

\subsection{RELATED RESEARCH}

As the availability of freight GPS data has increased, so too has research showing promise for using such data in transportation planning. This subsection provides a review of recent research focused towards development of systems and methodologies to process such data, as well as research that explores potential ancillary applications for the data. Table 4 provides a summary of research reviewed in this subsection. The freight performance measure categories included in the table are those that were discussed earlier in this report, and that have been receiving increasing attention at both the national and state levels. The work included in this table is not intended to be an exhaustive list, but rather a representation of research relevant to this project. 


\begin{tabular}{|c|c|c|c|c|c|c|c|c|c|}
\hline \multirow[b]{2}{*}{ 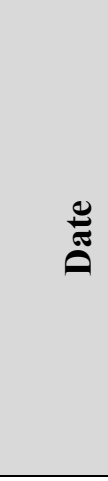 } & \multirow[b]{2}{*}{ Authors } & \multicolumn{5}{|c|}{ Performance Measures } & \multirow[b]{2}{*}{ 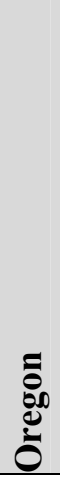 } & \multirow[b]{2}{*}{ 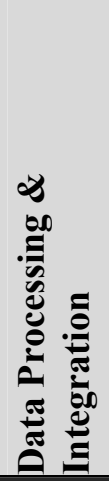 } & \multirow[b]{2}{*}{ 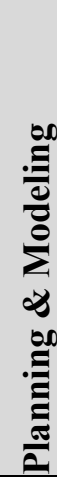 } \\
\hline & & $\frac{i}{i}$ & 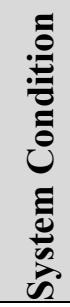 & 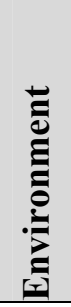 & $\frac{\vec{e}}{\frac{\pi}{E}}$ & 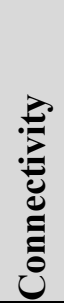 & & & \\
\hline 2008 & Greaves \& Figliozzi & & & & & & & & \\
\hline 2010 & Sharman \& Roorda & & & & & & & & \\
\hline 2010 & Holguin-Veras et al. & & & & & & & & \\
\hline 2011 & Wheeler \& Figliozzi & & & & & & & & \\
\hline 2011 & Figliozzi et al. & & & & & & & & \\
\hline 2011 & McCormack et al. & & & & & & & & \\
\hline 2012 & You \& Ritchie & & & & & & & & \\
\hline 2012 & FHWA/ATRI & & & & & & & & \\
\hline 2012 & Park, Pierce \& Short & & & & & & & & \\
\hline
\end{tabular}

Table 4 - GPS Data Research Summary

\subsubsection{Issues \& Applications - Greaves \& Figliozzi (2008)}

One of the earlier, successful urban scale examples of the use of commercial truck GPS data for transportation engineering applications was performed in Australia (Greaves and Figliozzi, 2008). This research used truck GPS data from a pilot study aimed at supporting a major update of freight data and modeling capabilities in the greater Melbourne region. GPS records were collected every second for 30 trucks over a week. This research focused on passive GPS methods - those in which the driver's involvement is minimal. Trucks were installed with GEOSTATS ${ }^{\circledR}$ in-vehicle GPS devices. PYTHON ${ }^{\mathrm{TM}}$ programming language and the scripting language of the TransCAD ${ }^{\mathrm{TM}}$ GIS package were used to apply computer software applications that would manage, manipulate and process the data. The processing routines used were based on those developed for passenger cars; minor modifications were made for use with trucks. The data processing method used consisted of the following steps: 
Step 1: Data Pre-processing. Simple reformatting steps including calculation of date and time, correction of latitude/longitude records, conversion of time format, and computation of distance and elapsed time. Routines to identify and deal with problematic records (i.e., no movement recorded, less than four satellites in view, or a Horizontal Dilution of Precision of five or more).

Step 2: Trip Identification Algorithm. Differentiate between "genuine" stops and "false positive" stops (those associated with congestion, signals, etc.) to determine trip ends. Trip ends were defined in part by an elapsed time of at least four minutes based on experimentation. This time threshold was determined to be the critical issue to complete the trip identification step.

Step 3: Signal Loss and Data Repair. Data was identified as missing if the elapsed time between records was more than one second but less than four minutes (the established time threshold for a trip end). Bad data was defined as having less than four satellites in view and/or a HDOP of five or more. Bad/missing data was found to account for a loss of approximately $5 \%$, or 70 hours' worth, of what would otherwise have been recorded. Logic was used to replace each bad/missing data point.

Step 4: Location Information. Use simple geocoding techniques to attach Traffic Analysis Zones (TAZs) and street addresses to each origin-destination stop. Businesses could also be included if the information is available.

Final output from the data processing consisted of: 1) Summary trip-level file for further analysis; 2) second-by-second file of all trips; and 3) daily map showing trip information. An example of the tabular and graphical trip-level output is included in Figure 4. The time required to run the automated process averaged one hour per truck (four minutes per truck day). An additional hour was required per truck to manually check the output. Pilot survey tour statistics (averages, medians, standard deviations, etc.) could be deduced from the data output for:

- Tour length

- Tour duration

- Proportion of tour time spent on the road

- Speed while on the road

- Tour stops 


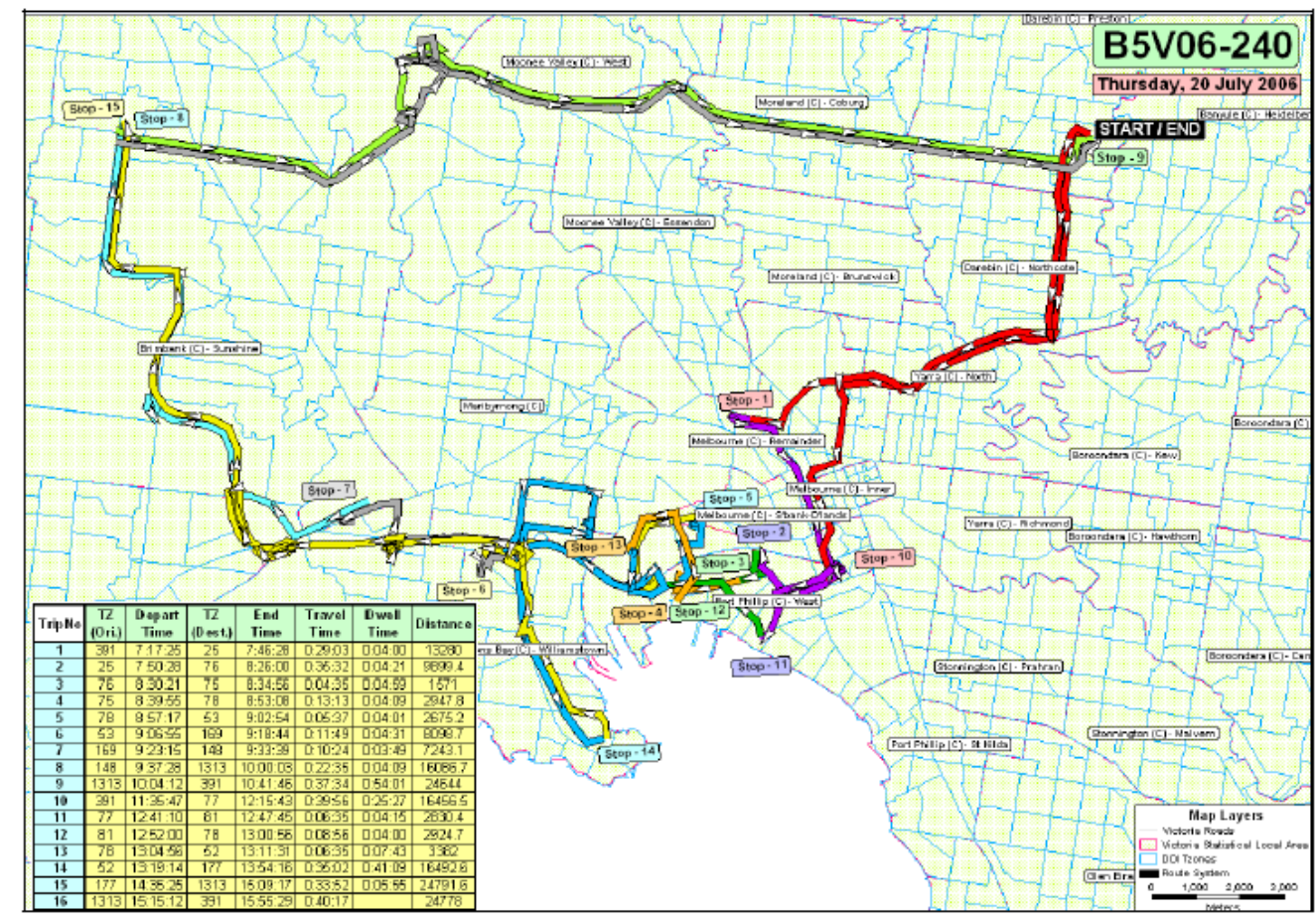

Figure 4 - Greaves \& Figliozzi - Example GPS Plot and Tabular Data of Truck Trips

\subsubsection{Processing GPS Data - Sharman \& Roorda (2010)}

Sharman and Roorda (n.d.) researched processing techniques used to convert GPS data into a form suitable for travel-demand modeling applications. Challenges encountered with the GPS data included resolution of GPS data (intervals of point collection ranged from 500 meters to two miles) and trip-end identification challenges. The GPS data was processed using a custom program created in C\#. The processing method used consisted of the following steps:

- Data cleaning - Identify infeasible latitude/longitude values and "false-positive stops." A stop was defined as a "false-positive" and removed from the data set if: a) it is located within a 40 meters buffer of the freeway; or b) the stop duration was under 15 minutes and the stop was located within 20 meters of a major arterial road.

- Tracking vehicle GPS points - Identify stops and vehicle trips including "false-negative" (missed) stops and remove short (within-yard) trips. Missed stops are assumed if: 1) the time interval between two GPS points exceed 30 minutes; and 2) the average speed is below $5 \mathrm{~km} / \mathrm{hr}$ and only one point is on a freeway.

- Clustering GPS trip ends into destinations - The researchers determined that Ward's clustering method, which is a hierarchical agglomerative clustering (HAC) method, produced the best results. Ward's method was combined with a two-step approach to determine appropriate "distance thresholds." Further details of this process can be found in the report by Sharman and Roorda. 
- Depot identification and tour creation-Depots are identified by: 1) the number of times the destination was visited by all vehicles in the same fleet; and 2) if vehicles routinely remain at the destination for extended periods of time. Vehicle tours were created by joining sequential trips observed in the data.

According to the research, through the use of GPS data, the model developed was an improvement on other travel-demand models in that it represents vehicle routing and scheduling over longer time periods to reflect daily, weekly or other schedule repetitions. It should be noted that the researchers were still in the process of developing the final step of this process (Depot Identification and Tour Creation) at the time of the report.

\subsubsection{Freight Demand Management - New York City Metropolitan Area (2010)}

Perhaps one of the more progressive uses of GPS data has been in the New York City metropolitan area (Holguin-Veras et al., 2010). In a research project completed under a cooperative agreement with the U.S. Department of Transportation (USDOT), data was collected from GPS enabled cell phones and the Copilot|Live turn-by-turn navigation software. The project was funded by the USDOT's Commercial Remote Sensing and Spatial Information Technology Applications Program in March 2007. The total funding provided by USDOT was about $\$ 1.2$ million; the project partners provided $\$ 0.64$ million in matching funds. Goals and objectives of the project included:

- Shift truck traffic to the off-peak hours - reduction of $20 \%$ expected for some sectors.

- Improve traffic congestion and environmental conditions.

- Increase competitiveness of NYC via tax deductions to local businesses.

- Productivity increases from improved traffic conditions.

- Reduce parking fines - frequently exceeded \$1,000 per truck per month prior to project.

This commercial truck GPS data from the NYC system was used for the following:

- Estimating travel times and delays

- Compliance verification

- Data sharing among participating partners

- Validation of the traffic models used to predict the effects of the program

Through the development of this project, state-of-the-art analytical formulations and traffic-simulation systems were verified. In addition, the results of the study assisted in the development of new policies. According to the research, industry support was gained as the business benefits of the traffic-management concepts became understood. The system served to effectively reduce truck traffic during congested hours through the use of incentives to receivers. The project focused on urban deliveries rather than external flows passing through the area, as urban deliveries account for about $80 \%$ of the freight traffic in the metropolitan area. The research notes that the conclusions and methodologies developed should be "assumed to be valid only for the urban delivery case." 


\subsubsection{Oregon I-5 Congestion - Wheeler \& Figliozzi (2011)}

In 2011, Wheeler and Figliozzi studied tools for estimating the impacts of both recurring congestion (due to high traffic volumes) and non-recurring congestion (due to incidents, weather or construction) on freight along Interstate 5 (I-5) in the Portland metropolitan area. Specifically, mobility (speed, travel time, travel-time reliability), monetary costs and emissions were among the areas of impact considered. The study area consisted of a 31.75-mile segment of northbound I-5 from milepost 283.93 in Oregon to 7.3 in Washington. The GPS data used for this project was 2007 data provided by the American Transportation Research Institute (ATRI) as part of a research contract between FHWA and Portland State University (PSU). The data included: truck ID, date, time, and position (latitude/longitude) for each truck reading. The time interval between readings varied (was not set at a constant). ODOT loop sensor data was also used via PORTAL. The loop sensor data included count and speed measurements from the Portland region.

Wheeler and Figliozzi confirmed that when used alone, traditional loop data tends to underestimate the impacts of congestion on freight travel time and variability. Subsequently, the researchers developed a new methodology and algorithms for combining freight GPS data with loop sensor data to more accurately model congestion (Wheeler and Figliozzi 2011). Integrating the two data sources allows for validation between the sources and improves the filtering process to identify trucks that have experienced congestion. The method used to process and analyze the data was as follows:

Truck ID Matching: Trucks providing GPS data are categorized into four groups: through, partial-through, partial-local and local as outlined in the schematic/algorithm process included in Figure 5. This serves to distinguish trucks moving along the freeway ("through" trucks) from those making local movements (deliveries, rest, refueling, etc.). Through trucks have at least one reading before and after the "start" and "end" of the corridor. 


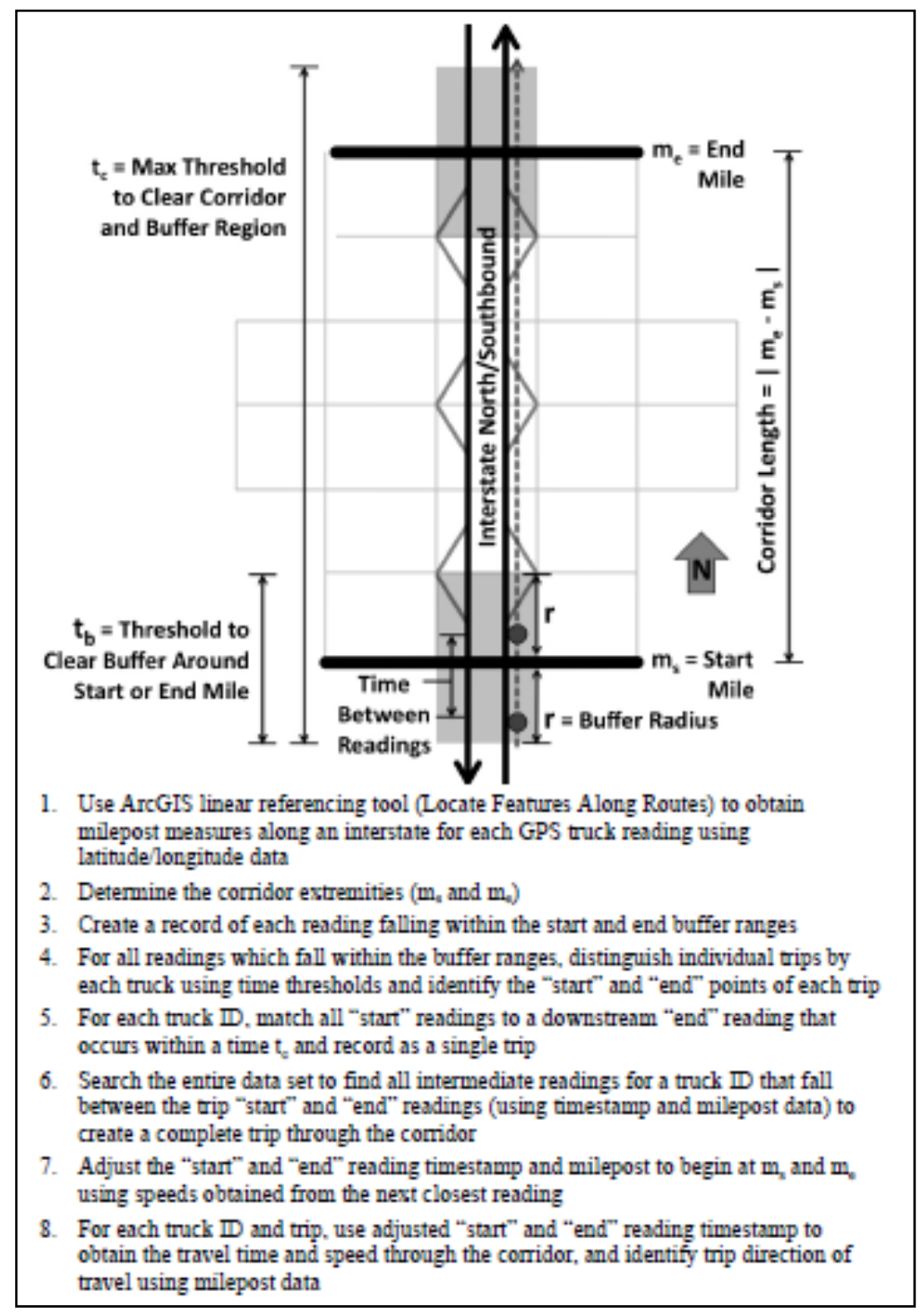

Figure 5 - Wheeler \& Figliozzi - Diagram Showing User-defined Parameters for Filtering Process 1 and Corresponding Algorithm Logic

Comparison to Loop Sensor Average Travel Time: Using methodology and algorithms developed by Wheeler and Figliozzi, integrate loop sensor data and GPS data to eliminate any remaining trucks that may have stopped midway through the corridor.

As expected, the data analysis indicated relatively high mean values and standard error of the mean values for through truck travel time on weekdays from 3-6 p.m. As such, the methodology was successful in determining that weekday PM peak hours have both longer and unreliable (inconsistent) travel times. In addition, a comparison of the coefficient of variation in travel time for the GPS data and PORTAL data indicated that the loop sensor data underestimates the impact of congestion on travel-time reliability.

Incident data available from PORTAL was used to determine whether congestion was recurring or nonrecurring. This data was from the ODOT Advanced Transportation Management System. Analysis of nonrecurring congestion was as described above, except that attention was restricted to a segment within five 
miles upstream of the incident. In comparison to the recurrent congestion results, the through-incident average speeds compared closely to the loop sensor data within the segment considered. An analysis was also performed using data for only partial-through and partial-local incident trucks. The results confirmed that standard error of the mean for partial-through/local trucks varies more so than for through only trucks, indicating that through trucks are the best indicator of performance estimations.

In addition to mobility analysis, the researchers used the results from the recurrent congestion analysis to estimate emissions. The hourly travel time and speed distribution results were used as input with EPA's MOVES2010 model to estimate average daily freight vehicle emissions per mile. The results provided the following indications that congestion and delay during peak hours are highly correlated to increased emissions:

- $80-120 \%$ increase in freight vehicle emission rates (per mile) during the PM peak period

- 24,099 gram daily increase (nearly 50\%) in CO2 emissions (per mile) as a result of congestion

- $65 \%$ daily increase in NOx emissions

- $13 \%$ daily increase in PM emissions

- $49 \%$ daily increase in SO2 emissions

The researchers note that further analysis could be completed using the new methodology for criteria beyond the three categories they analyzed: congestion, cost and emissions.

\subsubsection{Travel-Time Reliability Algorithms - Figliozzi et al. (2011)}

In 2011, Figliozzi et al. completed Algorithms to Study the Impacts of Travel Time Reliability along MultiSegment Trucking Freight Corridors, a project that explores the use of travel time as a performance measure for freight movement. This research consisted of a case study along the I-5 corridor in Oregon using commercial truck GPS data from ATRI. The researchers successfully applied corridor-level, traveltime reliability algorithms and programming logic to: 1) Identify natural segments in a corridor between major connecting points (i.e., interstate junctions); and 2) Estimate impacts of travel-time unreliability. The GPS data from ATRI provided a unique truck ID, timestamp and latitude-longitude coordinates for each data point. The following steps were then taken to process and analyze the data:

1) Map GPS latitude-longitude points to milepost measures and determine direction of travel - using ArcGIS linear referencing tool.

2) Determine cumulative truck counts - across the corridor for every mile.

3) Identify segments - identify sudden changes in truck counts; smooth cumulative truck counts using a moving average of 20 miles; note location, time of year and season of significant changes in cumulative count and break corridor into suitable segments; consider land use and speed limit when establishing segments. 
4) Estimate travel times for each segment using algorithm - The algorithm assumes that vehicle travel time within a segment is normally distributed. Data was imported into postgreSQL and scripts were written in PHP and Shell; provide outputs of 95th, 80th and 50th percentile travel times for each segment.

The researchers provided the following suggestions based on the results of this research:

- Use alternative systems, such as loop detectors, to calibrate "low speed threshold" - If this threshold is set too low it will include data from trucks that have left the interstate for an extended time; if it is set too high it will not include traffic that is accurately representing congestion.

- Use alternative systems to determine travel-time distributions - Other distributions such as lognormal or beta distribution might be a better fit than the assumed normal distribution.

- Conduct smaller case studies - Analyze data for segments over different days and different times of day, and compare different segment types (i.e., urban vs. rural).

- Compare to GIS data - Identified segments can be mapped against GIS data, such as that from the HPMS, in order to validate the results.

- Develop for other modes - Research and tools developed through this research can be expanded and adapted to develop performance measures for other modes.

\subsubsection{Washington DOT - Freight Performance Measures Program - McCormack et al. (2011)}

Considerable research has been done in the state of Washington on the use of commercial truck GPS data for developing transportation metrics. This research was generally aimed at evaluating the feasibility of such data to support a statewide network-performance measures program, and specifically, to monitor truck travel time and system reliability in order to guide freight investment decisions. In this regard, a series of research projects was conducted by McCormack et al. (McCormack, 2011; Bassok et al., 2011; Ma, McCormack and Wang, 2011; Y. Zhao, 2000) using data from private GPS vendors. Several projects completed in Washington prior to 2011 also provided background for this more recent research. The researchers noted the following disadvantages with purchasing and processing data from the GPS vendors:

- Time-consuming contracting - complex contracting process with GPS vendors due to privacy issues; non-disclosure agreements; attorneys required.

- Cost - ongoing cost to purchase data.

- Format inconsistencies - each vendor's data used different formats and communication methods.

- Data limitations - minimal information regarding truck size, truck class and freight being moved. 
(21); attempted to develop of a truck classification algorithm as a result, but with limited success.

- Data suitability - original intent of data was for fleet business needs; not an ideal data source for public performance measures.

- Data volume - over 100,000 location reads downloaded each day; programmers could eventually query nearly 10 million rows of data in a second.

The summary below outlines work that was performed in association with the 2011 research.

Step 1 - Development of a GPS Research Database: The researchers collected commercial-truck GPS data from private vendors for approximately 2,500 trucks in the Puget Sound region for over a year (Ma, McCormack and Wang, 2011). Trucking companies use GPS data from such vendors to dispatch and track their equipment. Table 5 provides an overview of the data collected from each vendor. GPS locations (latitude and longitude records) were then geocoded onto the road network (using a buffer of 100 feet from the roadway midpoint) for analysis by Geographical Information System (GIS) software. Analysis of the GPS data was performed using DriveNET - a transportation data analytical and visualization package operated at the University of Washington. Mapping errors due to assignment confusion were encountered in the areas of overpasses and frontage roads. As a result, post-processing of data (i.e., GIS scripting language) and error checking were required. Truck travel direction was then compared to the bearing of the roadway to confirm a match within 15 degrees. Using this process, approximately $60 \%$ of the points passed the screening process.

\begin{tabular}{|ccccc|}
\hline \multicolumn{5}{c}{ TABLE 2 } \\
\hline $\begin{array}{c}\text { GPS } \\
\text { Vendors }\end{array}$ & $\begin{array}{c}\text { Average } \\
\text { Total Daily } \\
\text { Records }\end{array}$ & Total Trucks & $\begin{array}{c}\text { Frequency of } \\
\text { reads (minutes) }\end{array}$ & Data type \\
\hline Vendor A & 94,000 & $\begin{array}{c}\text { Approx 2,500 } \\
\text { per day }\end{array}$ & $5-15$ & $\begin{array}{c}\text { In-vehicle } \\
\text { GPS with a } \\
\text { cellular } \\
\text { connection }\end{array}$ \\
\hline Vendor B & 12,000 & 25 & 0.5 & $\begin{array}{c}\text { In-vehicle } \\
\text { GPS with a } \\
\text { cellular } \\
\text { connection }\end{array}$ \\
\hline Vendor C & 3,000 & 60 & $1-5$ & $\begin{array}{c}\text { GPS cell } \\
\text { phone }\end{array}$ \\
\hline
\end{tabular}

Table 5 - McCormack - GPS Data Overview by Vendor

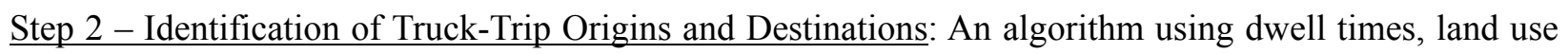
data and travel distance to differentiate between traffic-based stops (due to intersections or congestion) and stops at $\mathrm{O} / \mathrm{D}$ points. In addition, the algorithm resolved issues with the following (Ma, McCormack and Wang, 2011):

- Signal loss - GPS signals are blocked when overhead obstructions prevent GPS devices from 
communicating with satellites.

- Signal jiggle - the points input into a GIS system fluctuate around a position when a truck idles, creating a false report on movement.

- Multipath effects - GPS signals are reflected off the surface of objects located between the GPS satellites and the GPS device.

Step 3 - Development of Trip-Type Classification Algorithms: This step was required due to the aforementioned limitations of the data. Distance statistics between specified TAZs were collected from the Puget Sound Regional Council (PSRC) and then compared to corresponding statistics from the truck GPS data. This information was used to classify truck trips into three categories (access trips, local trips and loop trips) based on travel time, distance and stop characteristics (Ma, McCormack and Wang, 2011).

Step 4 - Development of Performance Measures: The GPS data was used to evaluate the following performance measures (Ma, McCormack and Wang, 2011):

- Free-flow speed and nominal travel time

- Average travel time

- Average travel speed

- Average travel distance

- Variability of travel time and variability of travel speed

- $95^{\text {th }}$ percentile travel time

- Travel-Time Index (TTI)

- Buffer-Time Index (BTI)

- $\quad$ Planning-Time Index (PTI)

Minimum sample size to determine link travel time and speed measures was determined using the below equation which has been widely used in previous research. This equation assumes that the speed of vehicles (or travel time) follows a normal distribution.

$$
n=\left(\frac{z_{\alpha / 2} S}{\varepsilon_{r} \bar{x}}\right)^{2}
$$

where,

$\alpha=$ significance level

$z_{\alpha / 2}=\mathrm{z}$ statistic for a given confidence interval $1-\alpha$, which does not rely on sample size

$\bar{x}=$ mean travel speed

$\varepsilon_{r}=$ user-selected allowable relative error in the estimate of the mean speed

$\mathrm{S}=$ sample speed standard deviation

With this process, the researchers also explored using the GPS data to develop trip-generation rates. Such 
rates would allow planners and modelers to relate land use types to the number of truck trips generated by that land use. However, it was concluded that additional data sources would be needed for this task, as the GPS data did not differentiate between truck types (McCormack, 2011). In this regard, the researchers also attempted to develop an algorithm to classify trucks by type (package, food service, drayage, etc.) and size (van, tractor trailer, etc.) using travel characteristics of the trucks and O/D results from Step 2. Although they were able to successfully classify trip types (see Step 3 above), they had only "limited success" with development of a truck-type classification algorithm. However, they noted a possibility that truck classification information might be provided by the GPS vendors to assist in this regard in the future.

Following development of the above process, an online system was created to make the resulting Washington state freight performance measures program available to WSDOT staff and other agencies. Figure 6 provides a schematic of the online system. This system allows users to monitor transportation network performance between economically important areas or zones using a "zone-based network O-D matrix tool." The researchers are also working with WSDOT and PSRC to use the processed GPS data to build and calibrate freight models.

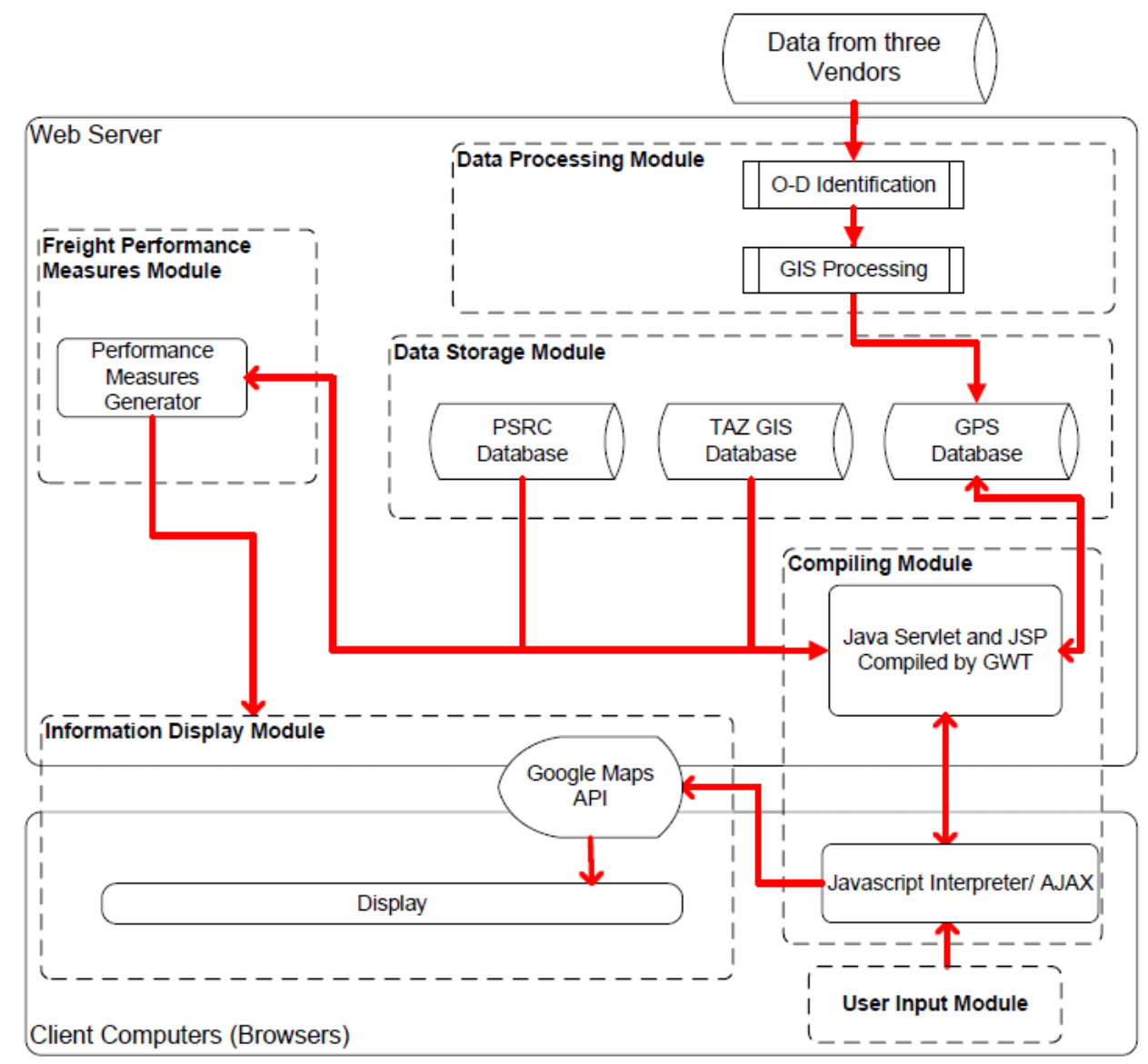

Figure 6 - McCormack et al. - Online Truck Freight Performance Measures System Flow Chart 


\subsubsection{Tour Behavior of Drayage Trucks - You \& Ritchie (2012)}

Research by You and Ritchie introduces an analytical framework to process truck GPS data. The data used for this research was collected from drayage trucks participating in the Clean Trucks Program (CTP) in southern California. Drayage trucks are those that have at least one trip end on a port or intermodal rail facility property. Per the CTP, trucks operating in California's San Pedro Bay Ports of Long Beach and Los Angeles are prohibited from having 1993 and older engines. However, funds for the purchase of "clean trucks" (those that meet 2007 model-year emission standards) are available. All trucks under the jurisdiction of the CTP are required to contain a radio frequency identification device for compliance monitoring. Trucks receiving replacement funds are required to also allow GPS units in their vehicles for movement monitoring. The research by You and Ritchie was performed using a year's worth of GPS data from 545 of the clean drayage CTP trucks (representing 7\% of the in-service clean trucks). Steps taken by the researchers to process the data were as follows:

Step 1: Select Potential O-D Stops. GPS data are recorded either every 15 minutes during truck operations or according to special requests as outlined in Table 6. Ignition on, ignition off, stop and start points (as defined in Table 6) are used to establish O-D stops.

\begin{tabular}{|c|c|c|}
\hline No. & Reason/Event & Description \\
\hline 1 & Ignition On & $\begin{array}{l}\text { Created when the vehicle's ignition is turned on and the Locator is powered } \\
\text { up }\end{array}$ \\
\hline 2 & Ignition Off & Created when the vehicle's ignition is turned to the off position \\
\hline 3 & Stop & $\begin{array}{l}\text { Created when the vehicle has moved less than } 25 \text { meters for longer than the } \\
\text { setting of the "travel stop" parameter ( } 2 \text { minutes) }\end{array}$ \\
\hline 4 & Start & Created when the vehicle has moved outside the default value of 25 meters \\
\hline 5 & Time Send & Created every five minutes and only when a vehicle is moving \\
\hline 6 & Distance & $\begin{array}{l}\text { Created when a vehicle travels a set distance like "Time Send"; every } 100 \\
\text { meters }\end{array}$ \\
\hline 7 & Wakeup & $\begin{array}{l}\text { Created for two reasons: 1) When the Locator is powered up and the } \\
\text { vehicle is parked for a } 24 \text { hour period, and 2) When the internal battery } \\
\text { wakes-up the Locator every five minutes }\end{array}$ \\
\hline 8 & Crossing Geofence & Created when a vehicle enters or exits a Geofence assigned to the vehicle. \\
\hline 9 & Demand & $\begin{array}{l}\text { Created when a vehicle is polled for its location using the Poll; The Poll } \\
\text { button function retrieves current location information for a vehicle or fleet } \\
\text { of vehicle }\end{array}$ \\
\hline $10-39$ & Additional Reasons & $\begin{array}{l}\text { Error Report, External Data Report, OBII fault, Server closed, Server Open, } \\
\text { Telemetry, Temperature report alarm, Over Speed, Under Speed, and etc. }\end{array}$ \\
\hline
\end{tabular}

Table 6 - You \& Ritchie - Reason Codes for Recording GPS Data

Step 2: Identify Truck Depots. Select the locations with the greatest major clusters of the last stops of the day. Match locations with Traffic Analysis Cell (TACs). Determine most frequently visited locations by minimizing the Mahalanobis distance,

$$
\operatorname{Min} \sum_{k} \sum_{j}\left[\operatorname{distance}\left(T_{j}^{k}(x, y), T_{i}^{k}(x, y)\right)\right]
$$

where, $T_{i}^{k}(x, y)$ represents the $\mathrm{x}, \mathrm{y}$ coordinates of GPS point $\mathrm{i}$ in a truck $\mathrm{k}$. Consider locations depots only if the 80th percentile of each truck's daily destination records fall into the corresponding TAC. 
Step 3: Geocode O-D stops and truck depots. Match each record with a TAC. Merge TACs using the following three steps to handle large facilities and/or smaller facilities that are part of a larger complex: (a) Find the centroid of each TAC; (b) Calculate Z scores by TACs; (c) Check the validity and generate new GPS clusters. Further details of this method can be found in the report by You and Ritchie.

Step 4: Identify closed/open tours. Identify tours corresponding to trips and truck depots. Use a maximum stop duration criteria (to identify open tours) and consider a stop a depot stop (representing a closed tour) only if $80 \%$ percentile of last stops for the day are within that area.

Step 5: Delete false-positive stops such as those on roads or irrelevant freight facilities. Use minimum stop duration criteria. The minimum stop criterion was set at 10 minutes based on previous research of the SPBP.

Step 6: Condense consecutive waiting activities caused by transaction and queuing.

Step 7: Assign new tours to waiting activities lasting longer than three hours in order to avoid a falsepositive tour.

Step 8: Delete abnormal pairs of tours/trips. Delete non-freight related "tours" such as those for truck maintenance activities. Delete trips with extremely low or high speeds. Low and high speed criteria are determined by the low and high speed limits and high speed limits determined by algorithms (MapQuest and Dijkstra's search algorithm using SCAG network information).

The clustering method proposed by You and Ritchie serves to determine individual distance thresholds for each TAC to determine how initial TACs should be merged. This differs from the method proposed by Sharman and Roorda, in that the latter suggests using a single distance threshold (determined using Ward's hierarchical agglomeration method) throughout the study area. In addition, You and Ritchie compared their clustering method to several conventional methods through analysis of partition

coefficients, partition indexes and separation indexes. The researchers concluded that the clustering algorithm they proposed is "relatively competitive" to the more conventional methods. In addition to the analysis performed by You and Ritchie, the third-party provider of the CTP GPS data generates basic statistics for the ports as well as individual truck emissions using the GPS speed profile. A non-profit company, PierPass Inc., in partnership with trucking companies, also conducts truck turn-time studies at terminals in order to improve terminal services.

\subsubsection{GPS Data for Congestion Mitigation - ATRI \& FHWA (2012)}

At the national level, as part of the FHWA Freight Performance Measures program, ATRI maintains GPS data for over six years of truck position records (Park, Pierce and Short, 2012). Much of this data is obtained through private-sector partnerships. ATRI currently uses the data to monitor congestion on the federal transportation system and to assess the impact of congestion on the freight system. ATRI has also used the GPS data to report performance characteristics of the nation's 30 worst bottlenecks (NCFRP, 2011). In addition, ATRI has published an online freight performance measure tool, FPMweb, which gives users access to aggregated truck-speed data from the trucks equipped with GPS devices. However, issues associated with the data include: (a) accuracy (errors up to $1 / 4$ of a mile were experienced); (b) 
limited data in areas of low traffic volume; and (c) inability to distinguish between stops due to congestion and stops for other reasons (i.e., rest stops (NCFRP, 2011). PSU research found that "PORTAL data compares well" with the aforementioned ATRI GPS data, but that PORTAL data tends to underpredict truck-specific congestion measures (McMullen and Monsere, 2010).

Further research by ATRI consisted of a recent pilot project to determine if spot-speed data contained within GPS truck data could be used as an alternative to traffic sensors to measure urban congestion. Data was analyzed for freight-significant highway segments in Louisville, KY., and Washington, D.C. Two performance measures were calculated for each pilot location: Travel-Time Index (TTI) and PlanningTime Index (PTI). This choice of performance measures was modeled in part on the Urban Congestion Report published by the FHWA's Office of Operations - a report which is based entirely on traffic-sensor data. The ATRI research concluded that GPS spot-speed data could be used at a national level to monitor urban congestion and to identify the location, severity and duration of freight congestion. This information could be used to assist in decision-making by public-sector planning and operations practitioners as well as the truck industry. The research further noted the potential for truck-based GPS data to be applied to overall system performance (i.e., personal vehicle travel).

\subsubsection{Summary of Academic Research}

In general, applications of truck GPS data for research have been limited because the data typically does not differentiate between different truck or commodity types. Further, use of truck GPS data often involves an ongoing cost as it is typically purchased from an outside provider or third party. As a result, researchers have had "limited success" in developing trip-generation rates with truck GPS data. It has also been determined that improvements in the data used for previous research would be needed before it could be used for freight transportation modeling (Zhao, Goodchild and McCormack, 2011).

Greaves \& Figliozzi (2008) - Issues \& Applications:

- Data pre-processing

- Trip-identification algorithm

- Signal loss and data repair

- "Genuine" stops vs. "false positive" stops

- Final output: Tour length, tour duration, proportion of tour time spent on the road, speed while

- on the road, tour stops

Sharman \& Roorda (2010) - Processing GPS Data:

- Clustering of GPS trip ends into destinations - Ward's clustering method.

- Depot identification and tour creation - still in development at time of research.

Holguin-Veras et al (2010) - Freight Demand Management - New York City:

- Shift truck traffic to off-peak hours

- Estimate travel times and delays 
- Validation of traffic models used to predict effects of program

Wheeler \& Figliozzi (2011) - Oregon I-5 Congestion:

- Comparison of GPS data to loop sensor average travel time

- Analysis of recurring and nonrecurring congestion

- PORTAL incident data - used to determine if congestion is recurring or non-recurring

- Emissions estimations - congestion analysis results used as input for MOVES2010

Figliozzi et al (2011) - Travel-Time Reliability Algorithms:

Programming Logic:

- Identify natural segments in corridors (i.e., interstate junctions)

- Estimate travel times for each segment

McCormack et al (2011) - Freight Performance Measures Program - Washington DOT

- Data from private GPS vendors - ongoing cost, does not differentiate truck types

- "Limited success" in developing trip-generation rates

- Equation used to determine minimum sample size: $n=\left(\frac{z_{\alpha / 2} s}{\varepsilon_{r} \bar{x}}\right)^{2}$

You \& Ritchie (2012) - Tour Behavior of Drayage Trucks

- Select potential O-D stops

- Identify truck depots

$\underline{\text { ATRI \& FHWA (2012) - GPS Data for Congestion Mitigation }}$

- FPMweb - online public access to aggregated truck-speed data 


\subsection{FREIGHT PLANNING AND MODELING}

\subsection{BACKGROUND}

Traditional analysis processes associated with passenger-transportation data have been found to be unsuitable for freight analysis (You and Ritchie, 2012; Wigan and Southworth, 2006). While most passenger travel is trip-based, commercial vehicles tend to make long, closed tours (tours that start and end at the same location, usually a depot) composed of multiple trips (You and Ritchie, 2012). The freight industry consists of a wide variety of players and logistical demands, creating a complex system with a wide variety of underlying "causal economics and institutional mechanisms" (Wigan and Southworth, 2006).

Research by Wigan and Southworth (2006) provides a comprehensive review of the variety of freightmodeling techniques and associated applications. Their list of modeling techniques includes:

- Linear and non-linear (i.e., logit) regression model estimations of traffic values, origin-destination flows, and modal shares

- Spatial interaction, neural network and Box-Cox models of zone-to-zone (region-to-region freight movements)

- Commodity-based, inter-regional input-output models

- Micro-simulation and agent-based models of individual freight-vehicle movements

- Engineering cost-based; statistical- (regression-) based; mixed statistical-engineering cost-based; and hedonic freight pricing models

- Least cost-based single and multiple path freight-traffic routing models

- Optimal facility location and combined site location-flow allocation models

- Network-based spatial price equilibrium models

A schematic outline of the major categories of freight models outlined by Wigan and Southworth is presented in Figure 7. The first column of Figure 7 outlines the four-step process of traditional passengertransportation models. The other columns provide a complex representation of the various models for freight transportation. This schematic demonstrates the inadequacy of the traditional four-step modeling approach in addressing impacts of policy decisions on freight shippers and carriers (i.e., freight delivery costs, travel time, service reliability). According to Figliozzi and Shabani (2010), there is a "growing gap between traditional four-step modeling approaches and the complex behavior of customer-driven responsive supply chains." Wigan and Southworth further note that freight models must consider the "causal economics and institutional mechanisms" (i.e., business relationships, market prices) within the freight industry that determine freight origins and destinations, mode, equipment selection, time of day, and routing behavior (Wigan and Southworth, 2006). Freight models must also take into account the impact of new policies in the areas of GHG emissions, energy prices and tolling (Figliozzi and Shabani, 2010). 


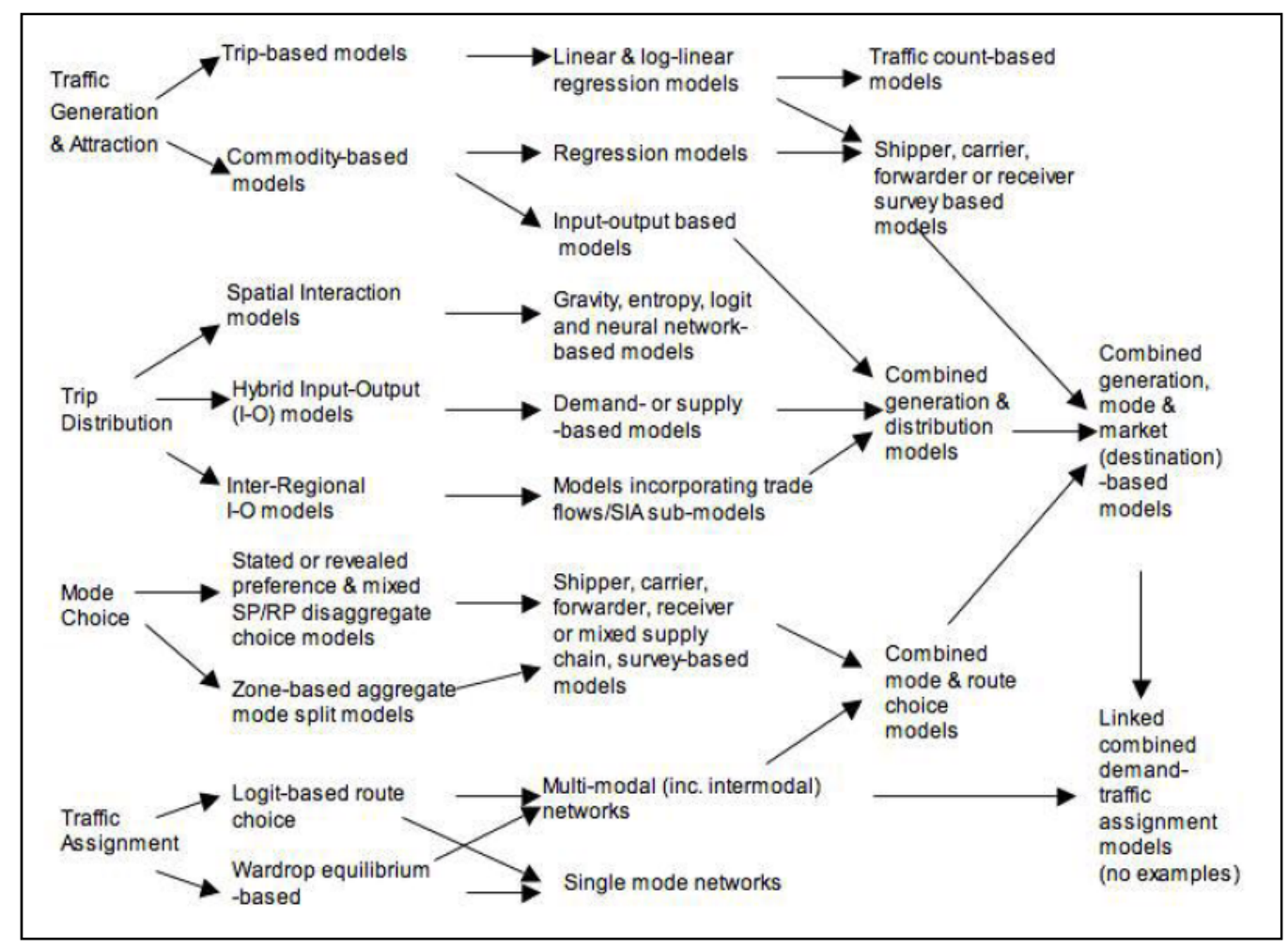

Figure 7 - Wigan \& Southworth - A Typology of Categories of Freight Models Linked to Four-step Tools

Proper use of freight-modeling techniques requires understanding which specific aspect of the planning process each technique can be applied to. Likewise, when using an existing freight model, it is important for users to have a thorough understanding of the original intent of that model. Although most freight models provide estimates of traffic volumes, costs and other impacts (i.e., environment and safety), in general, different modeling techniques are suitable for different applications (Wigan and Southworth, 2006). As such, a model that addresses all major aspects of the freight-planning process must use a combination of modeling techniques. However, as demonstrated by the included schematic, freight models often are subject to aggregation of various model elements. Aggregated models are often unable to respond appropriately to basic changes in the modeled system. In addition, use of some models is dependent on adequate data availability (Figliozzi and Shabani, 2010). Typical shortfalls of freight models include modeling capacity, data supply and data validation (Wigan and Southworth, 2006). Wigan and Southworth further concluded that although freight models are well suited to predict the present, they are typically not appropriate for use in forecasting future freight activity. However, this limitation is not a concern for many planning and policy decisions.

\subsection{OREGON'S TRANSPORTATION SYSTEM}

Any efforts towards system improvements within a DOT should consider opportunities to coordinate with, and build on, previous related efforts within and for the agency. In addition, an understanding of the related frameworks that already exist in relation to the organization is needed. Section 2.1 ("Freight Performance Measures") of this report provides background from the Freight Performance Measures: Approach Analysis written for ODOT. In supplement to that discussion, below is a review of relevant 
systems/plans currently in place and/or in development at ODOT.

User Fees \& Taxes: The system of fees and taxes on commercial trucks in Oregon, as in other states, might be considered a complex science; many resources (i.e., weight tables, Frequently Asked Questions documents, PowerPoint presentations, etc.) are available to assist in understanding the system. ODOT also publishes the Highway Cost Allocation Study (HCAS) every two years (Econorthwest 2011) - a study aimed at determining appropriate road user fees and taxes. The results of the HCAS serve in part to justify any proposals ODOT makes to the Legislature for changes to permit costs, as well as to weightmile and fuel taxes. Oregon is one of the few states that currently charge a commercial truck weight-mile tax (WMT) and the only state that has a WMT tax without a diesel fuel tax on heavy trucks (ODOT 2010). The Oregon WMT currently applies to trucks over 26,000 pounds; trucks over 80,000 pounds are taxed using an axle-based WMT. Mileage is currently self-reported by truck companies; approximately $25 \%$ of truck companies reported their mileage via Oregon Trucking Online in 2009. Audits of reported WMT are currently performed by ODOT using weigh-station records.

ODOT GIS Strategic Plan: ODOT's GIS Strategic Plan describes GIS as a means to integrate business lines across ODOT and to support decision-making (ODOT 2008). The plan's mission lists the following ways in which GIS should be used to assist the department:

- Managing the state's transportation system

- Evaluating relationships between state, regional and local transportation systems

- Evaluating the interactions between the manmade and natural environments

- Making transportation investment decisions.

GreenSTEP and the Statewide Transportation Strategy: The Greenhouse Gas Statewide Transportation Emissions Planning (GreenSTEP) Model is a sketch-level planning tool developed by ODOT to assess the effects of policies and other factors (i.e., gas prices) on GHG emissions from the transportation sectors (ODOT and DLCD 2011). A metropolitan version has also been developed, which Metro is using to support metropolitan planning. GreenSTEP is currently focused on emissions from household vehicles and light-duty commercial vehicles (i.e., autos, SUVs, pickup trucks, vans, etc.); modeling of GHG emissions from freight is still in development. Specifically, the model estimates and forecasts:

- Vehicle ownership

- Vehicle travel

- Fuel consumption

- GHG emissions

GreenSTEP has also been used as the primary analytical tool for the Statewide Transportation Strategy (STS). The STS works towards reducing transportation-sector GHG emissions by estimating the effect of potential policies in the following categories:

- Urban (urban growth, mixed-use, transit, parking, bicycles)

- Pricing (fuel and carbon taxes, VMT tax, Pay As You Drive insurance)

- Marketing (travel demand, management, eco driving) 
- Roads (capacity, incident management)

- Fleet (vehicle age, vehicle type, car sharing)

- Technology (fuel efficiency (mpg) standards, electric vehicles, etc.)

According to ODOT reports, estimates from GreenSTEP could further be used to assess the relative equity of costs and benefits of different policy proposals to different road users (ODOT and DLCD, 2011).

The Oregon Freight Plan (OFP): ODOT recently developed the OFP to consider infrastructure investment and policy options related to freight (Cambridge Systematics Inc. and ODOT Freight Mobility Unit, 2011). In order to account for the current economic uncertainty, the OFP proposes to analyze various alternative futures. Four hypothetical futures, or scenarios, were developed and estimates of economic growth were made for various economic sectors, infrastructure investments, and distribution of economic benefits. Each alternative future was modeled for a time period up to 2030. The following hypothetical futures were analyzed:

1) Reference scenario - Business-as-usual (likely future given current trends and policies).

2) Optimistic economic forecast - more economic growth.

3) Pessimistic economic forecast - assume three-fold increase in transport costs.

4) High transport costs - adds additional transport costs to the pessimistic forecast.

In accordance with Strategy 11.2 of the OFP ${ }^{1}$, Oregon's second-generation State Wide Integrated Model (SWIM2) has been used to complete the OFP analysis. The model inputs, outputs and parameters used for the Oregon Freight Plan SWIM2 analysis include:

Inputs:

- Economic commodity flows (long-distance markets)

- Transport model time and distance skims

- Economic activity by type in each transport zone

Outputs:

- Trip list and trip tables by truck type

- Information on non-truck mode commodities, truck tours

Parameters:

- Mode choice by commodity and distance

- Transshipment by commodity and distance

- Commodity attributes (VDF, shipment size, \% for hire)

- Truck attributes (GVW, capacity, shift duration, dwell time) (Hunt, 2011)

The output from SWIM2 (the performance of each alternative future) was determined based on metrics

\footnotetext{
1 "Strategy 11.2: Develop and maintain transportation models that account for freight logistics and routing behavior in order to evaluate effects of the disruptions on freight movement at the state, regional and urban levels."

(Cambridge Systematics, Inc. and ODOT Freight Mobility Unit 2011)
} 
related to the transportation system (miles traveled, hours traveled, trip costs, commodity flow) and economic welfare (industry output, commodity value, production costs). Results were evaluated on a statewide level as well as for each of six economic regions within the state.

SWIM2: According to Hunt et al (2011), SWIM2 is "the product of continuing work on transportation modeling improvement underway in Oregon." It is a spatial economic-modeling system that represents transportation, economic and land use systems as well as interactions between them. SWIM2 also includes a visualization tool that assists with: 1) reporting model results; 2) calibrating the model; and 3) model development. This framework allows the user to track commodity-flow patterns, travel and land use patterns, and interactions between economic sectors at the state and regional levels. According to a 2011 report by ODOT:

"SWIM2 includes twenty industry sectors; eighteen household income/size categories; forty-one SCTG goods commodities; fifteen service categories; eight labor occupations and nineteen floorspace types. It simulates how these interact and distribute across the state in response to economic forces and how the resulting flows of commodities and the trucks carrying them both influence and are influenced by the transportation system. (Hunt 2011)"

The SWIM2 visualization tool runs queries and produces maps, charts, line graphs and tables. A run of SWIM2 covering 20 years of simulating time generated about 80 gigabytes of data. Research by Hunt et al concluded that SWIM2 is expected to play "significant roles in future analysis work in Oregon" and that SWIM2 provides a wide range of outputs that "could potentially be used to support ODOT policy work." Figure 8 includes an example of visualization output from SWIM2; Figure 9 and Figure 10 provide further examples of SWIM2 output. 


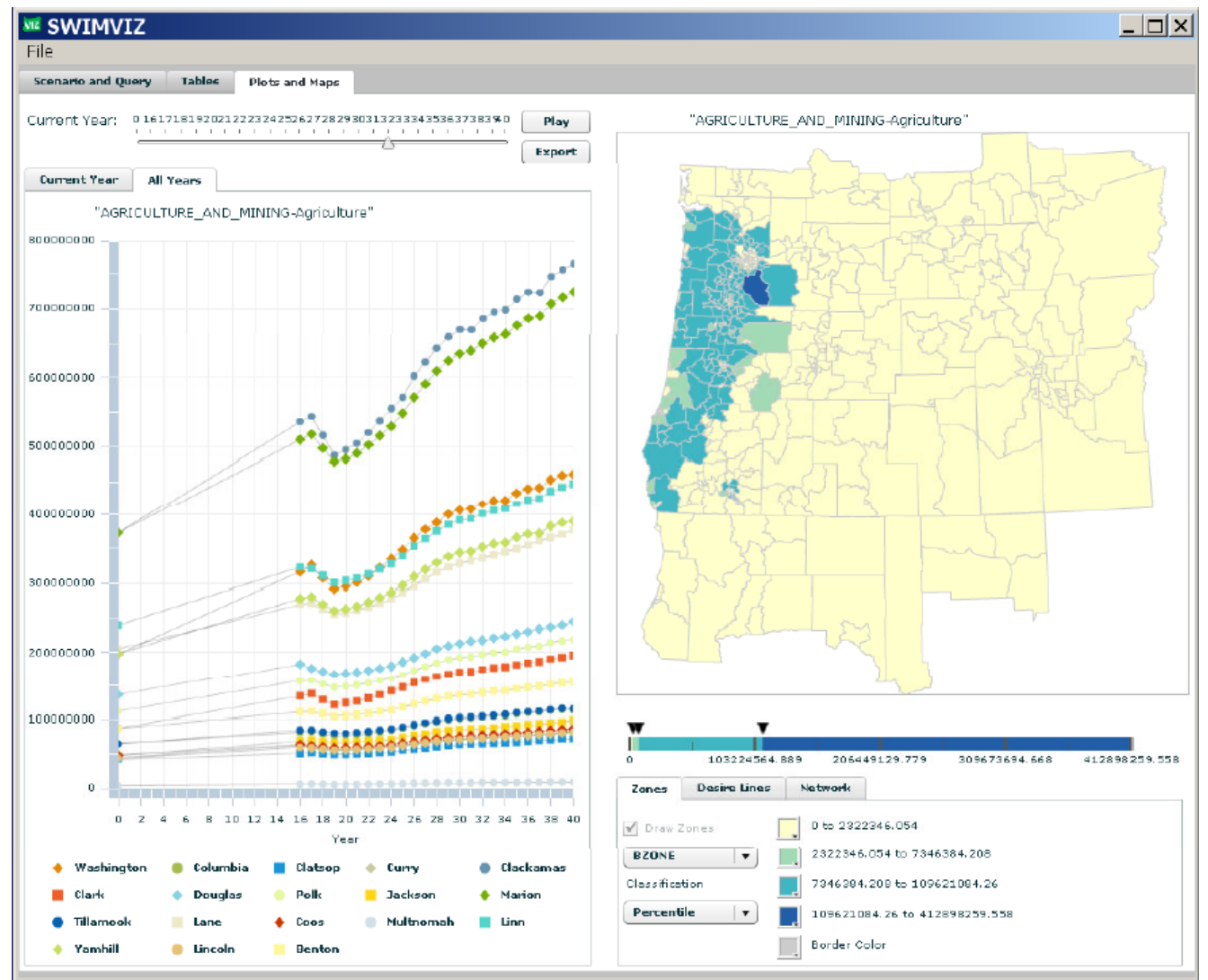

Figure 8 - SWIM2 - Example Output

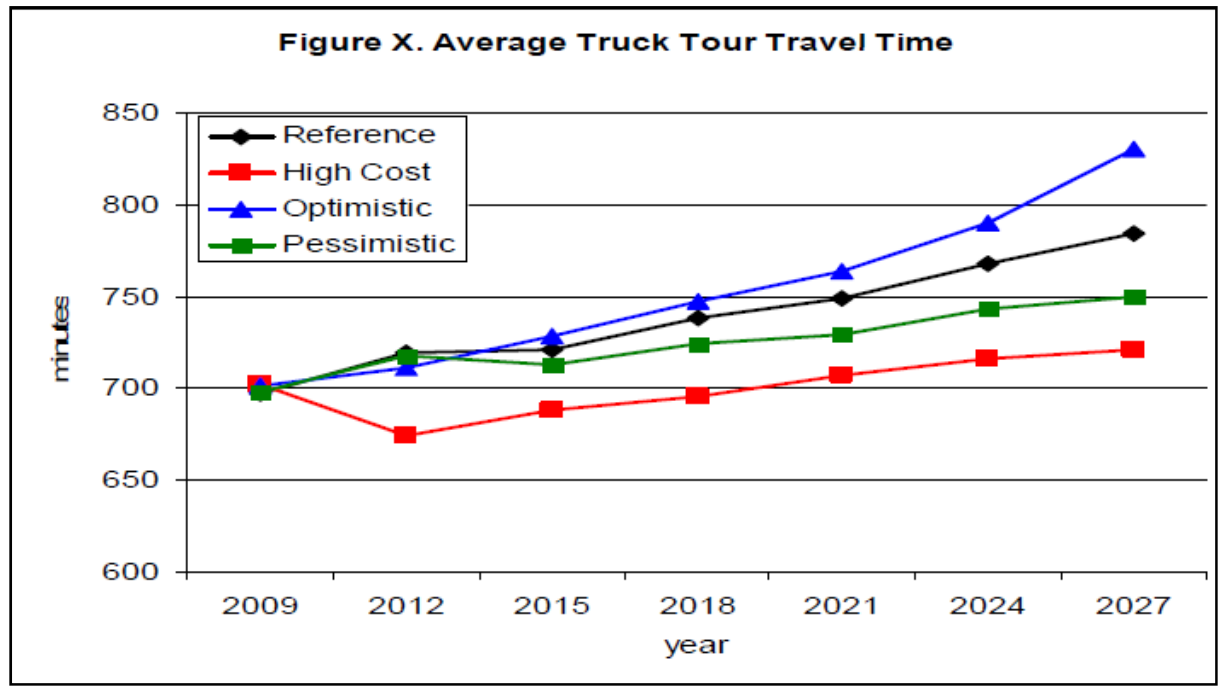

Figure 9-SWIM2 - Example Output 


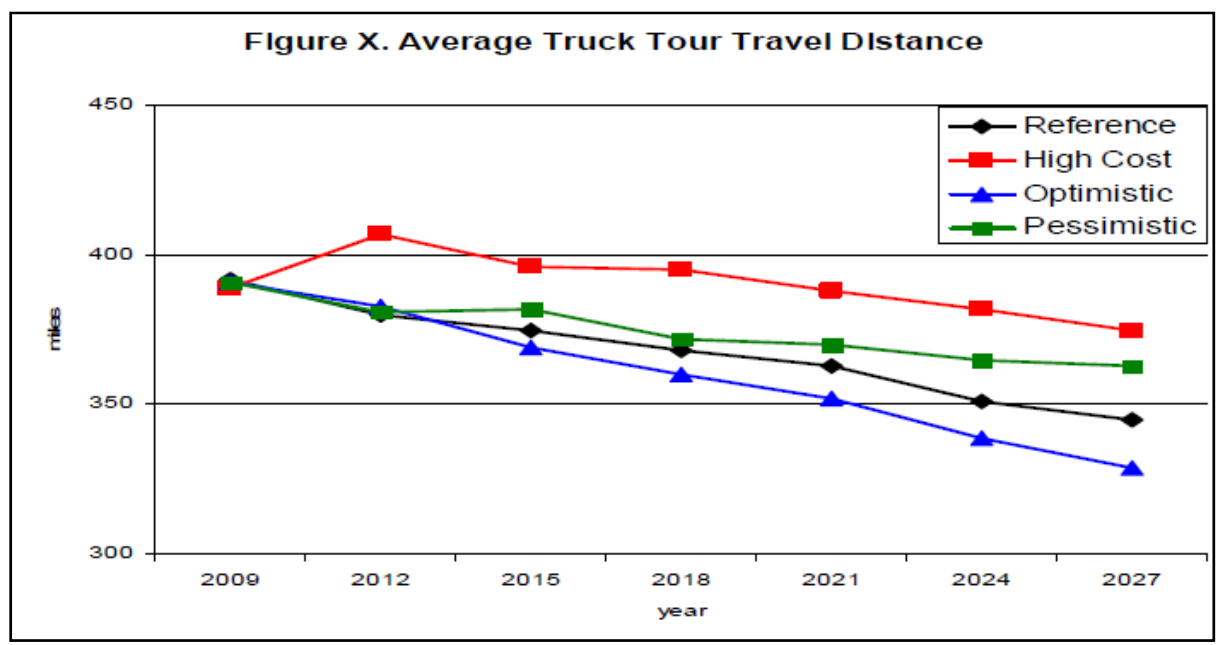

Figure 10 - SWIM2 - Example Output

In 2010, short-, mid- and long-term improvements were proposed to the Commercial Truck (CT) module of SWIM2 (Figliozzi and Shabani, 2010). It was noted that SWIM2 provides a comprehensive approach to household travel activity, but that the CT module was in need of enhancements to more adequately forecast freight movements and the impacts of energy price changes, and to provide sound policy analysis regarding GHG emissions taxes and tolling. According to the researchers, applications for the CT module are limited to "a subset of freight policy problems that can be appropriately modeled with simple behavior rules and limited data." The researchers noted the CT module lacks the following key aspects:

- Total logistics costs

○ Inventory costs

- Transportation costs per mode and shipment size

- Consolidation, handling and distribution costs

- Customer service costs (later penalties, time windows)

- Freight demand model

- Demand elasticities per product

- Firm location model

○ Product supply-chain characteristics, including time sensitivity

- Mode-choice model - Cross-mode elasticities

- Vehicle size-choice models - Fuel or energy choice sub-model

- Driving cycle - Speed - distance function 


\subsection{DATA DESCRIPTION AND ACCURACY}

Data available for this research consists of 172,385 records from the TRUE pilot study for the entire year of 2011. Data was collected for 17 vehicles belonging to three different carriers, each equipped with a TRUE device. The TRUE devices were configured to collect the latitude and longitude locations of each vehicle every five minutes. The data fields provided by the TRUE data in its "raw" format include latitude and longitude coordinates with corresponding timestamps, weight class and axle count of vehicles, and GPS record accuracy. The travel of the pilot study vehicles was tracked through seven U.S. states and three regions in Canada; however, the geographic limitations of future data collection would be dependent on the degree of partnership with the private sector. Through trips using Oregon's highway network still have to pay WMT, and hence may be included in future datasets if companies adopt the system. The intention of the pilot project was to test the TRUE system, potential applications, and associated data processes rather than to provide data that is representative of the entire population of trucks in Oregon. Likewise, regardless of the sample rate of this pilot study, the methodologies proposed could be applied to the TRUE system's statewide implementation. The initial data-processing steps consisted of formatting including conversion of the timestamp records to database readable time format. The data was then imported into the Geographic Information System (GIS), "ArcGIS," and latitude and longitude readings were converted to $\mathrm{X}$ and $\mathrm{Y}$ coordinates, respectively. The majority of the data analysis described in this section was completed in RStudio. Additional data processing required for specific applications is discussed in the respective sections of this report.

Figure 11 presents the density (records per square mile) of TRUE pilot project records in the Portland metropolitan area. This figure provides a preliminary view of where trucks are traveling most often within the metropolitan area. Particularly dense areas are likely those at which trucks regularly stop and/or are based (i.e., truck depots). As will be shown in later sections of this report, such information can be combined with the highway speed information derived from the WMT GPS data in order to consider causes for identified bottlenecks, as well as land use information in order to determine trip-generation rates. 


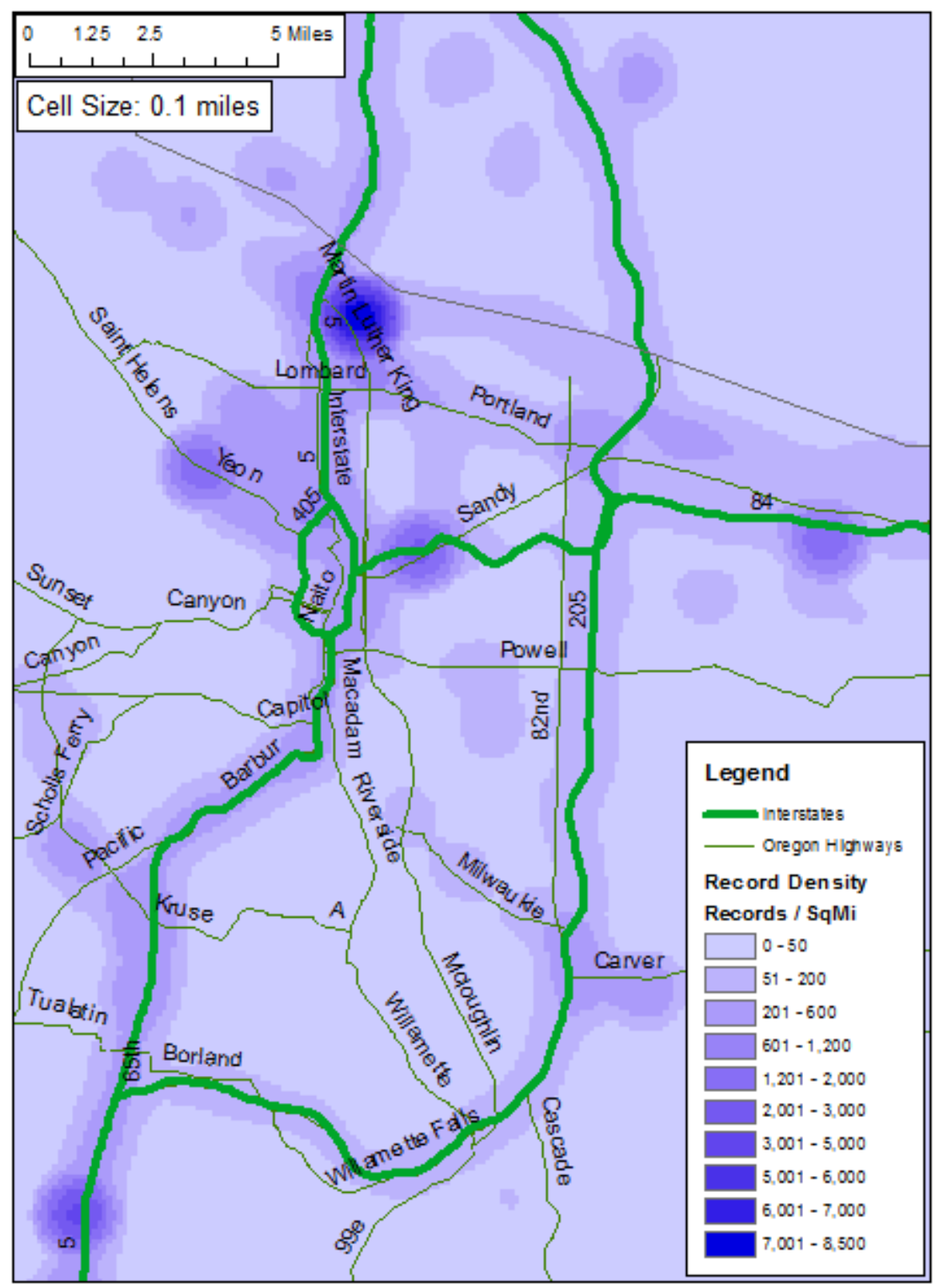

Figure 11 - Record Density - Portland Metropolitan Area

According to the "GPS_ACCURACY" field of the data, the accuracy of the GPS readings range from three to 840 feet. Figure 12 provides a histogram of the cumulative distribution of the values from the "GPS Accuracy" field for readings up to 80 feet (the small number of records with accuracy worse than 80 feet are not included in the figure). An accuracy of within 10 feet was recorded for over $50 \%$ of the GPS points; within 20 feet for over 75\%; within 53 feet for over 95\%; and within 79 feet for over $98 \%$. Of the data fields included in the TRUE dataset, the following fields were intended to be entered into the TRUE device by the truck driver at the beginning of each trip: weight class, number of axles, and odometer. Preliminary review of the dataset identified one GPS record with a weight class of " 0 " and an axle count of "0." The number of axles was recorded as "NA" for approximately $44 \%$ of the records from the dataset; these records represented 12 different vehicles. In fact, the number of axles was recorded as 
"NA" for all records associated with these 12 vehicles. These " 0 " and "NA" records are indicative of a data-entry error and a failure to enter data, respectively, on the part of the truck driver.

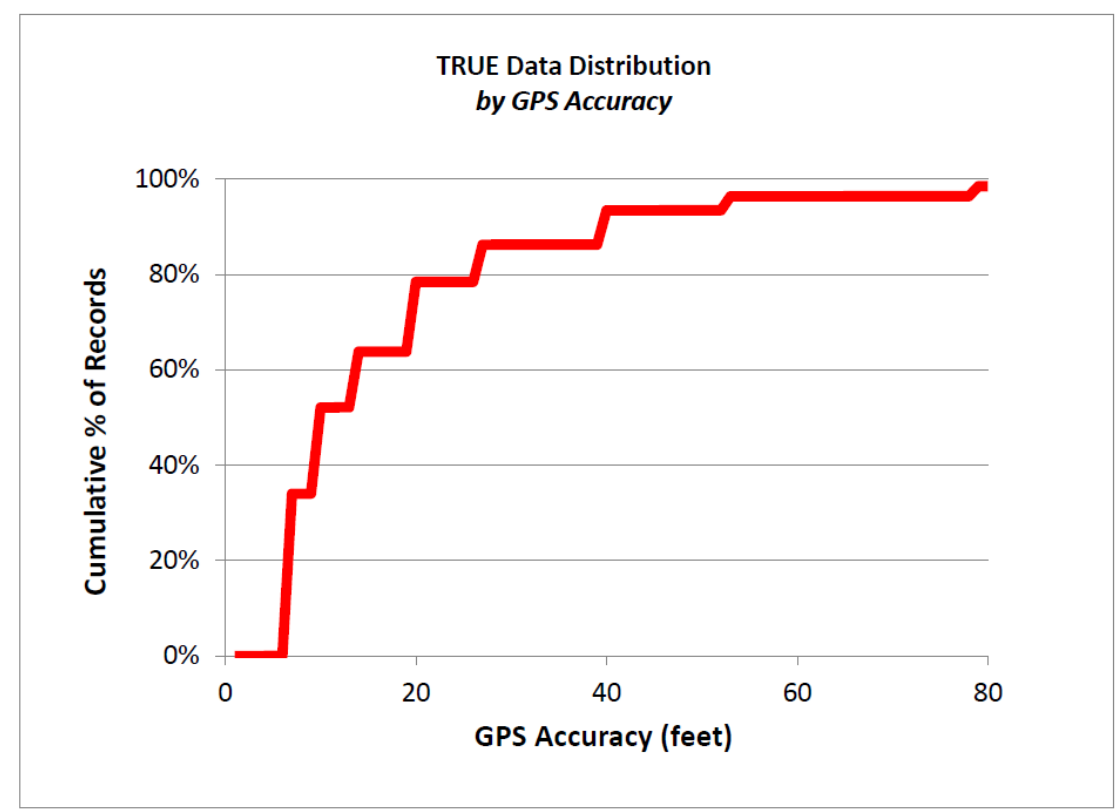

Figure 12 - Distribution of GPS Accuracies

Figure 13 provides a map of mean TRUE GPS accuracy for "cells" (50 square miles in area) that contained TRUE GPS records. As can be seen in the figure, the GPS Accuracy of the TRUE devices was relatively good along interstate corridors. 


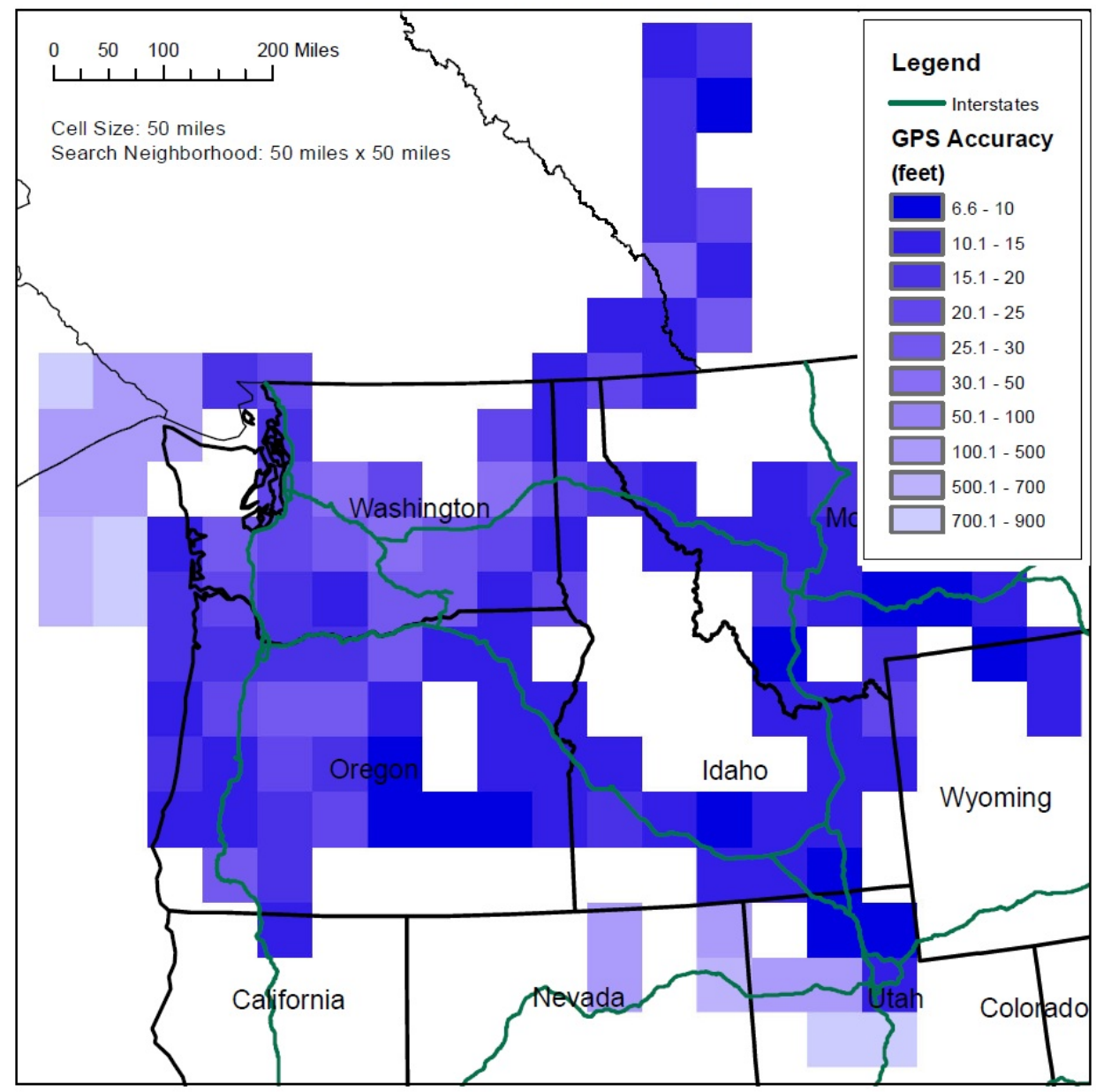

Figure 13 - Mean GPS Accuracy

The $95^{\text {th }}$ percentile "GPS Accuracy" from the TRUE pilot project is 53 feet; in other words, $95 \%$ of the TRUE records have coordinates that are accurate to within 53 feet of their actual location. Figure 14 provides a plot of the density of records (records per square mile) that have GPS accuracies of more than 53 feet (or worse than the $95^{\text {th }}$ percentile). According to the figure, a portion of the I-5 corridor (shown in red) had the highest density of these relatively inaccurate TRUE records. However, as shown in Figure 15 , such records are less than $10 \%$ of the total record counts along I-5, and as such are likely not a cause for concern. In contrast, although there is a low density of inaccurate records to the west of Washington state (see Figure 14), over $50 \%$ of the records in this vicinity are inaccurate (worse than the $95^{\text {th }}$ percentile). Similar figures are also included for records that have GPS accuracies worse than the $99^{\text {th }}$ percentile (105 feet). Figure 16 indicates a high percentage of relatively inaccurate records at the interchange of I-5 and I-84, as well as just south of there. However, according to Figure 17, less than 5\% of the records in these areas actually have GPS accuracies of worse than the $99^{\text {th }}$ percentile. In comparison, most (over 50\%) of the records west of Washington state have accuracies worse than the $99^{\text {th }}$ percentile. 


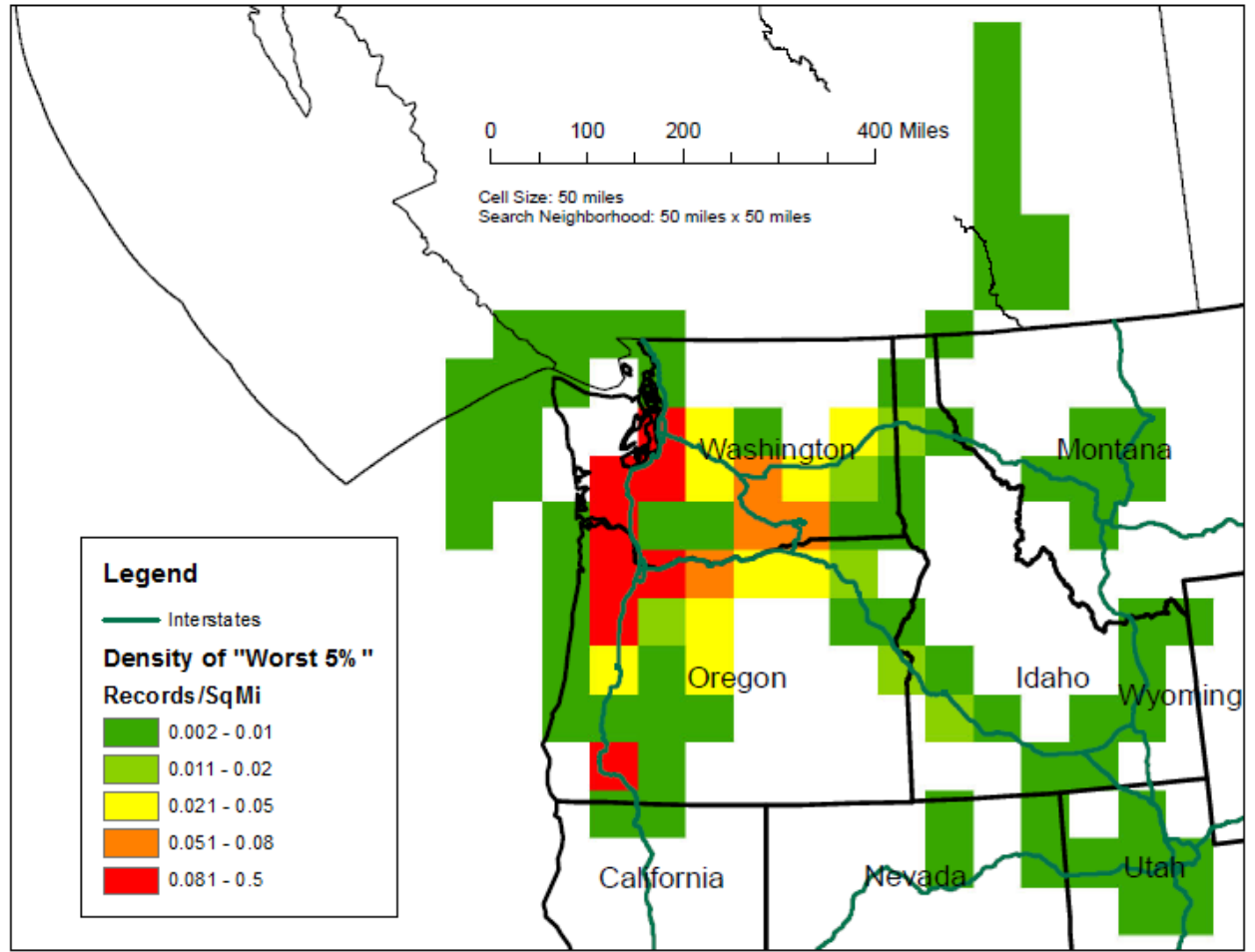

Figure 14 - Density of Records with Accuracy Worse than $95^{\text {th }}$ Percentile (53 feet)

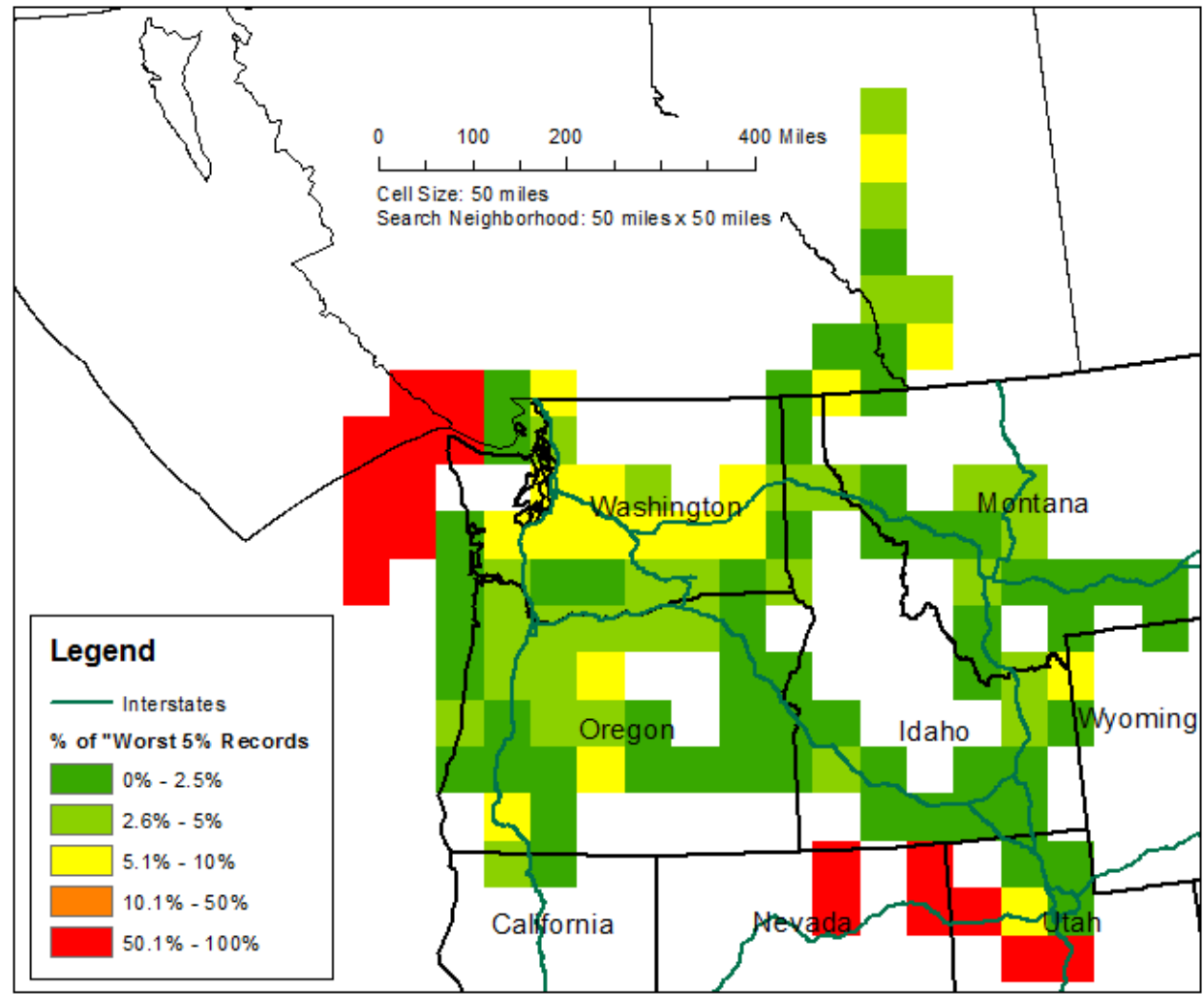

Figure 15 - Percentage of Records with Accuracy Worse than $95^{\text {th }}$ Percentile (53 feet) 


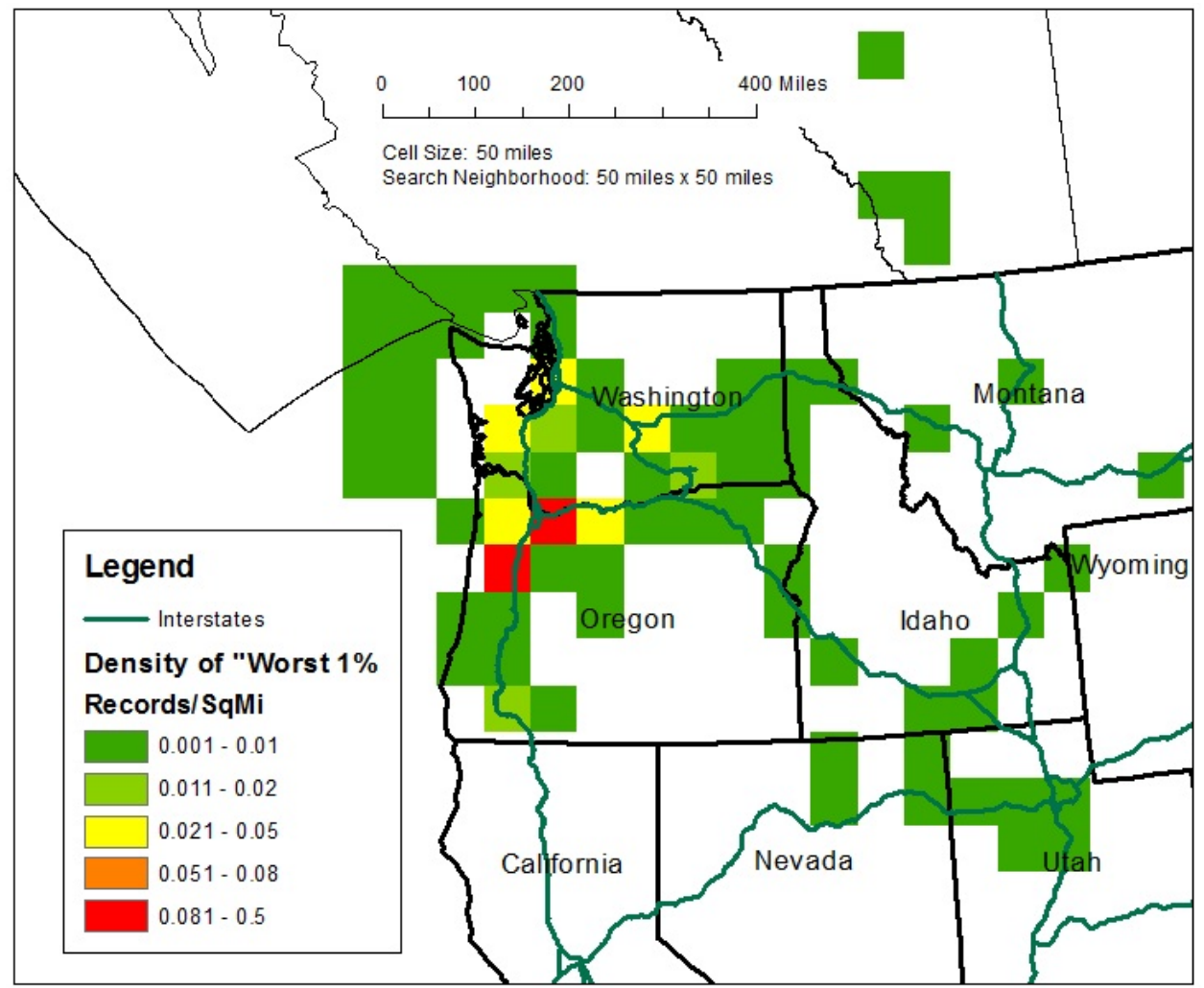

Figure 16 - Density of Records with Accuracy Worse than $99^{\text {th }}$ Percentile (105 feet)

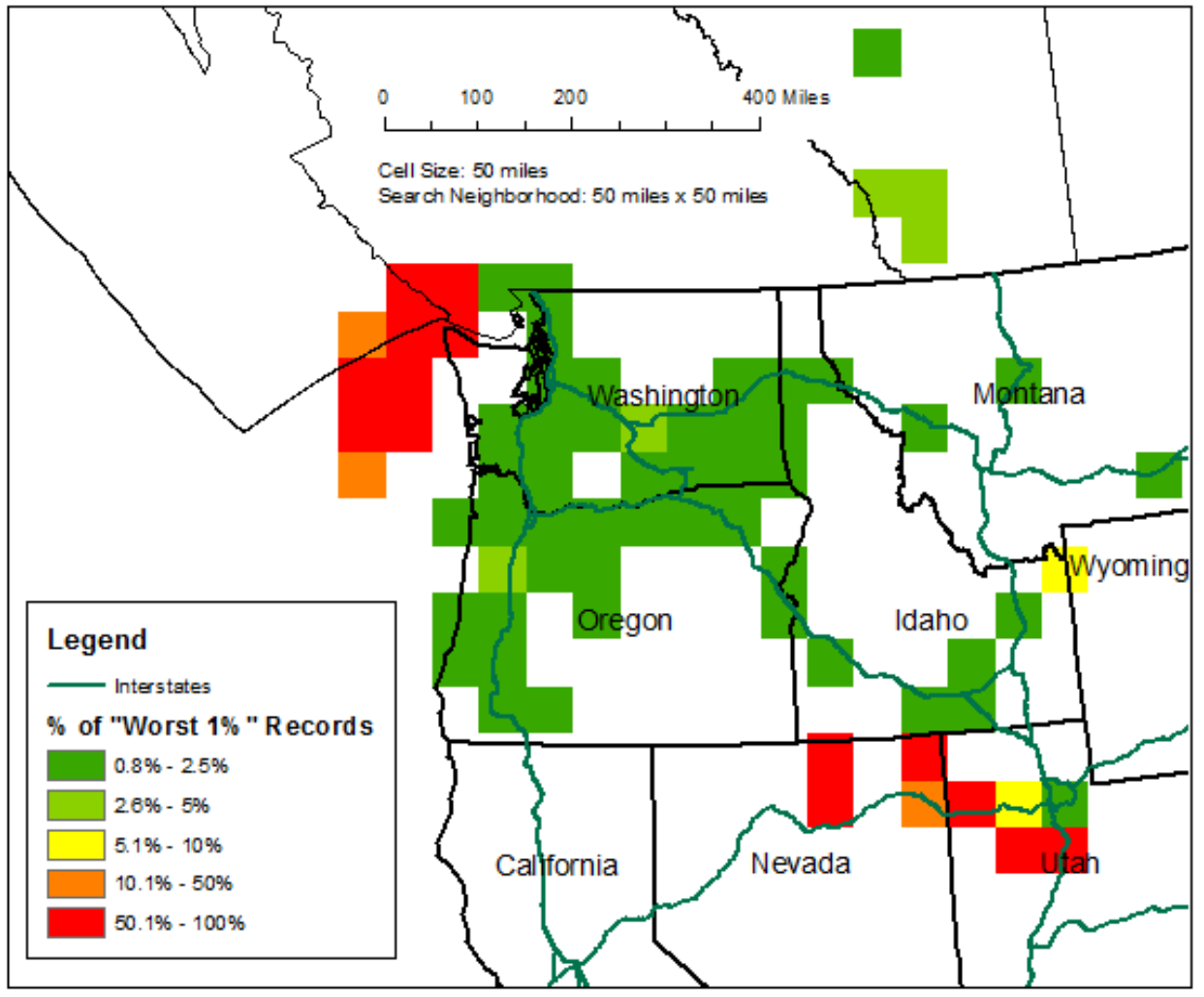

Figure 17 - Percentage of Records with Accuracy Worse than $99^{\text {th }}$ Percentile (105 feet) 
The analysis in this section indicates that the smart phone GPS readings from interstate locations generally had a high degree of accuracy. Records in Nevada, Utah and west of Washington are likely to have a low degree of accuracy; however, this should not be a concern, as records from these areas are not likely to be used for a regional analysis. Further analysis could be completed in order to review other potential commonalities between the low accuracy records, such as vehicle ID, time period, rural vs. urban, time of day, or speed. 


\subsection{WEIGH-IN-MOTION DATA INTEGRATION AND COMPARISON}

In addition to the GPS records, the data set available for this research includes corresponding weigh-inmotion (WIM) station records for the pilot project vehicles. Figure 18 provides a schematic showing data fields available through the TRUE data in its "raw" format and those available through the WIM dataset. The "DEVICE_ID" and "BASE_PLATE" fields can be used to link TRUE GPS records to the corresponding WIM records. The ability to link the detailed route and speed information from WMT GPS data with corresponding WIM records (Vehicle Classification and Gross Vehicle Weight (GVW) values) allows detailed emission estimates to be performed, not to mention the ability to cross check the WIM system data with TRUE data and vice versa. In order to integrate the two datasets, for each WIM record a TRUE record can be found that is: a) from the same truck as the WIM record; and b) within one hour of the WIM record. From this subset, the TRUE record closest to the WIM record can then be selected as the TRUE "partner record" to the WIM record. If no such TRUE record exists for a WIM record, then that WIM record is not assigned a TRUE "partner record." This process was completed with the TRUE pilot project data using RStudio. Following completion of the described integration methodology, further analysis was performed to compare TRUE and WIM datasets. Preliminary review of the GPS records and corresponding WIM data indicates that the GPS records from the pilot project represent vehicles ranging in weight from 46,000-105,500 pounds, with four to eight axles, and three different commodity codes ("empty," "machinery" and "other"). 


\begin{tabular}{|c|c|c|}
\hline & FIELD & DESCRIPTION \\
\hline \multirow{12}{*}{ 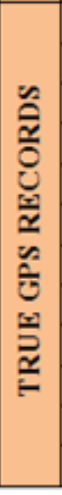 } & ROW_ID & System generated row id \\
\hline & DEVICE_ID & Unique identifier for each smartphone \\
\hline & LATITUDE & Latitude of device \\
\hline & LONGITUDE & Longitude of device \\
\hline & WAYPOINT_TIME & Timestamp of GPS record \\
\hline & WEIGHT_CLASS & Weight class of vehicle \\
\hline & AXLES & Axle count of vehicle \\
\hline & RECEIVED_TIME & Timestamp waypoint was received by server \\
\hline & LOCATION_NAME & General location name \\
\hline & PERMIT_NO & Permit number vehicle is operating under \\
\hline & GPS_ACCURACY & Accuracy of the GPS fix in meters \\
\hline & ODOMETER & Most recent odometer entry by driver \\
\hline & FIELD & DESCRIPTION \\
\hline \multirow{7}{*}{ 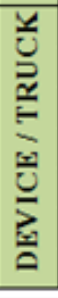 } & DEVICE ID & Unique identifier for each smartphone \\
\hline & ACCT_NO & Oregon taxpayer id \\
\hline & CARRIER_UNIT_ID & Unit number of vehicle assigned by carrier \\
\hline & PHONE NO & Phone number of mobile device \\
\hline & BASE_PLATE & Base plate of vehicle \\
\hline & BASE_ST & Base state of vehicle \\
\hline & ASSIGNED_DATE & Timestamp mobile device was assigned to carrier \\
\hline & FIELD & DESCRIPTION \\
\hline \multirow{16}{*}{ 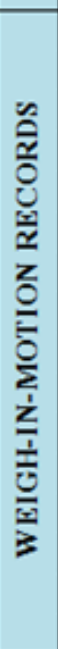 } & WEI_ID & System generated row id \\
\hline & WEI_AUTHNO & Oregon taxpayer id \\
\hline & WEI BASEPLATE & Base plate of vehicle \\
\hline & WEI_BASESTATE & Base state of vehicle \\
\hline & WEI_PSTDATETIME & Timestamp of event in PST \\
\hline & WEI_SCALENO & Scale number \\
\hline & WEI_LOCATION & Location \\
\hline & WEI_CARRIERNAME & Carrier name \\
\hline & WEI_VTID & Vehide dass id (VEHTYPE) \\
\hline & WEI_VCID & Vehicle type id (VEHCLASS) \\
\hline & WEI_AXLES & Vehide axle count \\
\hline & WEI_COMMODITY & Commodity code of what vehicle is hauling \\
\hline & WEI_GROSS & Gross weight \\
\hline & WEI WGT[1:12] & Weight at axle [1:12] \\
\hline & WEI_DIRECTION & Direction of lane \\
\hline & WEI_VEHICLE & Calculated value, based on class and type ids \\
\hline
\end{tabular}

Figure 18 - Data Fields

Axle Count Comparison: The axle count provided with each TRUE record from the pilot project was entered by the driver at the beginning of a trip; the axle count provided with each WIM record is measured by the WIM system. As summarized below, the axle count from the TRUE records did not match that from the WIM records for 39\% of the records compared. Of the comparisons that did not match, the reason was usually because the TRUE axle count was higher than the WIM axle count (see Table 7). 


\begin{tabular}{|c|c|c|}
\hline \multicolumn{3}{|c|}{ TRUE vs. WIM AXLE COUNTS } \\
\hline Scenario & \# of WIM records & $\%$ of WIM records \\
\hline TRUE axle count $=$ WIM axle count & 279 & $\mathbf{6 1 \%}$ \\
\hline TRUE axle count $<$ WIM axle count & 23 & $\mathbf{5 \%}$ \\
\hline TRUE axle count $>$ WIM axle count & 158 & $\mathbf{3 4 \%}$ \\
\hline & $\mathbf{4 6 0}$ & $\mathbf{1 0 0} \%$ \\
\hline
\end{tabular}

\section{Table 7 - TRUE vs. WIM Axle Counts}

Commodity Code: Although the WIM records reviewed for this project included commodity codes 0 ("empty"), 2 ("other") and 5 ("machinery"), "partner records" from the TRUE pilot project dataset were only found for WIM records with a commodity code of 2 . As such, code 2 is the only commodity code that is represented by the TRUE pilot project records.

Vehicle Weight: The "Weight Class" field in the TRUE data was entered by the driver of each vehicle at the beginning of a trip. The Weight Class value entered is intended to be the registered weight of the vehicle - the weight above which the vehicle is not legally authorized to operate based on the tax structure that the vehicle is registered under. The GVW values from the WIM data are weight measurements provided by the WIM systems.

An analysis was performed to compare each of the TRUE "Weight Class" values to the WIM GVW value from the corresponding "partner record" (if one existed). As indicated in Table 8, 16 (3\%) of the TRUE "Weight Class" values reviewed were less than the corresponding WIM GVW measurement. Such results might insinuate that $3 \%$ of the records analyzed were from vehicles that were operating in an "overweight" (illegal) condition; however, a comparison of the TRUE axle count to the WIM axle count for these records calls into question the accuracy of the TRUE Weight Class value.

\begin{tabular}{|c|c|c|}
\hline \multicolumn{3}{|c|}{ TRUE Weight Class VS. WIM GVW } \\
\hline Scenario & \# of WIM records & $\%$ of WIM records \\
\hline TRUE Weight Class > WIM GVW & 602 & $\mathbf{9 7 \%}$ \\
\hline TRUE Weight Class < WIM GVW & 16 & $\mathbf{3} \%$ \\
\hline & 618 & $100 \%$ \\
\hline
\end{tabular}

Table 8 - TRUE Weight Class vs. WIM GVW

As shown in Table 9, the TRUE and WIM axle counts could not be compared for 10 of the "overweight" "partner records" as the TRUE axle count was assigned a "NA" value, indicative of a failure to enter data on the part of the driver. The drivers' failure to enter data also calls into question the accuracy of the Weight Class values for these records. Of the six other "overweight" "partner records," five had a TRUE axle count of 6 , but a WIM axle count of 8 . Further analysis of the records indicated that the 16 "overweight" records represent three different trucks, all of which are from the same carrier. 


\begin{tabular}{|c|c|c|}
\hline \multicolumn{3}{|c|}{ "Overweight" Records (n= 16) } \\
\hline Scenario & \# of WIM records & $\%$ of Records \\
\hline TRUE axle count = WIM axle count & 1 & $\mathbf{6 \%}$ \\
\hline 6 TRUE axles vs 8 WIM axles & 5 & $\mathbf{3 1 \%}$ \\
\hline TRUE axle count = "NA" & 10 & $\mathbf{6 3} \%$ \\
\hline & $\mathbf{1 6}$ & $\mathbf{1 0 0 \%}$ \\
\hline
\end{tabular}

Table 9 - "Overweight" Records $(\mathrm{n}=16)$

This section demonstrates the successful integration of WIM and WMT GPS data. The use of such integrated data for applications such as detailed emissions estimations will be discussed in later sections of this report. However, the analysis outlined in this section also highlights the need for a reliable method for recording axle count and weight class values when using a system such as TRUE. The inconsistencies found between the two datasets calls into question the accuracy and reliability of these values in the TRUE dataset. If the Axle Count and Weight Class data from a system such as TRUE is to be used for future analysis, a more reliable method of input must be implemented. 


\subsection{POINT/LOCATION-BASED APPLICATIONS}

The ability to disaggregate the TRUE GPS data by vehicle type provides an opportunity for development of trip-generation rates that has not been available with previous truck GPS datasets. Such rates could allow planners and modelers to relate the number of truck trips from different categories of trucks to the land use (i.e., commercial, industrial, residential) that generated the trip. For example, the number of trips relative to the following vehicle categories can be determined using the TRUE data: weight class, number of axles, vehicle type, vehicle class, commodity code, gross weight, and calculated value of vehicle. In addition to truck trips associated with particular land uses, similar analysis could be completed considering areas of different population densities, employment levels, parcel sizes, counties, or other TAZs. As an example, an analysis was performed in ArcGIS to determine the proportion of GPS records from the TRUE pilot project that were within different land use categories in the Portland metropolitan area. A 2010 land use GIS file from Metro's Regional Land Information System (RLIS) (Metro, 2012) was used for this analysis. The results (provided in Figure 19) not only demonstrate the relative proportion of records within different land use categories (i.e., "Mixed-Use Residential" areas were generally traveled in more than "Rural" areas), but also the relative proportion of records from different weight classes for each land use category (i.e., trucks over 98,000 pounds traveled in "Rural" areas more than "Mixed-Use Residential" areas). The GIS plot in Figure 20 provides a second example of the ability to disaggregate this dataset by truck-type categories. This plot provides a visual analysis of the spatial distribution of the pilot project GPS records for the 1030 weight class trucks (103,000 pounds). The number of GPS records for various segments of interstate, U.S. and state highways in Oregon is shown for this weight class. Similar disaggregation by other vehicle-type categories (i.e., commodity type, gross weight and axle weight) is also possible. As demonstrated by Figure 19 and Figure 20, the TRUE GPS data provides the level of detail needed to determine the location of truck travel at the TAZ level, and thus to develop truck trip-generation rates with a level of accuracy that has not been possible using previous truck GPS data. However, the accuracy of such trip-generation rates could be further enhanced by identifying the TRUE GPS records that represent "trip ends" (origin and destination locations); for example, a methodology is presented in Greaves and Figliozzi (2008) to identify trip origins and destinations using GPS data. Subsequently, if the TRUE system were implemented statewide, the resulting data could be used to develop highly accurate trip-generation rates that could be used as an alternative to less accurate employment or production-based trip-generation rates. 


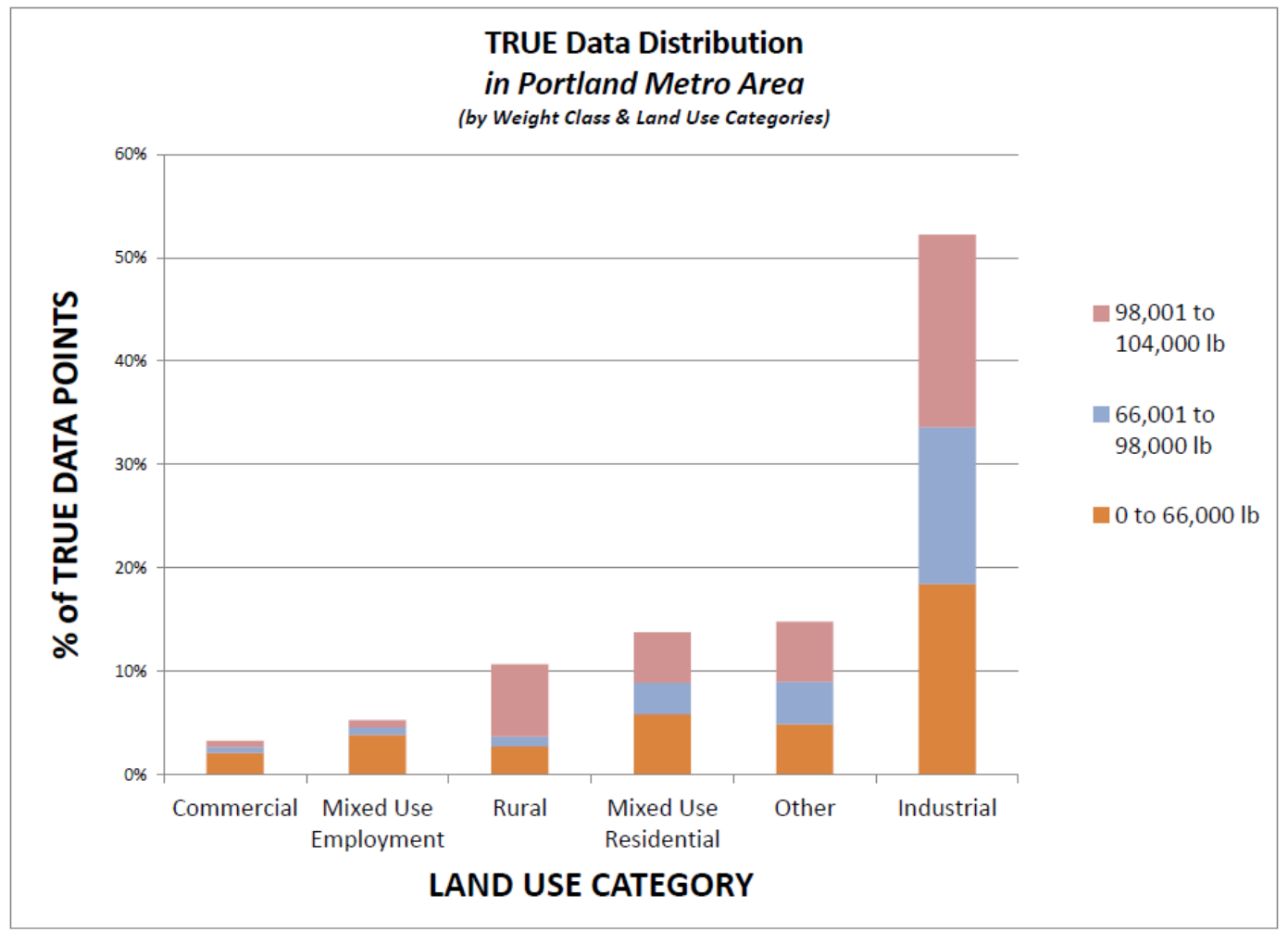

Figure 19 - Density of GPS Records by Weight Class and Land Use

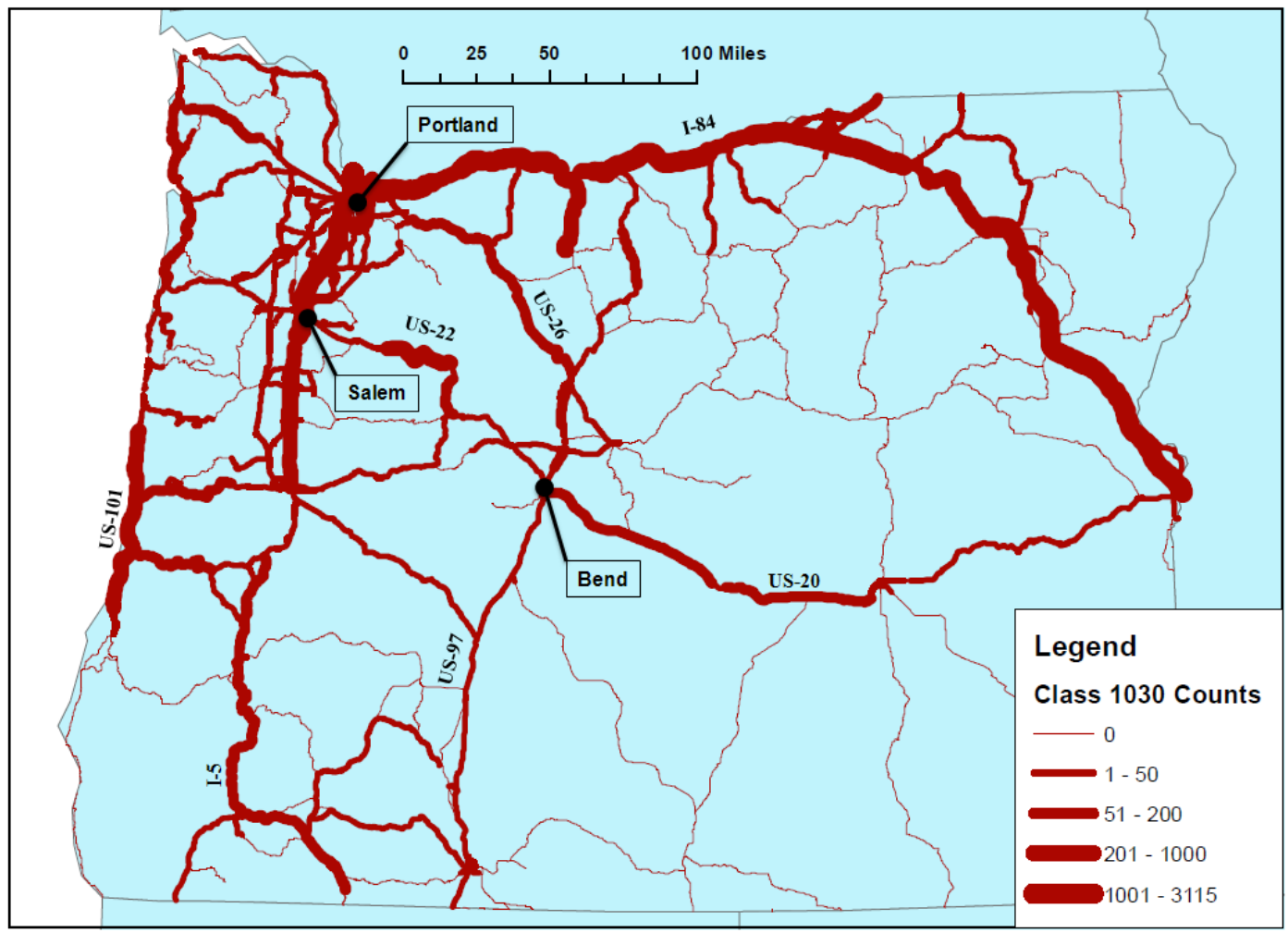

Figure 20 - GPS Record Counts for 1030 Weight Class 
The Freight Performance Measures: Approach Analysis report for ODOT (McMullen and Monsere, 2010) suggested the ratio of "total cost of freight loss and damage from accidents" to "total freight VMT" as the ideal safety freight performance measure for both statewide analysis and specific highway segments. "Total cost of freight loss" includes: 1) cost of lost and damaged equipment; 2) value of lost and damaged cargo; and 3) delay imposed to other freight carriers on the same highway corridor. The vehicle type, class, weight and commodity data available through TRUE data would assist in estimating such costs. The 2010 report also suggested "Motor Carrier Crash Rate" and "Triple Trailer Crash Rate" as worthwhile performance measurements for Oregon. If a system such as TRUE were implemented on a statewide level, it could be combined with Oregon's existing data sources for safety performance measures to assist in determining more accurate estimations for these performance measures.

Accessibility and connectivity performance measures are particularly relevant to Oregon due to the multimodal nature of the state with respect to freight (i.e., ports, airports and highways). Records from Oregon's current weight-mile tax system provide a source of data for such measurements; however, worthwhile performance measurements would become more feasible with commercial-truck GPS data. McMullen and Monsere suggest "percent of freight originating or terminating within a certain number of miles of LCV corridors" as a potential measure of accessibility. They note that shipment origin or destination data "does not contain [the] level of specificity" needed to make such a measurement; however, as demonstrated in Figure 19 and Figure 20, the new Oregon source of GPS data could likely provide the level of such detail. Truck turnaround time at terminals (ports) as measured in the research by You and Ritchie (2012) is another potential measurement for Oregon.

Maintenance and preservation efforts by state DOTs typically focus on highway bridge and pavement management (McMullen and Monsere, 2010). Bridge wear is primarily a function of GVW; pavement wear is primarily a function of axle weights. As such, the capability of TRUE data (in combination with WIM data) to provide estimates of both GVW and axle spacing of traveling vehicles on virtually any segment of state highway could be very useful to determine user impacts. DOTs typically allocate a large portion of their budgets to pavement maintenance projects. Further, most pavement damage is caused by heavy vehicles. For these reasons, it is pertinent to consider applications of truck GPS data within the field of pavement management. Applications for detailed truck GPS data could include: 1) pavement forensics; 2) more accurate estimates for highway design equivalent single-axle loads (ESALs); and 3) decreases to the frequency of pavement condition surveys for highway segments receiving minimal truck traffic. The TRUE data could also provide the route information for trucks of various gross vehicle weights in order to determine weight limit violations on bridges.

In summary, given the accuracy of the data (shown in Figure 12), and the associated analysis capabilities (i.e., represented in Figure 19 and Figure 20), it is clear that several applications ranging from trip generation, commodity and land use planning, to infrastructure management would greatly benefit from the statewide utilization of WMT GPS data. 


\subsection{SPEED ESTIMATES AND APPLICATIONS}

Of the freight performance measures listed in Table 1 and Table 4, those associated with mobility have probably received the most attention on a national level, specifically in relation to travel-time reliability and congestion at bottlenecks (McMullen and Monsere, 2010). As was demonstrated in Table 4, all of the research reviewed for this report explored applications in this area. Some commonly used mobilityperformance measures for which the TRUE data could provide estimations include Travel Time, TravelTime Reliability, TTI and PTI. Most of the research reviewed explored mobility performance as it relates to the transportation system as a whole. Wheeler and Figliozzi (2011) deviated from this approach slightly by also considering the impacts of mobility performance on the freight industry. There is some overlap between the two approaches, but performance measures will differ depending on which approach is taken.

\subsection{SPACE-MEAN SPEED ESTIMATES}

In order to estimate space-mean speeds using the TRUE dataset, highway mileages between GPS records were used rather than "straight-line" or "great-circle" distances. The distances between GPS records in the TRUE dataset are typically on the order of five miles. As such, significant error would result along curved highway segments if "straight-line" or "great-circle" distances were used. The use of highway mileages reduces such error, and thus is a more accurate measure of traveled distance. The highway mileages of the GPS records were determined through interpolation by comparing latitude/longitude measurements of the GPS records to those of known mileposts. The source of the highway milepost locations was an ArcGIS file from Metro's RLIS (Metro, 2012). The interpolation process was completed using RStudio. Subsequently, an automated process was developed in RStudio to determine the speeds between GPS records. In order to assess the accuracy of space-mean speeds calculated from the GPS data, the calculated space-mean speeds were compared to speeds from the Portland Oregon Regional Archive Listing (PORTAL) - the official Archived Data User Service (ADUS) for the Portland metropolitan area. Speed measurements available through PORTAL are based on inductive-loop detector data from nearly 600 sensors located throughout the Portland metropolitan area on I-5, I-205, I-405, I-84, OR-207 and US26 (Li and Bertini, 2010).

A set of all TRUE GPS records within 2.5 miles of a PORTAL station was created and a random sample of 30 TRUE records was selected from this set. For each of the 30 TRUE records in the random sample, the next downstream TRUE record was determined in order to calculate space-mean speeds. Subsequently, the PORTAL station closest to each of the sampled TRUE records was determined in order to create 60 "TRUE-PORTAL pairs" (or 30 "TRUE-PORTAL groups"). PORTAL speed estimates corresponding to the location and timestamp of the each of the corresponding TRUE records were then determined. At the time of analysis, speeds were available at PORTAL stations in five-minute increments. As such, PORTAL speed records just before and just after the corresponding TRUE timestamp were selected for each "TRUE-PORTAL pair." The PORTAL speeds at the exact times of each corresponding TRUE record were then determined by interpolation. The average speed between PORTAL stations in each "TRUE-PORTAL group" was then determined for comparison to the calculated space-mean speed between the corresponding TRUE records. PORTAL speed records are available for each individual lane at the location of each PORTAL station. For the purposes of this analysis, it was assumed that trucks from 
the TRUE dataset were always traveling on the right "truck lane" (the lane furthest from the median); likewise, PORTAL records from the "truck lane" were used for comparison to the TRUE space-mean speeds.

It should be noted that records representing destinations or origins were identified and removed from the speed estimation process. Destinations or origins usually consist of a cloud of observations which can be consolidated into one observation (representing a trip origin or trip end) to avoid erroneous speed calculations (false low speeds). In addition, Tukey's method to identify outliers (Sullivan, 1967) was used to determine if the "\% difference" for any of the 30 "TRUE-PORTAL pairs" was an outlier. Outliers were then removed from the analysis and a randomly selected TRUE record was chosen as a replacement. Such outliers were often indicative of a geocoding error in which ArcView GIS assigned one of the two TRUE GPS records to an incorrect highway segment. Removal of outliers also served to eliminate records from the analysis that represented trucks at rest or slowing down in an auxiliary lane, thus limiting the review to "through movements" more representative of the general traffic conditions.

As can be seen in Figure 21, over 50\% of the space-mean speeds calculated from the TRUE dataset were within $8 \%$ of the speeds calculated from PORTAL; all of the TRUE speeds were within $25 \%$ of the PORTAL speeds. The absolute values of the speed differences averaged $9 \%$; however, the TRUE speeds were, on average, approximately 7\% (3.65 mph) less than the PORTAL speeds; the speed differences had a standard deviation of $8 \%$ (4.41 mph). Eighty percent of the TRUE speeds were less than the PORTAL speeds. This is likely because PORTAL speeds are an aggregation of speed measurements from a variety of vehicle types (i.e., vehicles that typically travel at faster speeds than trucks). The TRUE speeds ranged from $21 \%$ (12.4 $\mathrm{mph}$ ) less than the PORTAL speeds to $10 \%(5.6 \mathrm{mph})$ greater than the PORTAL speeds. The results of a paired sample t-test indicate that at the 0.01 significance level there is sufficient evidence from the tested sample to conclude that the difference between the PORTAL speeds and those calculated from the TRUE data is significant. This conclusion appears to be consistent with the findings of previous research on the same freeway segments in the Portland region (Wheeler and Figliozzi, 2011). Previous research results indicated that during the peak PM period, speeds estimated from loop detectors were generally greater than speeds estimated by truck GPS data provided by the American Transportation Research Institute (ATRI). 


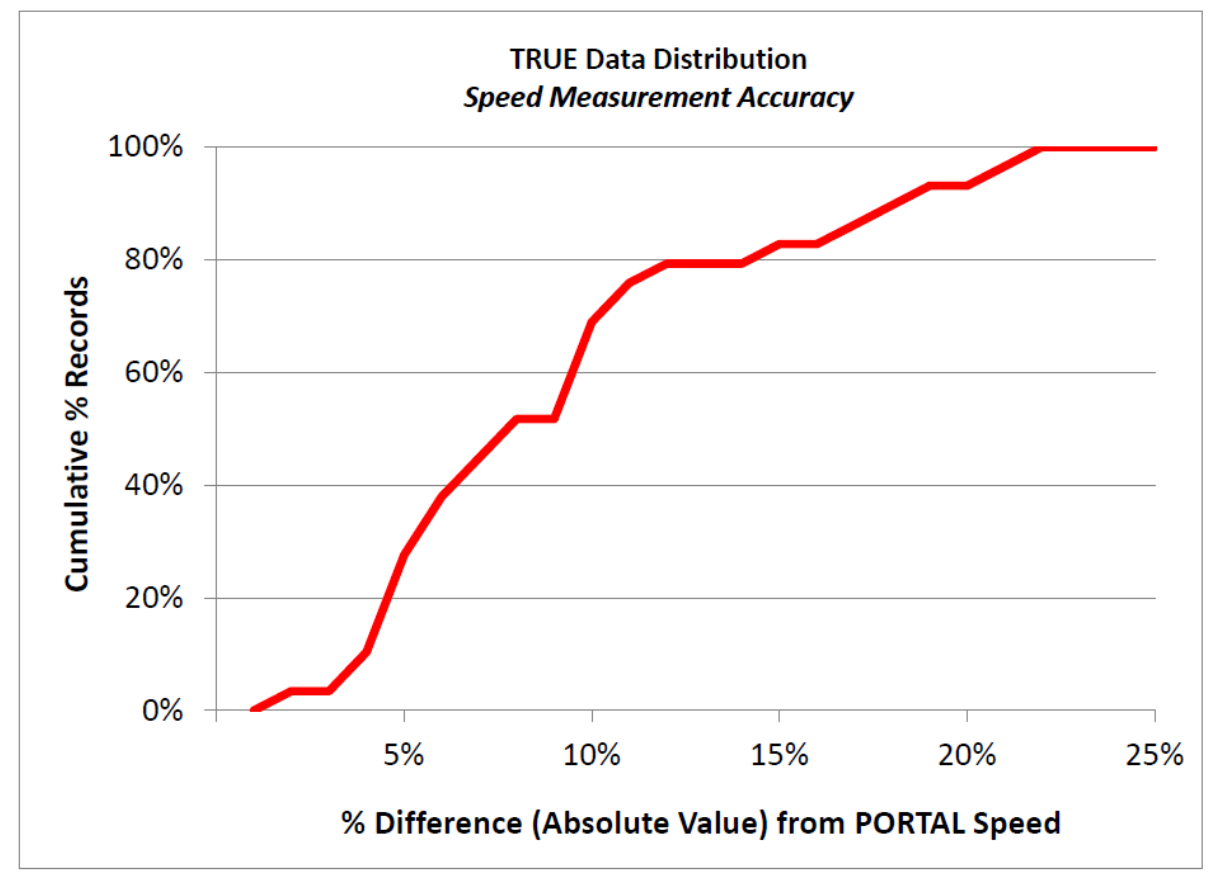

Figure 21 - Space-Mean Speed Measurement Accuracy

This analysis provides a statistical comparison of speeds estimated by TRUE to those estimated by PORTAL; however, possible limitations of the analysis should be considered:

1) PORTAL speed estimates are time mean speeds; TRUE speed estimates are space-mean speeds. Differences in the methods used to calculate each type of speed estimate will impact the results, especially when loop detectors are far apart. In the case of the PORTAL system, loop detectors are on average separated approximately one mile, and hence the error is not likely to be high.

2) Limitations of sample size - the analysis included a variety of locations and time periods; the change in relationship for different locations and time periods was not considered.

3) Errors in interpolation - this could be of particular concern for hours during the transition to peak periods; however, 22 of the 30 "TRUE-PORTAL pairs" represented time periods well outside peak hours ( 8 p.m. to 5 a.m. and 11 a.m. to 3 p.m.). This is likely because commercial trucks typically avoid traveling during more congested, "unreliable" times.

Space-mean speeds calculated with TRUE data using the described methodology were further used to perform a case study on a segment of I-5 that crosses the border between Oregon and Washington. The segment of I-5 used for the case study was approximately from Oregon milepost 293.93 to Washington milepost 7.3. This segment was chosen in order to compare the results to those of a previous case study that was performed in this area using commercial-truck GPS data (Wheeler and Figliozzi, 2011). Figure 22 shows a plot representing average speeds of pilot project vehicles traveling through the study area. In order to create this plot, a methodology was developed to identify "through trips" passing from the start to the end of the study area without leaving I-5. The speed values for these through trips were then averaged and plotted by applying the ArcView GIS "Spatial Analyst / Neighborhood / Point Statistics / Mean" tool on the speed values. A "search neighborhood" of one square mile was used to develop this plot, meaning 
that speeds were averaged across a mile. This analysis was performed for northbound traffic only.

The accuracy of the results in Figure 22 is limited by the sample size of trips through the study area from the TRUE pilot project data, as well as the relationship of the study area to the vehicles from the pilot project. The following requirements had to be met in order for a group of GPS records to be considered a through point:

- All GPS records are from the same vehicle.

- The GPS records are spaced consecutively 4.95-5.05 minutes apart.

- The first record in the trip is within 15 miles of Oregon I-5 milepoint 293.93.

- The last record in the trip is within 15 miles of Washington I-5 milepoint 7.3.

- The first and last records in the trip are within six hours of each other (which corresponds to speeds of at least $5 \mathrm{mph}$ ).

The above requirements were met by 170 through trips (consisting of a total of 1,077 records). As shown in Figure 11, a high density of records from the pilot project exists at a location that is just east of I-5 and just south of the Oregon-Washington border. This are of high record density might provide some explanation for the decrease in speed on I-5 just south of the high-density area. However, the trips associated with these low speeds would likely not have met the "through trip" requirements if the "buffer sizes" had been smaller as these slower trips likely leave the highway in the vicinity of the high-density location. Further, the areas at the south end of the start buffer and the north end of the end buffer likely had few trips relative to other areas of the study area. As such, the accuracy of the speeds shown in Figure 22 in those areas is likely limited also. The usefulness of this plot is further limited by the variation in the speeds as records were included for all days and all hours. In summary, an accurate speed analysis was difficult to perform with the small sample size available from the TRUE pilot project. However, the analysis in this section provides a methodology to analyze locations of bottlenecks related to freight using WMT GPS data. If a system such as TRUE were implemented statewide, speed analyses such as the one in this section could be performed for specific time intervals (i.e., weekday peak hours) in order to analyze specific bottleneck locations. 


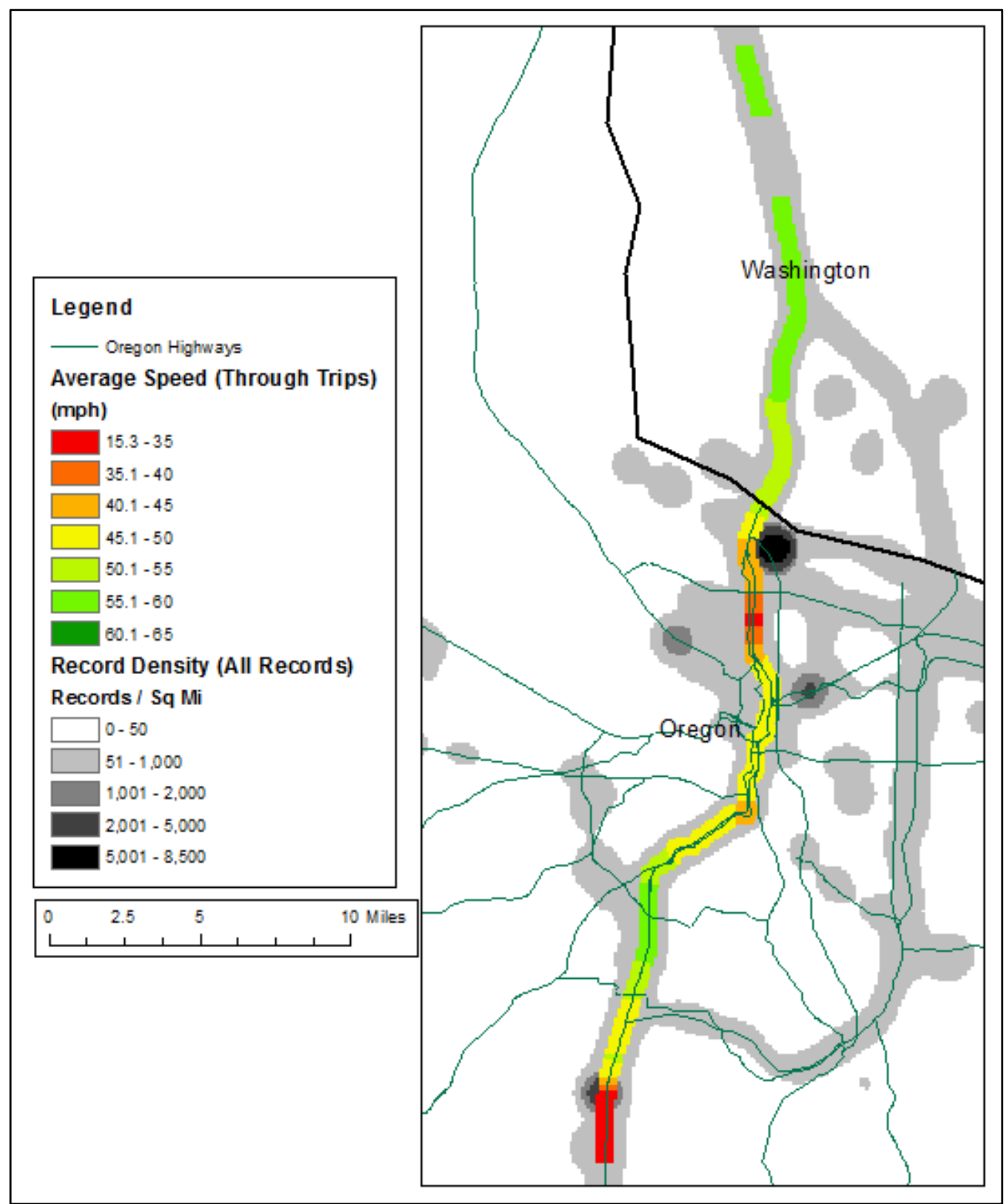

Figure 22 - Average Space-Mean Speeds - Columbia River Crossing Case Study

\subsection{RECORD DENSITY SPEED ESTIMATES}

This subsection presents a methodology to estimate vehicle speeds by making use of the consistent timestamp between TRUE GPS points. The TRUE GPS readings for each vehicle are typically 4.95-5.05 minutes apart. Important considerations and limitations associated with the outlined methodology are also addressed. The proposed methodology consists of the following basic steps:

1) Identify the optimal highway length from which to measure "record counts" and "trip counts" in order to estimate the average speed at a given point on a highway. A "record count" is the number of GPS records within a given highway length. A "trip" is a set of records that are all from the 
same vehicle and that have timestamps at consecutive five-minute intervals. Likewise, a "trip count" is the number of trips within a given highway length.

2) Determine the record count for a segment of highway that spans the optimal highway length.

3) Determine the trip count for the same segment of highway used in Step 2.

4) Estimate the average speed for the segment of highway used in Steps 2 and 3.

$$
\text { Estimated Speed }(\mathrm{mph})=\frac{1}{\frac{\text { Record Count } / \text { Trip Count }}{\text { Highway Segment Length }\left(\frac{5 \text { minutes }}{60 \text { minutes } / \mathrm{hr}}\right)}}
$$

5) Repeat Steps 2-4 for each location on the highway for which an estimated speed is desired.

When using record densities to estimate the speed at a given location, it is important to determine the optimal highway length from which to take record and trip counts. The highway length from which record counts and trip counts are taken should be large enough to contain at least one record from each vehicle trip through the segment. If a highway segment is used that is too short to contain at least one record from each vehicle trip, then the record count will be accurate for the segment but the trip count will be falsely low. Therefore, a calculation of "Record Count/Trip Count" will be falsely high, and a subsequent calculation of the Estimated Speed using Equation 1 will be falsely low. That said, the smallest possible segment length that will provide an accurate trip count should be used in order to obtain a more precise speed estimate. Because the TRUE GPS records are consistently recorded five minutes apart, the appropriate highway-segment length to use for speed estimates can be estimated by assuming a maximum vehicle speed. If it is assumed that vehicles from the TRUE pilot project traveled at a maximum speed of $70 \mathrm{mph}$, a highway segment length of 5.83 miles should be used to estimate the average speed at a given location.

Optimal Highway Segment Length for Average Speed Estimates

$$
=5 \text { minutes }\left(\frac{70 \text { miles }}{\mathrm{hr}}\right)\left(\frac{\mathrm{hr}}{\text { minutes }}\right)=5.83 \text { miles }
$$

Record density speed estimates were calculated using RStudio and the above methodology for the same segment of I-5 that was analyzed in "Space-Mean Speed Estimates" section of this report. Figure 23 provides a plot of the results for vehicles traveling through the case study area. 


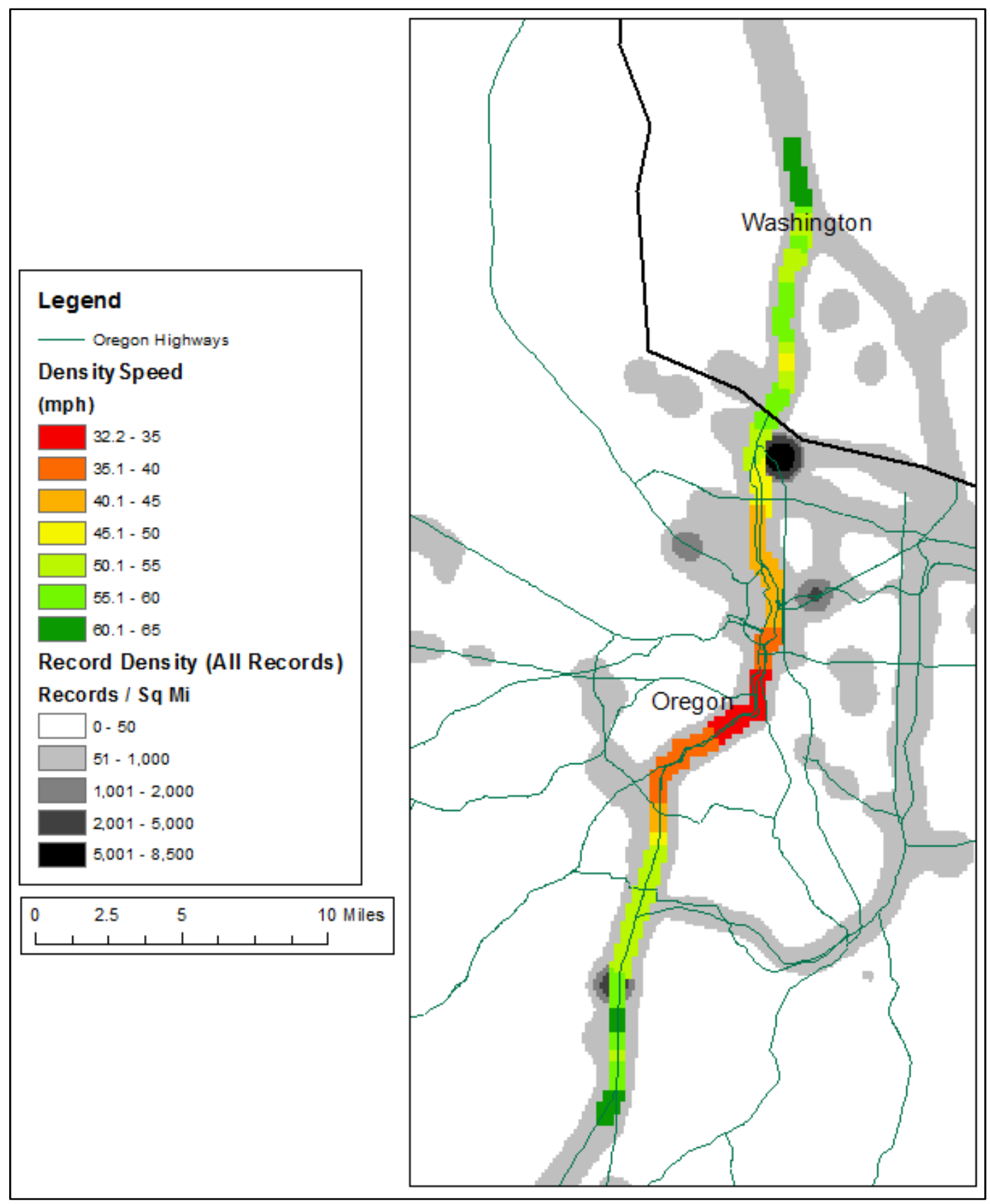

Figure 23 - Record Density Speed Estimates - Columbia River Crossing Case Study 


\subsection{EMISSIONS ESTIMATES}

Environmental performance measures often correspond to some extent with those for mobility; however, a more direct environmental application for the TRUE data is for emissions estimations. EPA currently requires that organizations use the "best data available" when creating air-quality models; however, requirements are likely to become more stringent as better data becomes available. Truck GPS data integrated with WIM data can be input into modeling programs such as EPA's MOVES in order to improve the accuracy of model results. The methodology employed by Wheeler and Figliozzi (2011) can be used and further developed to estimate freight emissions using ODOT's TRUE GPS and WIM data. This section of the report evaluates the use of the TRUE data for emission estimates that take into account truck-type details, truck weight and detailed speed profiles. A sensitivity analysis using EPA's MOVES2010b is performed in order to understand the level of error that might be encountered in emission estimates when such detailed data is not available.

\subsection{FRAMEWORK}

This section describes the MOVES2010b input parameters and potential output as it relates to the analysis presented in this report. Table 10 provides a description of the model inputs (U.S. EPA, 2012); those selected for the model presented in this report are highlighted and in bold.

\begin{tabular}{|c|c|c|}
\hline \multicolumn{2}{|c|}{ Variable } & \multicolumn{2}{|c|}{ Inputs } & \multicolumn{1}{|c|}{ Description } \\
\hline \multirow{3}{*}{ Scale } & National & The 'Scale' chosen for a MOVES model depends on the level of detail that will \\
be represented by the model inputs. The 'Project' level analysis allows the user \\
to model the emissions effects of a single roadway link.
\end{tabular}

Table 10 - MOVES Inputs 
In addition to the inputs presented in Table 10, the user can also define the geographic area from which default inputs (i.e., meteorological data) are based. Time period for which the model will be run must also be defined in terms of years, months, days (i.e., weekend, weekday) and start and end hours. The level of aggregation of results with respect to time can also be set in terms of year, month, day or hour. Other relevant input parameters include vehicle age and pollutant process (i.e., running exhaust, start exhaust, brake wear).

Depending on the information available for each roadway link modeled, a MOVES user may enter data for a vehicle operating-mode distribution, drive schedule, average speed and/or speed profile (U.S. EPA, 2012). When an average link speed is used as an input, MOVES uses a default drive schedule (with an average speed as close as available to the average speed given) to model the driving behavior (changes in speed) across the link.

Weights can be input into the "SourceMass" field in the input database. A truck-type's default weight is equal to the average GVW for that truck type based on a variety of data sources analyzed by EPA. The input values, "rollingTerm" and "rotatingTerm," are a function of vehicle weight. MOVES does not automatically update these values when the weight input is changed. Equations for these coefficients are based on study by V.A. Petrushov (1997).

\subsection{MOVES SENSITIVITY ANALYSIS}

The sensitivity analysis described herein focuses primarily on the truck type, weight, speed, and grade variables. Analysis was performed to examine changes in emissions from variations of these parameters in isolation. The impact of each parameter on emissions is evaluated by determining the percent change in emissions resulting from an incremental change in each parameter. Unlike previous truck GPS data sources, truck type and weight data is available through the TRUE system (in combination with WIM data). Further, the accuracy of speed estimates from the TRUE system has been shown through comparison to estimates from loop detector data and other truck GPS data. As such, this sensitivity analysis serves to evaluate the potential of the TRUE data to improve the accuracy of emission estimations at the project and regional level.

$\underline{\text { Method }}$

A project-level analysis was performed in order to analyze the sensitivity of emissions estimates at the link (highway segment) level. All parameters were kept constant except truck type, weight, speed and grade variables. Four heavy-duty diesel vehicles were included in the analysis: Single-Unit Short-Haul (SUSH), Single-Unit Long-Haul (SULH), Combination Short-Haul (CSH) and Combination Long-Haul (CLH). These vehicle types were chosen as they are consistent with the vehicle types applicable to the TRUE system. However, the bulk of this analysis focuses on the CSH vehicles, as this was the most common vehicle type in the TRUE pilot study.

Emissions considered include atmospheric CO2, CO2e, NOx, PM10 and PM2.5 and MSAT (Benzene, 1,3-Butadiene, Acetaldehyde and Acrolein) emissions. Preliminary analysis indicated that atmospheric $\mathrm{CO} 2$ typically follows similar trends to CO2e; PM2.5 typically follows similar trends to PM10. As such, the results for $\mathrm{CO} 2$ and PM2.5 emissions are not included in this report. Although emission rates vary for 
different MSAT emissions (see Figure 24), all mobile source air toxics (MSAT) emissions analyzed followed the same trends with regard to sensitivity to the variables considered. Thus, in each of the sensitivity analysis graphs included in this report, a single series is used to represent MSAT emissions. As an initial effort to examine MOVES' sensitivity to the variables being considered, this analysis focused on emission changes related only to "running exhaust" emissions. In addition, the "Age" variable was held constant at zero (i.e., new trucks) for all analyses. Further input values used for the analysis are presented Table 11.

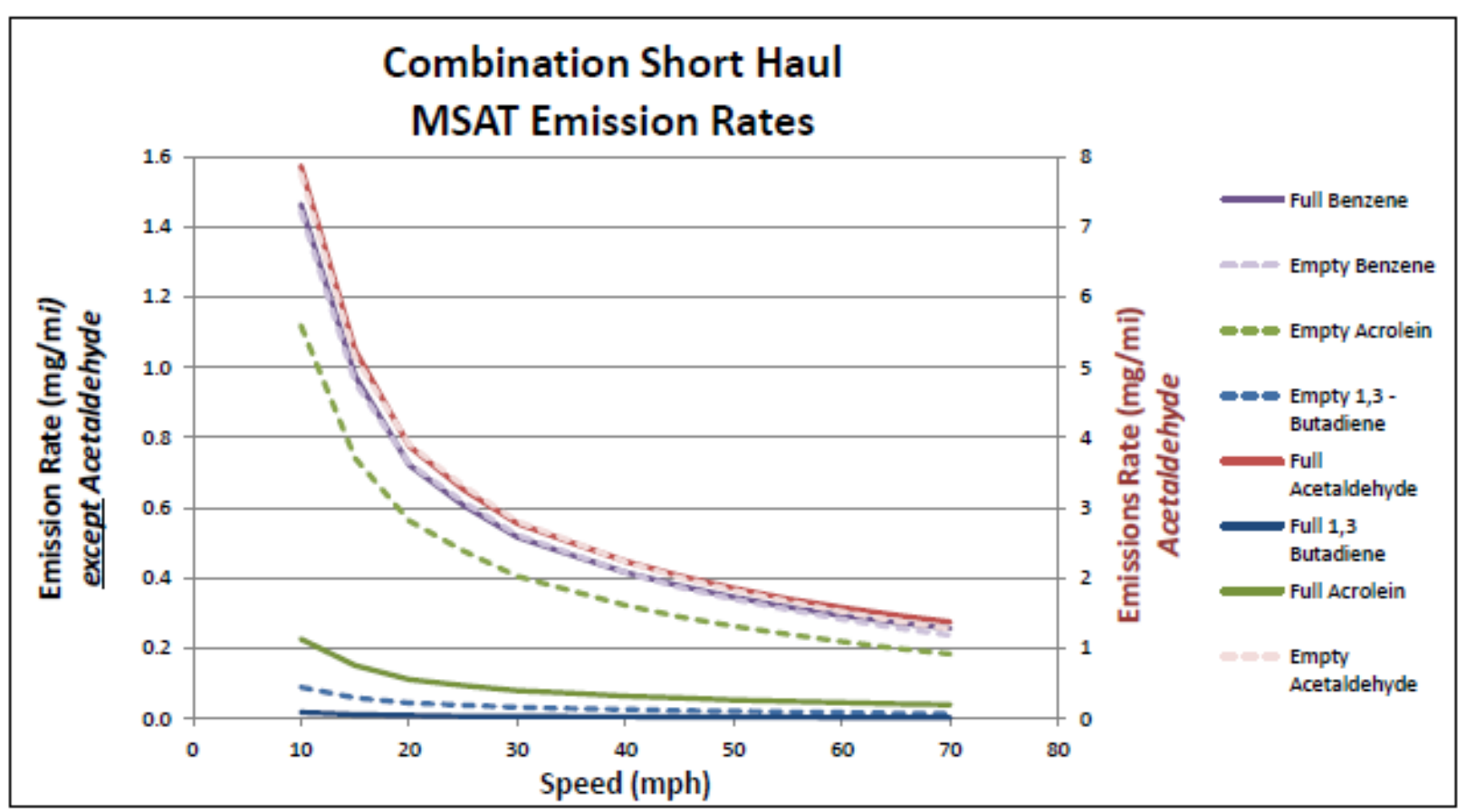

Figure 24 - MSAT Emissions vs. Speed

\begin{tabular}{|c|c|c|}
\hline \multicolumn{3}{|r|}{ SENSITIVITY ANALYSIS INPUTS } \\
\hline Variable & Input & Description \\
\hline $\begin{array}{l}\text { Geographic } \\
\text { Bounds }\end{array}$ & \begin{tabular}{|c|} 
Multnomah County, \\
OR
\end{tabular} & $\begin{array}{l}\text { This is the geographic area containing the majority of records from the } \\
\text { TRUE pilot project. }\end{array}$ \\
\hline Fuel Type & Default & $\begin{array}{l}\text { The default fuel type for Multnomah County, OR (provided by the } \\
\text { MOVES Default Database) was used. }\end{array}$ \\
\hline Roadtype & Restricted Access & $\begin{array}{l}\text { This roadtype was used in order to represent the freeway/interstate } \\
\text { condition. }\end{array}$ \\
\hline Year & 2011 & 2011 is the year from which the TRUE data is available \\
\hline Month & May & $\begin{array}{l}\text { May was chosen as it is typically a month of fairly mild (average) } \\
\text { weather conditions in the state of Oregon. }\end{array}$ \\
\hline Days & Weekdays & \multirow{2}{*}{$\begin{array}{l}\text { These are the times at which a high percentage of TRUE records on } \\
\text { Interstate- } 5 \text { (the primary north-south interstate in Oregon) have } \\
\text { timestamps. }\end{array}$} \\
\hline Time & 4-5pm & \\
\hline
\end{tabular}

Table 11 - Sensitivity Analysis Inputs 
In order to determine the appropriate weight ranges to model for each truck type, weight measurements from ODOT's WIM data were analyzed. A histogram representing the total truck weight versus frequency was plotted for each truck type using records spanning several years. An example is provided in Figure 25 for Type 17 (seven axles) truck. The two peak record frequencies exhibited in these histograms indicate two different weight situations (Figliozzi, Harrison and McCray, 2000): 1) an empty vehicle (tractor and semitrailer weight) at the first peak frequency (i.e., approximately 36,000 pounds in Figure 25); and 2) the truck weight limit at the second peak frequency (i.e., approximately 92,000 pounds in Figure 25). Records between these two zones represent trucks that are partially loaded or that carry a full load of lighter commodities.

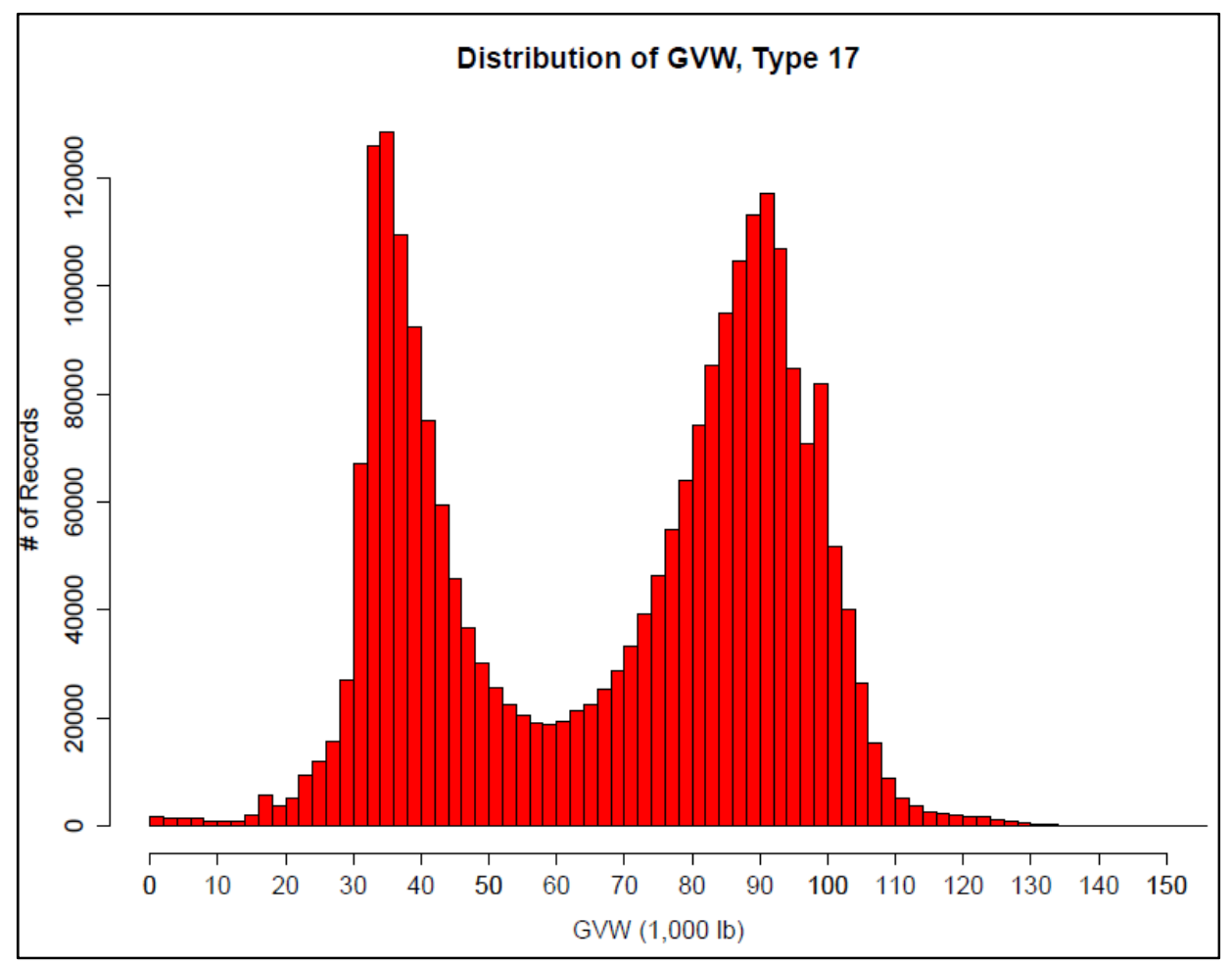

Figure 25 - Distribution of GVW, Type 17

Table 12 presents the assumptions that were made regarding which ODOT vehicle classes (ODOT, n.d.) were considered "Single-Unit" and "Combination" truck types. Weight distribution histograms (such as that in Figure 25) were created using ODOT WIM data for each of the vehicle classes listed in Table 12 in order to determine appropriate weight distribution assumptions for modeling the Combination truck type in MOVES. Based on an analysis of the weight distribution histograms, "empty weights" for the Combination truck type range from 33,000-40,000 pounds. "Full weights" for the Combination truck type range from 73,000-98,000 pounds. As such, weight variations from 20,000-110,000 pounds at 10,000pound increments were analyzed for CSH trucks. The weight distribution histograms for the Single-Unit truck types each displayed only one peak weight distribution. Classes 8, 9 and 10 displayed peaks at $12,000,28,000$ and 49,000 pounds. As such, emissions estimates were performed for SUSH trucks at $12,000,28,000$ and 49,000 pounds. 


\begin{tabular}{|c|c|}
\hline Truck Type & ODOT Vehicle Class \\
\hline \multirow{3}{*}{ Single-Unit } & 8 \\
\cline { 2 - 2 } & 9 \\
\cline { 2 - 2 } & 10 \\
\hline \multirow{3}{*}{ Combination } & 11 \\
\cline { 2 - 2 } & 15 \\
\cline { 2 - 2 } & 17 \\
\cline { 2 - 2 } & 18 \\
\hline
\end{tabular}

Table 12 - Vehicle Classification

Grade variations were analyzed from -6 to $6 \%$ at $1 \%$ increments. Average speed entries of 10 to $70 \mathrm{mph}$ in 5-mph increments were used, as these are the speeds at which MOVES drive schedules are available for the truck types considered.

\section{$\underline{\text { Results }}$}

$\mathrm{CO} 2 \mathrm{e}$ emission rates $(\mathrm{g} / \mathrm{mi})$ from Combination trucks were generally found to be higher than those for Single-Unit trucks at the same weight. However, as shown in Figure 26, the slope for the percentage change in $\mathrm{CO} 2 \mathrm{e}$ emissions with speed was much steeper for Single-Unit trucks compared to Combination trucks. This indicates that for $\mathrm{CO} 2 \mathrm{e}$ emissions, Single-Unit trucks are more sensitive to changes in speed than Combination vehicles.

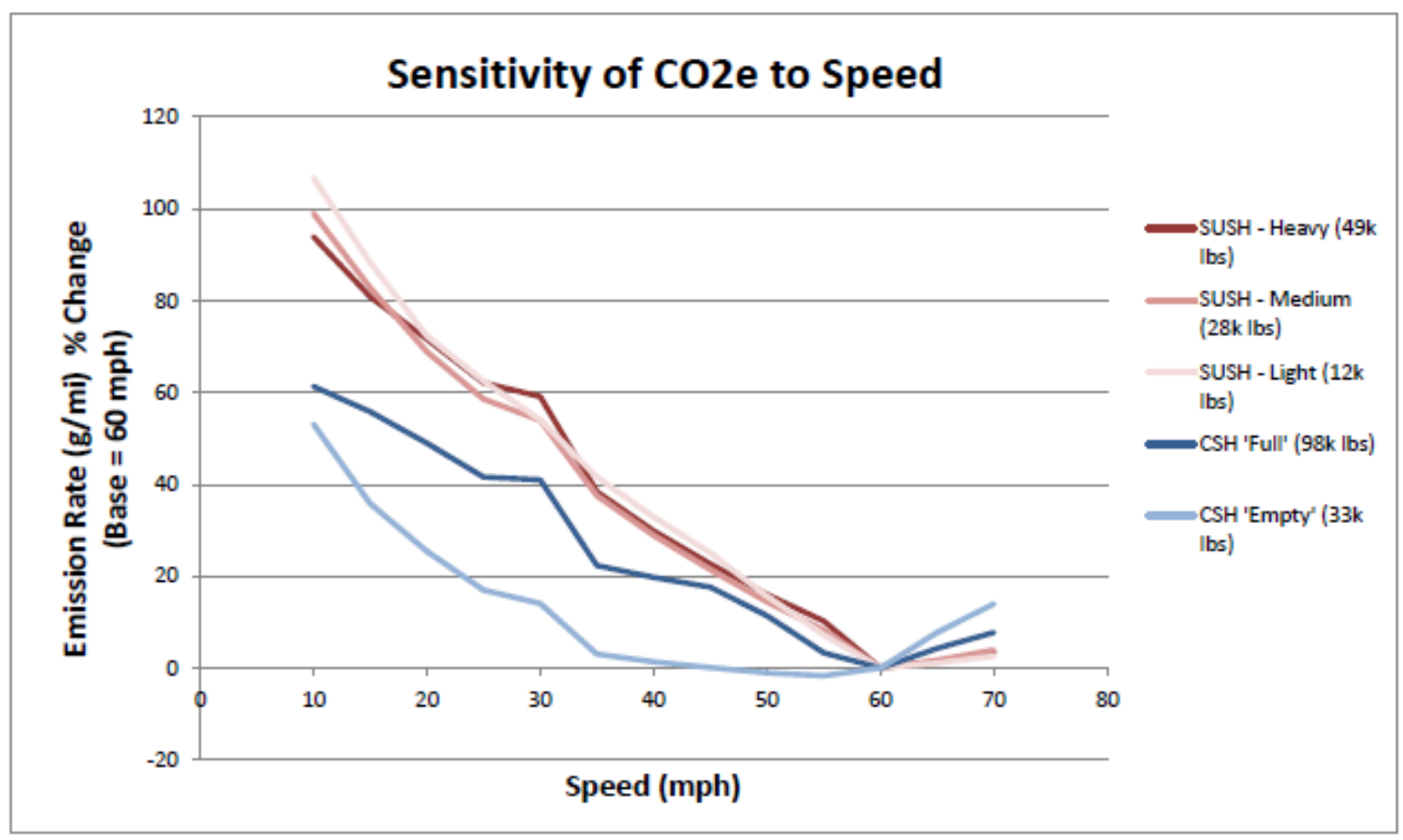

Figure 26 - Sensitivity of CO2e to Speed

Percent change in CO2e, NOx, PM10 and MSAT emissions in relation to incremental changes in speed are illustrated in Figure 27 for CSH vehicles. The percent change in emissions was calculated using 60 
mph as the base. Trends are provided for a weight in the CSH "empty" spectrum (33,000 pounds) as well as a weight in the "full" spectrum (98,000 pounds). As shown in Figure 27, emissions of each type of pollutant analyzed generally increase with decreases in speed. The slopes for PM10 and MSAT emissions are generally steeper than those for other emissions, indicating that these pollutants are more sensitive to speed differences than the others. MSAT emissions exhibit a particularly high level of sensitivity at speeds below $20 \mathrm{mph}$. The graph also indicates that for CO2e, NOx and PM10, emissions from full vehicles are generally more sensitive to decreases in speed than those from empty vehicles. The variation in slope with change in speed is likely related to the variation in drive schedule patterns (driving behavior) with different average speeds.

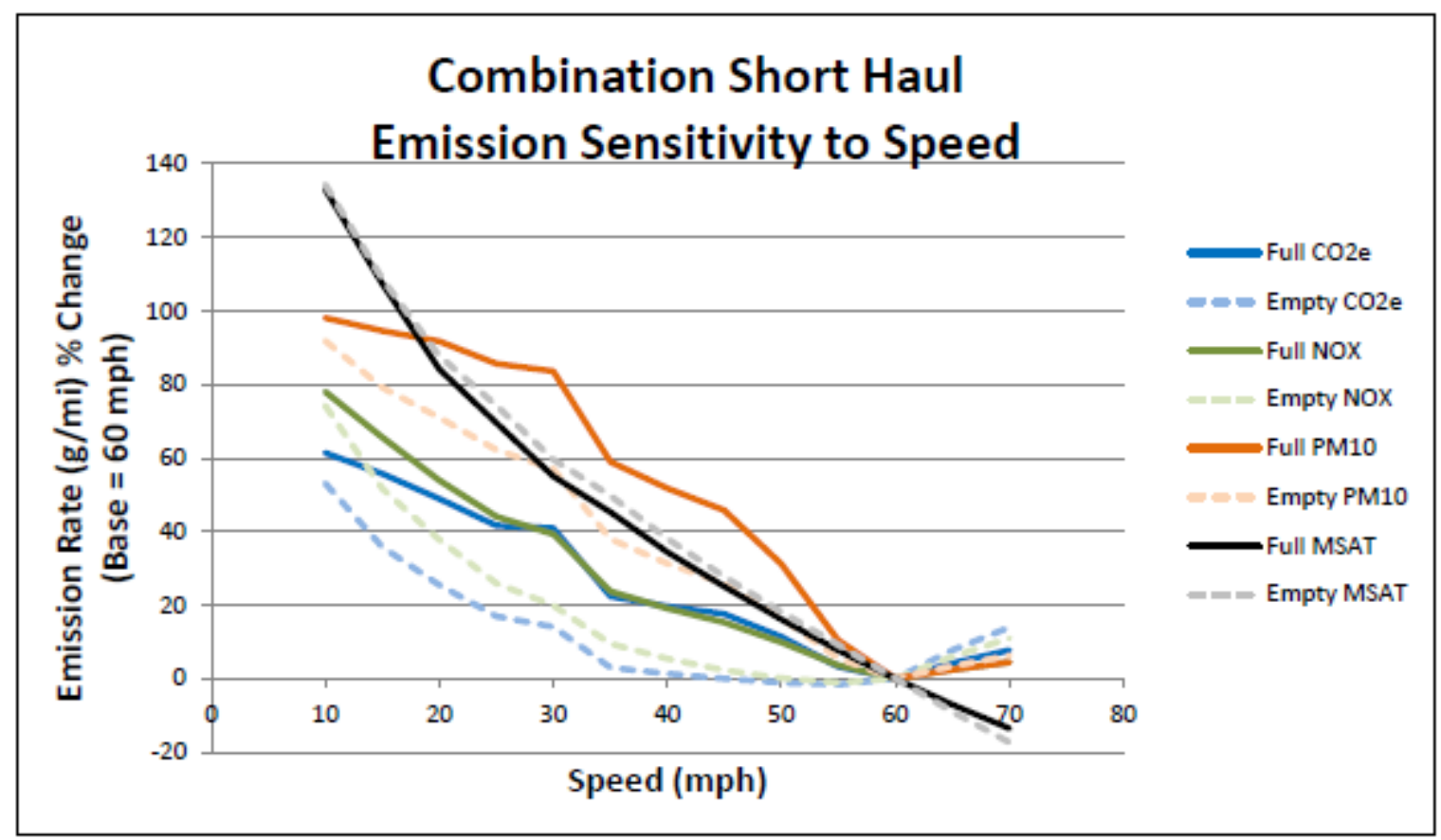

Figure 27 - Combination Short-Haul Emission Sensitivity to Speed - Grade 0\%

Sensitivity also varies by grade. Full vehicles are generally more sensitive to changes in grade than empty vehicles across the pollutants analyzed. As indicated in Figure 28, for CO2e, NOx and PM10, the sensitivity of empty vehicles is generally constant with changes in grade; however, results indicate that full vehicles generally become less sensitive to changes in grade with increasing grades. For both full and empty vehicles, $\mathrm{CO} 2 \mathrm{e}$ is the most sensitive to changes in grade; the sensitivity of MSAT emissions to grade is relatively low. 


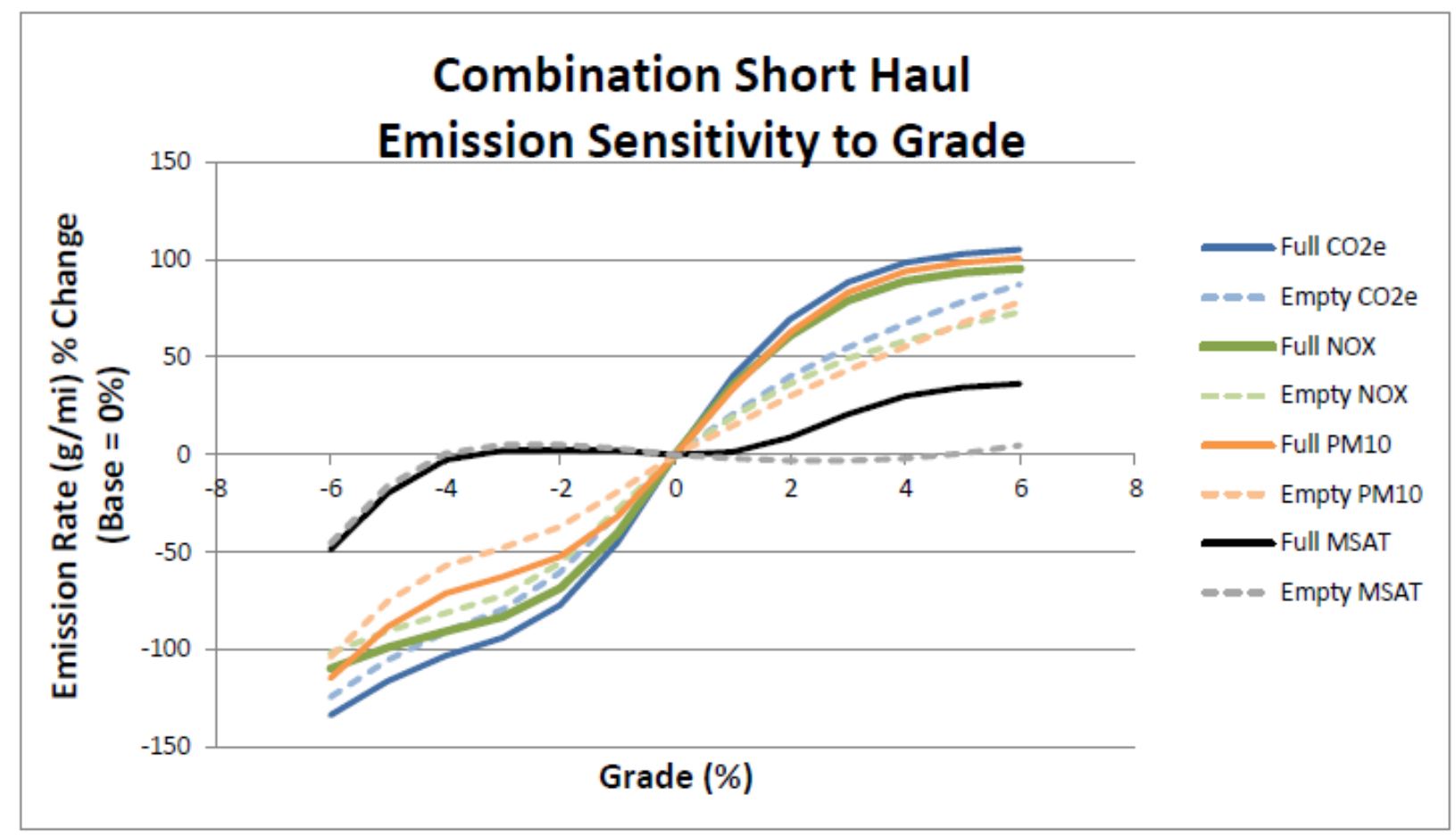

Figure 28 - Combination Short-Haul Emission Sensitivity to Grade - Speed $60 \mathrm{mph}$

Figure 29 represents the sensitivity of emissions from CSH vehicles with change in weight. Results indicate that vehicles are more sensitive to changes in weight at slow speeds. CO2e and PM10 have similar sensitivities to weight; CO2e and PM10 are more sensitive to changes in weight than NOx. MSAT emissions exhibit a relatively low sensitivity to weight. At a constant average speed, the sensitivity of each pollutant remains fairly constant across changes in weight. 


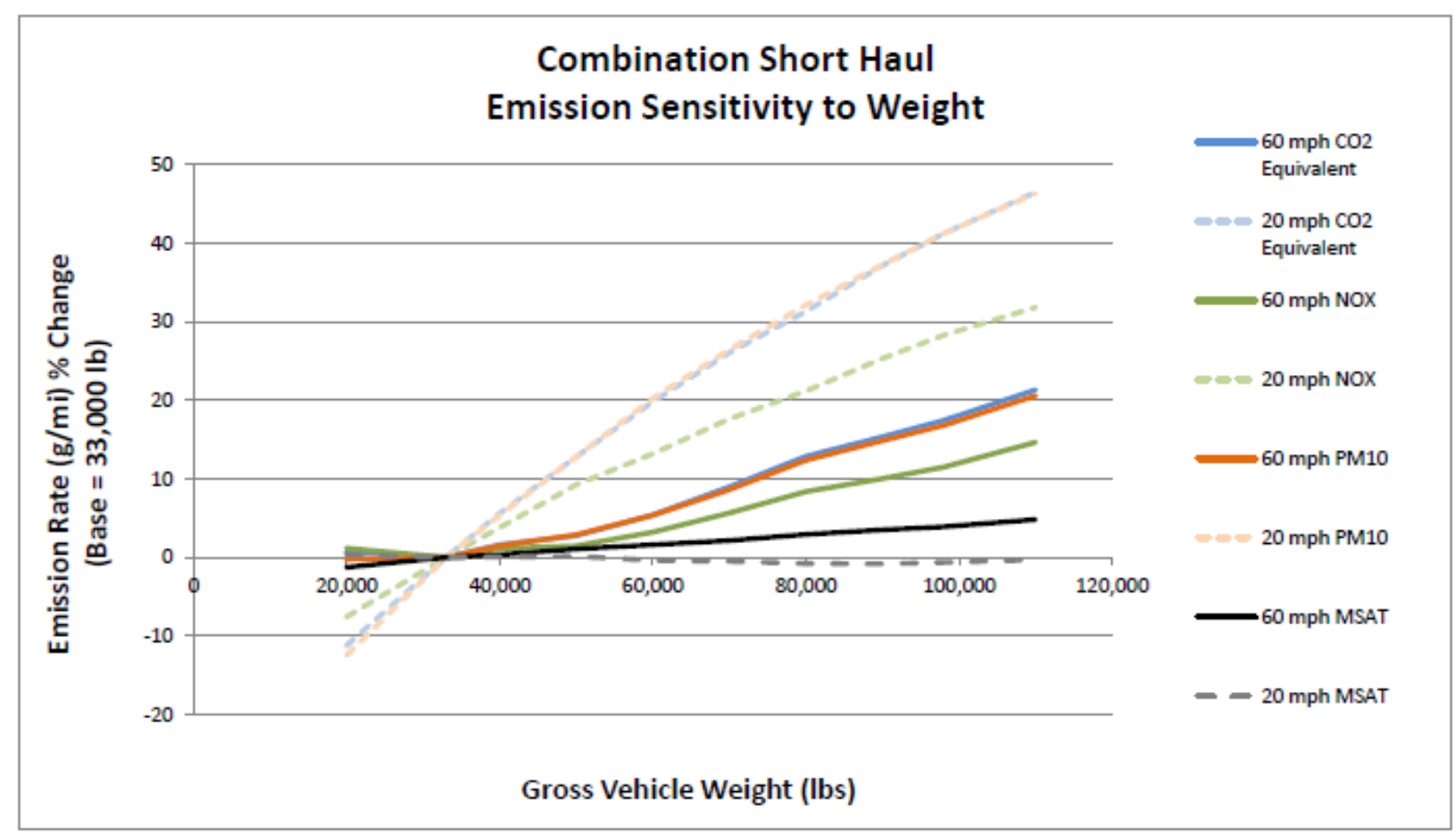

Figure 29 - Combination Short-Haul Emission Sensitivity to Weight - Grade 0\%

Table 13 provides a summary of the sensitivity analysis. The most sensitive scenarios (based on range of emission rates) are highlighted for each Parameter-Pollutant-Range combination. Overall, MSAT emissions are the most sensitive to speed changes; CO2e emissions are the most sensitive to grade and weight changes.

\begin{tabular}{|c|c|c|c|c|c|c|c|c|c|c|c|}
\hline \multirow{3}{*}{$\begin{array}{c}\text { Variabl } \\
\text { e }\end{array}$} & \multirow[b]{3}{*}{ Base } & \multirow[b]{3}{*}{ Range } & \multirow{3}{*}{$\begin{array}{c}\text { Constan } \\
t\end{array}$} & \multicolumn{8}{|c|}{$\%$ Change from Base } \\
\hline & & & & \multicolumn{4}{|c|}{ Empty } & \multicolumn{4}{|c|}{ Full } \\
\hline & & & & $\begin{array}{c}\mathrm{CO} 2 \\
\mathrm{e}\end{array}$ & NOx & $\begin{array}{c}\text { PM1 } \\
0\end{array}$ & $\begin{array}{c}\text { MSA } \\
\text { T } \\
\end{array}$ & $\begin{array}{c}\mathrm{CO} 2 \\
\mathrm{e}\end{array}$ & NOx & $\begin{array}{c}\text { PM1 } \\
0\end{array}$ & $\begin{array}{c}\text { MSA } \\
\text { T } \\
\end{array}$ \\
\hline Speed & $60 \mathrm{mph}$ & $\begin{array}{c}10 \text { to } 70 \\
\text { mph }\end{array}$ & $0 \%$ grade & $\begin{array}{l}-2 \text { to } \\
53\end{array}$ & $\begin{array}{c}-1 \text { to } \\
74\end{array}$ & $\begin{array}{l}0 \text { to } \\
92\end{array}$ & $\begin{array}{c}-17 \text { to } \\
134\end{array}$ & $\begin{array}{c}0 \text { to } \\
61\end{array}$ & $\begin{array}{c}0 \text { to } \\
78\end{array}$ & $\begin{array}{l}0 \text { to } \\
98\end{array}$ & $\begin{array}{c}-14 \text { to } \\
133\end{array}$ \\
\hline Grade & $0 \%$ & -6 to $6 \%$ & $60 \mathrm{mph}$ & $\begin{array}{l}-124 \\
\text { to } 87\end{array}$ & $\begin{array}{l}-102 \\
\text { to } 73\end{array}$ & $\begin{array}{l}-104 \\
\text { to } 78\end{array}$ & $\begin{array}{l}-46 \text { to } \\
5\end{array}$ & $\begin{array}{c}-134 \\
\text { to } \\
105\end{array}$ & $\begin{array}{l}-109 \\
\text { to } 95\end{array}$ & $\begin{array}{c}-115 \\
\text { to } \\
101\end{array}$ & $\begin{array}{l}-49 \text { to } \\
36\end{array}$ \\
\hline $\begin{array}{c}\text { Variabl } \\
\text { e }\end{array}$ & Base & Range & $\begin{array}{c}\text { Constan } \\
t\end{array}$ & \multicolumn{4}{|c|}{ Congested (20 mph) } & \multicolumn{4}{|c|}{ Free Flow (60 mph) } \\
\hline Weight & $\begin{array}{c}33,000 \\
\text { lbs } \\
(\text { 'Empty' } \\
)\end{array}$ & $\begin{array}{c}20,000 \\
\text { to } \\
110,000\end{array}$ & $0 \%$ grade & $\begin{array}{c}-11 \text { to } \\
47\end{array}$ & $\begin{array}{c}-8 \text { to } \\
32\end{array}$ & $\begin{array}{c}-12 \text { to } \\
46\end{array}$ & -1 to 0 & $\begin{array}{c}0 \text { to } \\
21\end{array}$ & $\begin{array}{c}0 \text { to } \\
15\end{array}$ & $\begin{array}{c}0 \text { to } \\
21\end{array}$ & -1 to 5 \\
\hline
\end{tabular}

Table 13 - Sensitivity Analysis Summary 


\subsection{TRUE-MOVES EMISSION ESTIMATES}

EPA currently requires that organizations use the "best data available" when creating air-quality models; however, requirements are likely to become more stringent as better data becomes available. Although previous research had limited success with the use of commercial-truck GPS data for planning and modeling purposes, the TRUE data has an advantage in its level of disaggregation and its ability to differentiate between vehicle types. The methodology employed by Wheeler and Figliozzi (2011) provides an example of the successful use of truck GPS data in MOVES. However, the TRUE data (in combination with WIM data) provides an opportunity to enhance the accuracy of MOVES estimates by incorporating vehicle weight and speed profile estimates more representative of actual conditions. A framework for future emissions estimates with the TRUE data is presented in Figure 30.

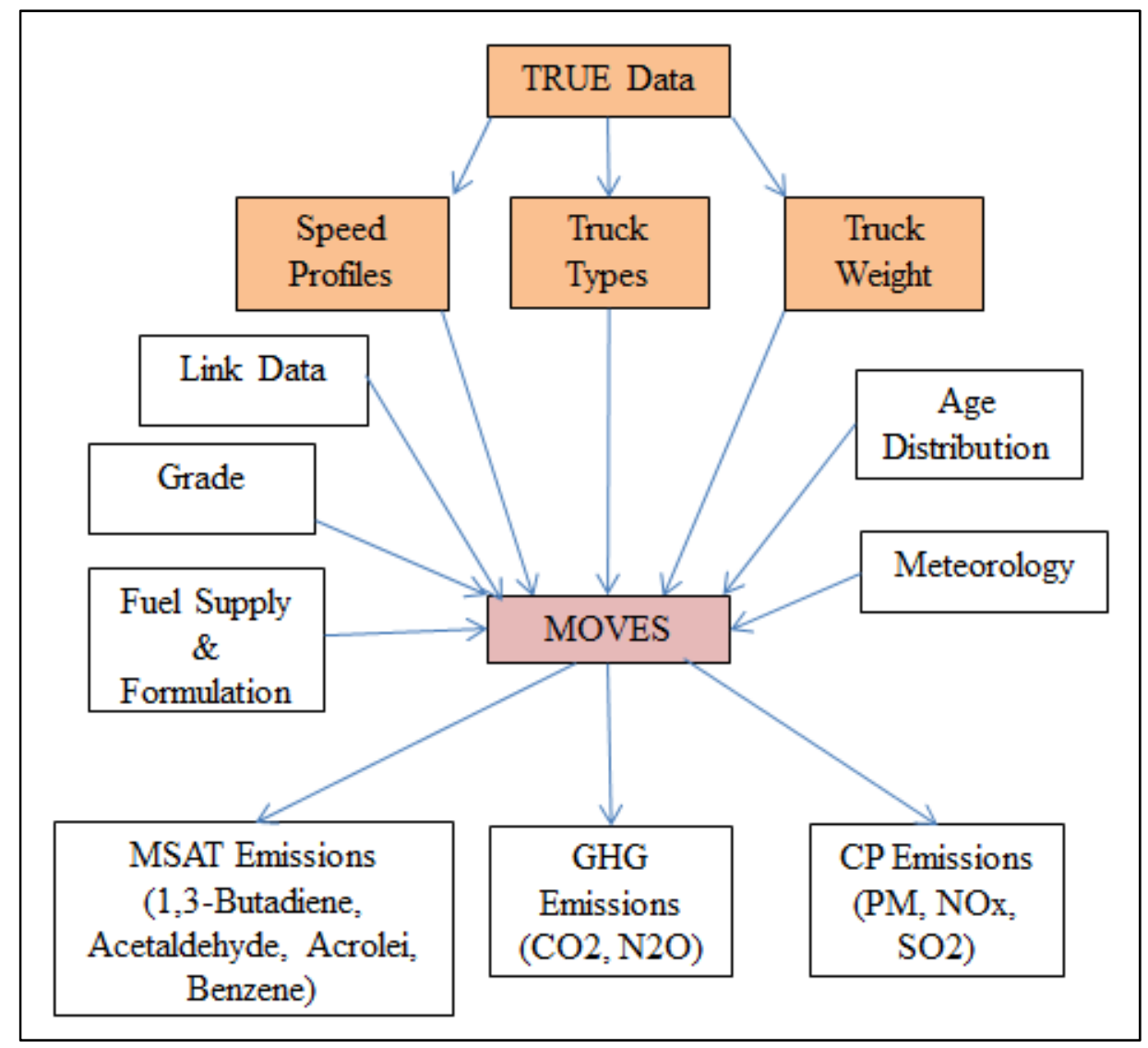

Figure 30 - TRUE-MOVES Emissions Estimates

As an initial analysis, emissions estimates were performed using TRUE GPS records from one CSH truck trip on an approximately 30-mile segment of northbound I-5 just north of the Portland metro area. The records used were from a weekday trip between 4-5 p.m. The truck's TRUE GPS records were integrated with the applicable WIM records in order to determine the weight value input for MOVES. Other inputs used were consistent with those described in the "MOVES Sensitivity Analysis" section of this report. Table 14 presents a comparison of emissions estimates obtained when using the average speed (and associated default drive schedule from MOVES) for this trip compared to those obtained when using the trip's speed profile. Results indicate that the emissions estimates obtained from MOVES using the TRUE 
average speed and associated default drive schedules overestimated emission quantities. PM emissions were most sensitive to the change in speed input method; NOx emissions were least sensitive.

\begin{tabular}{|c|c|c|c|}
\hline \multicolumn{4}{|c|}{ MOVES Emissions with TRUE Data } \\
\hline & $\begin{array}{c}\text { Using TRUE Speed } \\
\text { Profile }(\mathrm{g} / \mathrm{mi})\end{array}$ & $\begin{array}{c}\text { Using TRUE Average } \\
\text { Speed }(\mathrm{g} / \mathrm{mi})\end{array}$ & $\%$ Difference \\
\hline $\mathrm{CO} 2$ & 1555 & 1764 & -13.4 \\
\hline CO2 Equivalent & 1556 & 1765 & -13.4 \\
\hline Nox & 0.97 & 1.05 & -8.5 \\
\hline PM10 & 0.016 & 0.018 & -14.7 \\
\hline PM2.5 & 0.015 & 0.018 & -14.7 \\
\hline
\end{tabular}

Table 14 - MOVES Emissions with TRUE Data

Previous research (Wheeler and Figliozzi, 2011) used truck GPS data to obtain emissions estimates in MOVES for the same northbound segment of I-5 analyzed in Table 14. Subsequently, a methodology was presented to estimate the cost effects of such emissions. The analysis presented in Table 14 could be repeated for other truck trips represented by the records from the TRUE pilot project. The results of the analysis could then be compared to those from the analysis performed by Wheeler and Figliozzi for the same highway segment in order to further understand the impact of the more detailed truck data available through TRUE. Similarly, such an analysis would allow a more robust understanding of the impact of detailed speed profiles on emissions estimates in comparison to average speed values and the associated default drive schedules in MOVES.

\subsection{EMISSION ESTIMATES - CONCLUSIONS AND FUTURE}

The impact of the selected MOVES input parameters on CO, NOx, PM and MSAT emissions were examined by comparing the percent change in emissions to base input values. The results demonstrate that speed, grade and weight can have a substantial impact on MOVES' estimates of emissions. Overall, MSAT emissions are the most sensitive to speed changes; CO2e emissions are the most sensitive to grade and weight changes. The results of the analysis represent the value of the detailed weight and speed data available through TRUE. In the future, the accuracy of emission estimates could be further enhanced through the use of more accurate inputs for other variables such as age distribution and inspection and maintenance programs.

According to ODOT reports (ODOT and DLCD, 2011), estimates from ODOT's GreenSTEP model could further be used to assess the relative equity of different policy proposals for different road users. ODOT's GreenSTEP model has previously focused on emissions from household and light-duty commercial vehicles (i.e., autos, SUVs pickup trucks, vans); modeling of GHG emissions from freight is still under development. Given that commercial vehicle emissions are greatly dependent on vehicle weight and speed, emissions estimates from the TRUE data (in combination with the WIM data) would be highly valuable in further developing the freight portion of GreenSTEP. 


\subsection{PRIVATE-SECTOR APPLICATIONS}

\subsection{COMMERCIAL-TRUCK GPS DATA - PROPRIETARY APPLICATIONS}

\subsubsection{INRIX}

A private company, INRIX, is a provider of travel information for a variety of users including individual travelers, commercial fleets and the public sector. INRIX anonymously collects GPS data from "probe vehicles," in part through agreements with fleet operators who have GPS devices in their trucks but also from personal vehicles (individuals who have downloaded the INRIX application to their smart phone) and taxis (Schrank, Lomax and Eisele, 2011). The data is compiled into average speed profiles for freeways, highways and arterials in every major metropolitan area in the U.S. This data is not publicly available, but can be purchased from INRIX (McMullen and Monsere, 2010). Customers of INRIX include private fleets to which they provide services such as dispatch services, traffic map overlays, fastest routes, next-day planning and congestion pricing (INRIX Inc., 2012). In addition, INRIX provides the majority of the data used to produce the Texas Transportation Institute's Urban Mobility Report (UMR). The UMR combines INRIX speed data with traffic volume data from states to provide mobility measures for each state. Additional information regarding the UMR can be found in Section 2.11 "Mobility, Congestion \& Reliability" of this report. In 2008, INRIX provided vehicle probe data to the I95 Corridor Coalition (a partnership of state DOTs from Maine to Florida) to support dissemination of real-time travel information for phone hotlines, websites, variable message signs, traffic management and performance measurement (INRIX Inc., 2012). INRIX also offers a mobile application developer kit for smart phone application developers wishing to use the INRIX data. On a regional level, Oregon recently acquired the availability of INRIX GPS data for use on transportation projects (Platman, 2012).

\subsubsection{Xata Turnpike}

A technology with applications similar to ODOT's TRUE system is "Xata Turnpike." Xata Turnpike is a fleet management and optimization technology that provides real-time information for commercial trucking companies. The technology uses Xata's electronic on-board recorder, called "RouteTracker," which tracks vehicle logistical data via connection to drivers' existing cell phones, smart phones and tablet computers. The recorder tracks data for:

- Electronic hours of service driver logs

- International Fuel Tax Association and state mileage reporting, including official forms

- Actual route driven via GPS - online mapping

- Auto arrival and departure

- Engine diagnostics

- Speed, RPM and hard braking

- Idle time, fuel efficiency and PTO

- Fault code reporting 
Xata charges users a subscription price per vehicle per month (Xata Corp., 2012). Benefits of Xata Turnpike are stated to be:

- Reduced operating costs

- Reduced hours of service violations and faster DOT audits

- Electronic Driver Vehicle Inspection Reports

- Optimized driving techniques

- Increased driver productivity - save 15-30 minutes a day

According to Xata, the Xata Turnpike technology has been cited by the Federal Motor Carrier Safety Administration (FMCSA) as "the most cost-effective compliance device for electronic driver logs."

\subsubsection{EROAD}

In 2009, EROAD used a device similar to TRUE to implement the world's first autonomous Global Navigation Satellite Systems/Cellular Network tolling system for commercial trucks in New Zealand (EROAD Limited, 2011). New Zealand has operated a WMT system since 1978; taxes are applied to trucks over 3.5 tonnes (3.9 tons, U.S.) and light diesel vehicles (Michie, 2012). EROAD uses a secure On Board Unit (OBU) to collect road charges based on vehicle distance, location, mass, time and emissions. The OBU has been approved by the New Zealand government as an electronic replacement for mechanical hubodometers. According to EROAD, the OBUs consume little electrical power and can be installed on cab dashes by ERAODS in one to two hours. Truck operators in New Zealand have the option of using either the traditional paper-based system or the electronic EROAD system to manage and pay their weight-mileage taxes (Michie, 2012). In addition, EROAD provides the option of web-based fleet management services. EROAD has a web application that monitors logistical information for clients, including tracking driver compliance, fuel, messaging and maintenance. According to EROAD, benefits of its product include:

- Reduced weight-mileage tax administration

- Reduced fuel and operating costs

- Improved compliance

- Greater transparency

- Enhanced management control

- Higher private/off-road tax refunds

- Improved working capital

- Less stress for drivers and managers

The EROAD website also lists efficiency, safety, sustainability, economic prosperity and social well-being as aims of its product.

EROAD has successfully negotiated a signed agreement with the Oregon Trucking Association (OTA) to collaborate on a 90-day pilot demonstration project of its product in Oregon (ODOT, n.d.). This pilot 
project was performed from October to the end of December 2012.

\subsection{COLLABORATION WITH THE PRIVATE SECTOR}

In July 2012, members of the Transportation Research Board (TRB) Freight Transportation Data Committee met for a workshop to discuss private sources of supply chain data and the use of such data to support public decision-making. A Transportation Research Circular, Measuring the Transportation System from a Supply Chain Perspective, (TRB Freight Transportation Data Committee, 2012) consisting of summaries from the workshop, was released the following October. According to the circular, "Several recent TRB activities concluded that critical supply chain data are not currently available to inform research, planning and policy making that impact freight movements, the transportation system and the U.S. economy." The circular suggests that in order for the public sector to gain better access to freight data: 1) privacy concerns of private freight carriers must be addressed; and 2) public use of the data must have benefits that are valuable to the private sector.

The proprietary nature of freight data has been said to be one of the primary challenges towards the affective use of freight data by the public sector. Due to privacy concerns, freight data that might be used by the public sector is usually incomplete, scarce and expensive to collect (McMullen and Monsere, 2012; TRB Freight Transportation Data Committee, 2012). In order to gain access to supply chain data, the public sector must consider the competitive risks private entities are exposed to in allowing the collection of supply chain data (TRB Freight Transportation Data Committee, 2012). Sound data-security measures should be developed to ensure that data is adequately protected. Security measures should be clearly communicated to the private partners. Raw data, as well as any files associated with models or analysis, should be stored in a secure data center. Intended uses for the data, and the data elements that are required for these uses, should be clearly communicated.

Freight policy impacts several aspects of the economy - congestion, safety, environment, jobs and economic competitiveness. Transportation infrastructure that fails to serve the freight sector effectively and efficiently incurs hidden costs on regional economic growth and competitiveness. As such, there are great benefits to minimizing supply chain costs for both the private and public sectors. In order to assure the private sector that public use of the data will have benefits to private freight carriers, the sectors should collaborate to develop a "supply chain based regional-strategic framework to identify multimodal freight transportation problems and priorities" (TRB Freight Transportation Data Committee, 2012). This should include improvements to infrastructure and policies that will benefit freight providers as well as the public. The following are uses of detailed freight data that the circular suggests could impact both the private and public sectors:

- Detailed freight data is particularly effective in measuring the performance of transportation system infrastructure such as critical links, corridors and terminals in ways that "better reflect the role of public infrastructure in regional and national economic competitiveness."

- Detailed freight data can allow agencies to better map key industries to known commodity flows, transportation routes and modes, and to assist commodities that are vital to the regional economy. 
- Detailed freight data can provide an understanding of multiple trips within a region that make up the transportation portion of a supply chain for an industry, that, when viewed separately, are random trips averaged into the indicator. Viewed together in a comprehensive manner, they reveal the transportation system's performance and economic impact for a key industry.

It should also be understood that some private-sector performance measures are similar to the public sector, while others are different. Performance measures common to both sides are speed, cost and predictability. However, private-sector managers work under shorter time frames for performance assessment due to the level of flexibility demanded of supply chain transportation. Transportation planners should also understand that supply chains require multiple types of facilities at different locations - each type of facility has a distinct purpose with unique infrastructure needs. An understanding of location factors can allow public staff to support a more successful approach to economic development. The circular suggests that a useful approach could be to focus on the critical 10 to 12 industries in a chosen study area. These industries likely account for the majority of the supply chains that impact the regional economy and transportation systems. A focused approach will assist planning staff in successfully incorporating the supply chain perspective with a manageable dataset. Further, development of a series of illustrative case studies could assist agencies in more fully understanding the importance of supply chains to transportation operations and economic development.

A major theme from the Freight Data Committee's workshop was the benefit of public-private collaborations in pilot projects. Collaboration through pilot projects provides a valuable opportunity to identify benefits of data sharing for the public and private sectors as well as ways to manage disclosure concerns of the private partners. Likewise, the workshop summaries also suggest that the public sector engage private sector stakeholders such as the Chamber of Commerce and other professional organizations associated with supply chain management.

\subsection{PRIVATE- AND PUBLIC-SECTOR APPLICATIONS FRAMEWORK}

Private data-collection efforts and applications should ideally complement public-sector data-collection efforts. It is vital to recognize private-sector privacy needs but also to understand public-sector data needs for better freight planning and transportation system operation. Future VMT data-collection efforts should ideally be designed keeping in mind the broad range of ancillary applications described in Table 15 .

Previous work related to the use of freight GPS data has provided a valuable starting point for this research. The "Balanced Scorecard" methodology proposed by NCFRP Report 10 (NCFRP, 2011) and the suggestions from the Freight Performance Measures: Approach Analysis prepared for ODOT (McMullen and Monsere, 2010) provide a useful framework from which to develop ancillary applications for the Oregon WMT GPS data. Past research has served to develop transportation metrics which use commercial-truck GPS data. However, uses for the data were somewhat limited as the data did not differentiate between different truck types. Use of the data typically also required an ongoing cost as it was collected by an outside provider. As a result of data limitations, past researchers have had limited success in developing trip-generation rates with the GPS data they used. However, Oregon's WMT GPS source has the potential to differentiate between vehicle types; development of trip-generation rates is a 
valuable planning application for Oregon's GPS data that this research explores. Other research projects encountered challenges when GPS data was collected by different vendors using different formats and communication methods. Further processing was needed to transform the data into a consistent format; however, this would not be required with the TRUE data as it is all from the same source. Use of TRUE data would allow ODOT to eliminate some of the steps used by other researchers to process GPS data. For example, Step 4 of the process used by WSDOT ("Develop a truck classification algorithm") would not be needed with this use of TRUE data. The Oregon GPS data will include truck identification information which has potential to be linked to WIM data to provide truck type and size. In summary, Error! Reference source not found. Table 15 provides a list of potential applications, along with the data fields required to provide accurate results for each. All of the data fields listed in Table 15Error! Reference source not found. are provided by the TRUE system.

\begin{tabular}{|c|c|c|c|c|c|c|c|c|c|c|c|}
\hline & & \multicolumn{10}{|c|}{ Data Fields } \\
\hline Category & Performance Measure / Application & 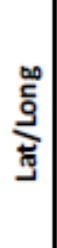 & 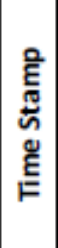 & 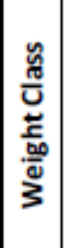 & 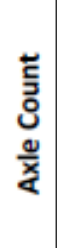 & 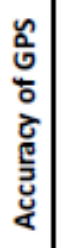 & 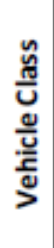 & 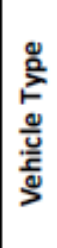 & 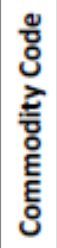 & 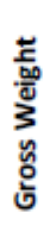 & 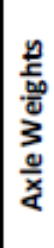 \\
\hline \multirow{8}{*}{ Mobility } & Travel Time & & & & & & & & & & \\
\hline & Travel Time Reliability & & & & & & & & & & \\
\hline & Trave Time Index (TTI) & & & & & & & & & & \\
\hline & Planning Time Index & & & & & & & & & & \\
\hline & Volume to Capacity (V/C) & & & & & & & & & & \\
\hline & $\%$ Congested Miles & & & & & & & & & & \\
\hline & Interstate MC VMT & & & & & & & & & & \\
\hline & Freight tonnage by commodity & & & & & & & & & & \\
\hline \multirow{4}{*}{ System Condition } & Estimate Pavement Condition & & & & & & & & & & \\
\hline & Scope Pavement Condition Surveys & & & & & & & & & & \\
\hline & Pavement Forensics & & & & & & & & & & \\
\hline & Bridge Weight Limit Violations & & & & & & & & & & \\
\hline \multirow{3}{*}{ Environment } & GHG Emissions Estimations & & & & & & & & & & \\
\hline & Other Emissions Estimations & & & & & & & & & & \\
\hline & GreenSTEP Integration & & & & & & & & & & \\
\hline Safety & Miscellaneous & & & & & & & & & & \\
\hline \multirow{2}{*}{$\begin{array}{c}\text { Assessibility \& } \\
\text { Connectivity }\end{array}$} & LCV Network Access & & & & & & & & & & \\
\hline & Truck turnaround time at terminals & & & & & & & & & & \\
\hline \multirow{8}{*}{ Planning \& Modeling } & Trip Generation Rates & & & & & & & & & & \\
\hline & SWIM2 Integration & & & & & & & & & & \\
\hline & Visual Analysis (i.e., GIS) & & & & & & & & & & \\
\hline & Partner with Regional Projects & & & & & & & & & & \\
\hline & Route Choice & & & & & & & & & & \\
\hline & Vehicle Choice & & & & & & & & & & \\
\hline & Freight Activity Modeling & & & & & & & & & & \\
\hline & Mode Choice & & & & & & & & & & \\
\hline
\end{tabular}

Table 15 - Applications Framework 


\subsection{CONCLUSIONS AND RECOMMENDATIONS}

This research demonstrates the potential to use TRUE data for a variety of important applications. The Applications Framework presented in the previous section proposes applications in a variety of modeling, performance measure and planning categories, along with the data fields required to provide accurate results in each. All of the data fields required for the proposed applications are available through the integration of TRUE and WIM data using the methodology presented in this report. The TRUE data was found to exhibit strong potential to be used for each of the listed applications. Applications considered through this research include, but are not limited to, those in the performance measure categories of safety, accessibility and connectivity, and system condition. It is recommended that consideration for the future use of the TRUE data (or data from a similar system) initially focus on three areas of application: 1) trip-generation rates and route-choice models, 2) mobility performance measures, and 3) environmental performance measures. This section of the report provides a summary of findings related to the suggested focus areas, including recommendations for next steps associated with each. Each of these application areas provides an opportunity for integration with, and development of, existing ODOT planning and modeling tools. Following the discussion of specific applications, general considerations and recommendations associated with the TRUE system are discussed.

1) Trip-Generation Rates and Route-Choice Models: This research has demonstrated that highly accurate commodity or vehicle type trip-generation rates are possible given that the accuracy of most TRUE GPS data is within 50 feet; this is an accuracy level that is more than appropriate to determine the location of truck travel at the TAZ level (TAZ areas are usually several miles wide/long). The accuracy of such tripgeneration rates could be further enhanced by identifying the TRUE GPS records that represent "trip ends" (origin and destination locations of truck tours). If the TRUE system were implemented on a larger scale, the resulting data could be used to develop highly accurate trip-generation rates as an alternative to more inaccurate employment or production-based trip-generation rates, and to calibrate the outputs of statewide freight models such as the CT module of SWIM2 and the OFP. Previous assumptions made within SWIM2 and the OFP regarding freight behavior could be reassessed since they were made in a significantly poorer freight-data environment. In addition, TRUE data would provide invaluable insights and data to develop motor carrier route-choice models as well as vehicle-choice models. There is an enormous potential in the TRUE data to improve Oregon freight-modeling efforts and the SWIM2 model (Figliozzi and Shabani, 2010).

2) Mobility Performance Measures: TRUE data provides a valuable resource towards mobility performance measures specific to freight-vehicle type and commodity type. Some commonly used mobility performance measures for which the TRUE data could provide estimates include Travel Time, Travel-Time Reliability, TTI and PTI. A spatial analysis of the "GPS Accuracy" field indicates that the TRUE records from interstate locations generally have a high degree of accuracy (within 20 feet) with regards to coordinate measurements. Further 
analysis of the "GPS Accuracy" field could be completed in order to review potential commonalities between low accuracy records such as vehicle ID, time period, rural vs. urban, time of day or speed.

This report presents a methodology to estimate space-mean speeds using the TRUE data. The accuracy of such estimates is assessed by comparing speed estimates calculated using TRUE data to those from PORTAL loop detectors. The findings indicate that in general, space-mean speeds calculated from the TRUE data are less than those estimated from loop detector measurements, and that the difference is statistically significant. This finding is consistent with previous research (Wheeler and Figliozzi, 2011), which found that for peak afternoon periods, speeds estimated by truck GPS data were generally less than those measured by loop detectors. However, the accuracy of the analysis was limited due to the small sample size available - the analysis included records from a variety of locations and time periods; the change in relationship of the TRUE and PORTAL speeds for different locations and time periods was not considered. Given a larger sample size of WMT GPS data, a more robust evaluation of space-mean speed estimates could be performed.

Space-means speeds calculated with the TRUE data were further used to perform a mobility analysis case study on a segment of I-5. Given a larger sample size of WMT GPS data, the methodology presented could be used to perform speed analyses for specific time intervals (i.e., weekday peak hours) in order to analyze specific bottleneck locations. However, an accurate speed analysis was difficult to perform with the available TRUE pilot project data due to the small sample size available.

A methodology to estimate vehicle speeds by making use of the consistent timestamp between TRUE GPS points is presented in this report. This methodology proposes the use of record densities to estimate speeds at a given location. Based on a comparison of TRUE record density speed estimates to TRUE space-mean speed estimates from the same segment of I-5, it can be seen that although the estimates are not exactly the same, record densities of TRUE data have the potential to provide speed approximations for mobility measures. However, similar to space-mean speed estimates, the mobility analysis case study using TRUE pilot project record densities was limited by the small sample size available.

3) Environmental Performance Measures: The daily increase in emissions due to recurrent congestion on I-5 has been estimated to be substantial (Wheeler and Figliozzi, 2011). However, the emission sensitivity analysis presented in this report demonstrates the level of error encountered when data as detailed as the integrated TRUE and WIM data is not available for emission estimates. The results demonstrate that speed, grade, weight and truck type can have a substantial impact on emissions estimates.

ODOT's GreenSTEP model has previously focused on the impact of policies and investments on emissions from household and light-duty commercial vehicles. The TRUE data provides an opportunity to develop the freight portion of this model by providing details of vehicle type and travel behavior, as well as the possibility of more accurate weight loads, fuel consumption and speed estimates. Given that commercial vehicle emissions are greatly 
dependent on vehicle weight and speed, TRUE data would be highly valuable in further developing the freight portion of GreenSTEP and in anticipating impacts of proposed policies as they relate to the freight sector. The more accurate emission estimates that are possible using the TRUE data could serve to justify policy decisions aimed at decreasing freight emissions, such as incentives to the private sector for decreased emissions and/or financial support to companies to assist with the expense of truck retrofits and/or new trucks. Further, data collected following policy implementation could be used to monitor actual impacts.

This report has presented many direct and important applications for WMT GPS data. Freight performance measures and planning and modeling tools serve as mechanisms to improve the efficiency and decrease the external costs of our freight system. Such measures and tools can provide insight to guide planning and policy efforts such as the Statewide Transportation Strategy and the Oregon Freight Plan. However, without accurate and detailed measurements and input parameters, it can be difficult to make sound policy decisions that can be justified to tax payers and to the freight industry.

In April 2012, ODOT concluded collection of the TRUE pilot project data. Subsequently, a private company, EROAD, began a similar pilot project in Oregon through an agreement with the Oregon Trucking Association (OTA) (ODOT, n.d.). Gregg Dal Ponte, MCTD administrator, provided the following statement regarding the TRUE system and the pilot project with EROAD:

"We have been more successful in this effort than we ever imagined we would be and therefore find ourselves in the position of being able to shut down our own TRUE development work much sooner than we originally thought would be the case. We are pleased to see the private sector firm EROAD stand up and successfully negotiate a signed agreement with the Oregon Trucking Association to collaborate on a pilot demonstration project for their product offering in Oregon."

Over 20 trucks representing at least 11 carriers are represented by the EROAD-OTA pilot project data (EROAD Limited, 2011). Data from the EROAD-OTA pilot project and from future use of EROAD for WMT collection in Oregon could be used to more completely consider the data applications presented in this report, as further development of some applications is currently limited by the small sample size of the TRUE pilot project. A critical challenge towards availability of this new data is successful collaboration between Oregon's public and private sectors.

This report presents an outline of recommended steps towards collaboration between the public and private sectors with regards to the use of private-sector data. In particular, for public-sector use of Oregon WMT GPS data to be possible in the future, the privacy concerns of the private sector must be addressed. Security measures and intended uses for the data should be clearly communicated to the private partners. Further, use of the data must have benefits that are valuable to the private sector. Transportation problems and priorities to be addressed through use of the data should be identified through a collaborative process. Transportation planners and engineers involved with the use of the data should develop an understanding of the unique concerns of the freight industry (i.e., responsive and adequate performance measures). Future collaborative pilot projects to collect and review WMT GPS data could provide an excellent opportunity for progress in this regard. 
With its recent exploration of WMT GPS data collection, Oregon has a unique and valuable opportunity. Oregon WMT GPS data (whether collected through TRUE, EROAD or another system) has enormous advantages over data used for previous research due to its level of detail and potential to differentiate between vehicle types. Such data could be used to guide the future of freight planning, modeling and performance measure research and to better inform freight transportation policy for the state and other jurisdictions. It is recommended that ODOT apply the approaches presented in this report to pursue further collaborative opportunities with the private sector with regard to the future use of WMT GPS data. 


\section{REFERENCES}

Barbeau, S., et al. Dynamic Management of Real-Time Location Data on GPS-Enabled Mobile Phones. UBICOMM 2008, The Second International Conference On Mobile Ubiquitous Computing, Systems, Services and Technologies, 2008, 2008, 343-348.

Bassok, A., E. McCormack, M. Outwater, and C. Ta. "Use of Truck GPS Data for Freight Forecasting." Transportation Northwest, 2011.

Boile, M., K. Ozbay, and P. Narayanan. "Infrastructure Costs Attributable to Commercial Vehicles." Final Report, 2001.

Cambridge Systematics, Inc. and ODOT Freight Mobility Unit. Oregon Freight Plan, An Element of the Oregon Transportation Plan. Transportation Development Division Planning Section, Salem, OR: ODOT, 2011.

Choi, D., M. Beardsley, D. Brezezinski, J. Koupal, and J. Warila. MOVES Sensitivity Analysis: The Impacts of Temperature and Humidity on Emissions. Office of Transportation and Air Quality (OTAQ), U.S. Environmental Protection Agency (EPA), Ann Arbor, MI: U.S. EPA - 19th Annual International Emission Inventory Conference, 2010.

Econorthwest. Oregon Highway Cost Allocation Study, 2011-2013 Biennium. Oregon Department of Administrative Services, Office of Economic Analysis, 2011.

Equivalent Single Axle Load. n.d. http://pavementinteractive.org/index.php?title=ESALs (accessed December 9, 2011).

EROAD Limited. 2011. http://eroad.com/ (accessed February 10, 2012).

Figliozzi, M. A., and K. Shabani. "Critical Review and Analysis of Existing CT Module." Technical Memorandum and Final Report, Portland State University, Portland, OR, 2010.

Figliozzi, M., N. Wheeler, E. Albright, L. Walker, S. Sarkar, and D. Rice. Algorithms to Study the Impacts of Travel Time Reliability along Multi-Segment Trucking Freight Corridors. Transportation Research Record, 2011.

Figliozzi, M.A., R. Harrison, and J.P. McCray. Using Weigh-in-Motion Data to Calibrate Trade-Derived Estimates of Mexican Trade Truck Volumes in Texas. The Center for Transportation Research, University of Texas at Austin, Austin, TX: Transportation Research Record (TRR), 2000, 129135.

Froehlich, J., et al. UbiGreen: Investigating a Mobile Tool for Tracking and Supporting Green Transportation Habits. Boston, MA, USA: ACM: Proceedings of the 27th International Conference on Human Factors in Computing Systems, 2009, 1043-1052.

Greaves, S., and M. Figliozzi. Commercial Vehicle Tour Data Collection Using Passive GPS Technology: Issues and Potential Applications. Melbourne, Australia: Transportation Research Board (TRB) 2008 Annual Meeting, 2008.

Holguin-Veras, J., K. Ozbay, A. Kornhauser, A. Shorris, and S. Ukkusuri. Integrative Freight Demand Management in the New York City Metropolitan Area. Final Report, United States Department of Transportation, 2010.

Houk, J. "FHWA MOVES Sensitivity Testing." Conference Proceedings: Midwest Transportation Air Quality Summit. Springfield, IL: U.S. Federal Highway Adminstration (FHWA), 2009.

Hunt, J.D., Knudson, B., Weidner, T., Bettinardi, A. \& Wardell, E. Applying the SWIM2 Integrated Model in Freight Planning in Oregon. Transportation Research Board (TRB) 2011 Annual Meeting, 2011. 
INRIX, Inc. 2012. http://inrix.com/ (accessed February 11, 2012).

Li, H., and R.L. Bertini. Comparison of Algorithms for Systematic Tracking of Patterns of Traffic Congestion on Freeways in Portland, Oregon. Civil and Environenmental Engineering, Portland State University, Portland, OR: Transportation Research Record: Journal of the Transportation Research Board, 2010, 101-110.

Ma, X., E. McCormack, and Y. Wang. Processing Commercial GPS Data to Develop a Web-Based Truck Performance Measures Program. Transportation Northwest, Transportation Research Record, 2011.

Manzoni, V., D. Manilo, K. Kloeckl, and C. Ratti. "Transportation Mode Identification and Real-time CO2 Emission Estimation Using Smartphones." SENSEable City Lab, Massachusetts Institute of Technology, n.d.

McCormack, E. Developing Transportation Metrics from Commercial GPS Truck Data. Department of Civil and Environmental Engineering, University of Washington, Seattle, WA: Transportation Northwest (TransNow), 2011.

McMullen, S.B., and C. Monsere. Freight Performance Measures: Approach Analysis. Oregon State University \& Portland State University, ODOT/OTREC, 2010.

Michie, B. "Oregon Electronic Weight-Mileage Tax Trial: Questions and Answers." Auckland: EROAD, February 7, 2012.

NCFRP. Performance Measures for Freight Transportation. National Cooperative Freight Research Program, Transportation Research Board (TRB), 2011.

ODOT and DLCD. "Greenhouse Gas Strategic Transportation Energy Planning Model." OREGON.gov; Oregon Sustainable Transportation Initiative (OSTI). Oregon Department of Transportation and Department of Land Conservation and Development. October 2011. http://www.oregon.gov/ODOT/TD/OSTI/docs/Media/Model.pdf?ga=t (accessed February 25, 2012).

ODOT. Geographic Information Systems (GIS) Strategic Plan. ODOT GIS Steering Committee, Oregon Department of Transportation, 2008.

- Traffic Counting Program. Oregon Department of Transportation. n.d. http://www.oregon.gov/ODOT/TD/TDATA/Pages/ata/tsm/tvt.aspx (accessed December 15, 2012).

- Truck Road Use Electronics Pilot Project. Oregon Department of Transportation. n.d. http://cms.oregon.egov.com/ODOT/HWY/OIPP/Pages/TRUE.aspx (accessed July 31, 2012).

ODOT. Truck Road Use Electronics Work in Progress Documentation. Oregon Department of Transportation, 2010.

Oregon State Legislature. Oregon Revised Statutes - 2011 Edition. Oregon State Legislature. 2011. http://www.leg.state.or.us/ors/ (accessed March 20, 2013).

Park, L., D. Pierce, and J. Short. A System for Utilizing Truck GPS Data to Monitor Urban Highway Congestion. American Transportation Research Institute (ATRI), Transportation Research Board (TRB) 2012 Annual Meeting, 2012.

Pavement Interactive. Equivalent Single Axle Load. Inc. Pavia Systems. 2012. http://www.pavementinteractive.org/article/equivalent-single-axle-load/ (accessed July 31, 2012).

Petrushov, V.A. "Coast Down Method in Time-Distance Variables." 1997.

Platman, D. "TransPort Meeting Agenda." Metro Agenda. Portland, OR, April 11, 2012. 
Portland Metro. RLIS Live, Geographic Information System Data. Metro. 2012. http://www.oregonmetro.gov/index.cfm/go/by.web/id=593 (accessed June 4, 2012).

Schrank, D., T. Lomax, and B. Eisele. "TTI's 2011 Urban Mobility Report Powered by INRIX Traffic Data." Texas Transportation Institute, 2011.

Sharman, B., and M. Roorda. "Analysis Tool to Process Passively-Collected GPS Data for Commercial Vehicle Demand Modelling Applications." University of Toronto, Toronto, Ontario, n.d.

Singh, S.K. Urban Transport in India: Issues, Challenges, and the Way Forward. Indian Institute of Management Lucknow, European Transport, 2012.

Sullivan, M. Statistics: Informed Decisions Using Data. Fourth. Pearson, 1967.

TRB Freight Transportation Data Committee. Measuring the Transportation System from a Supply Chain Perspective. Transportation Research Circular, Irvine, California: Transportation Research Board of the National Academies, 2012.

USEPA. Modeling and Inventories. U.S. Environmental Protection Agency. December 11, 2012. http://www.epa.gov/otaq/models.htm (accessed December 15, 2012).

USEPA. Motor Vehicle Emission Simulator (MOVES) - User Guide for MOVES2010b. Assessment and Standards Division; Office of Transportation and Air Quality, U.S. Environmental Protection Agency, 2012.

USEPA OTAQ. MOVES (Motor Vehicle Emission Simulator). U.S. Environmental Protection Agency. February 6, 2012. http://www.epa.gov/otaq/models/moves/index.htm (accessed February 11, 2012).

Wheeler, N., and M. Figliozzi. Multicriteria Freeway Performance Measures for Trucking in Congested Corridors. Civil and Environmental Engineering, Portland State University, Portland, OR: Transportation Research Record: Journal of the Transportation Research Board, 2011, 82-93.

Wigan, M.R., and F. Southworth. What's wrong with freight models, and what should we do about it? Oxford Systematics, Heidelberg, Victoria, Australia: Transportation Research Board (TRB) 2006 Annual Meeting, 2006.

Wunnava, S., K. Yen, B. Tadeusz, R. Zavaleta, R. Romero, and C. Archilla. "Travel Time Estimation Using Cell Phones for Highways and Roadways." Florida Department of Transportation, 2007.

Xata Corporation. Xata Turnpike. 2012. http://www.xata.com/fleet-management-solutions/xata-turnpikeenterprise-fleet-management/ (accessed February 5, 2012).

You, S., and S. Ritchie. Tour Behavior of Clean Drayage Trucks in Southern California. Civil and Environmental Engineering, University of California, Irvine, CA: Transportation Research Board (TRB) Annual Meeting, 2012.

Zhao, W., A.V. Goodchild, and E.D. McCormack. Evaluating the Accuracy of Spot Speed Data from Global Positioning Systems for Estimating Truck Travel Speed. Civil and Environmental Engineering, University of Washington, Seattle: Transportation Research Record: Journal of the Transportation Research Board, 2011, 101-110.

Zhao, Y. Mobile Phone Location Determination and Its Impact on Intelligent Transportation Systems. Intelligent Transportation Systems, IEEE Transactions, 2000, 55-64.

Zheng, Y., L. Liu, L. Wang, and X. Xie. Learning Transportation Mode from Raw GPS Data for Geographic Applications on the Web. Bijing, China: ACM: Proceedings of the 17th International Conference on World Wide Web, 2008, 247-256. 



\section{GOTREC \\ AND EDUCATION CONSORTIUM}

P.O. Box 751

Portland, OR 97207

OTREC is dedicated to stimulating and conducting collaborative multi-disciplinary research on multi-modal surface transportation issues, educating a diverse array of current practitioners and future leaders in the transportation field, and encouraging implementation of relevant research results. 